\title{
Indentation of glasses
}

\author{
Tanguy Rouxel ${ }^{1,2}$, Jae-il Jang ${ }^{3}$, Upadrasta Ramamurty ${ }^{4,5}$ \\ ${ }^{1}$ Institut de Physique, UMR UR1-CNRS 6251, Université de Rennes 1, 35042 Rennes, France \\ ${ }^{2}$ Institut Universitaire de France, France \\ ${ }^{3}$ Division of Materials Science and Engineering, Hanyang University, Seoul 04763, Republic of \\ Korea \\ ${ }^{4}$ School of Mechanical and Aerospace Engineering, Nanyang Technological University, Singapore \\ 639798. \\ ${ }^{5}$ Institute of Materials Research and Engineering, Agency for Science, Technology and \\ Research (A*STAR), Singapore 138634
}

\begin{abstract}
Indentation, owing to its ability to induce permanent deformation in a controlled manner even in highly brittle materials that are otherwise not amenable to critical mechanical testing experiments, is widely used for studying the mechanical behavior of amorphous solids. In this paper, an overview of the current understanding on the indentation response of inorganic glasses - both metallic and nonmetallic - is presented. The stresses underneath a sharp indenter, such as the Vickers indenter that is most commonly used to evaluate hardness of glasses, can be substantial, which, in turn, can induce densification, plastic deformation, viscous flow, and cracking, depending on a number of material and experimental variables. In this paper, the physics and mechanics of these processes, the interplay between them, and their effect on hardness of glasses are reviewed. The effect of composition in various glass systems such as chalcogenides, phosphates, silicates, and silicon oxynitrides, on hardness are discussed. Different microcrack patterns that occur during indentation and fracture resistance of glasses are summarized. The effects of extrinsic parameters such as time, temperature, and pressure on the deformation behavior of glasses are highlighted. The use of the bonded-interface and nanoindentation techniques for studying incipient as well as the localized nature of plastic flow and its pressure sensitivity, and hardness in metallic glasses is summarized. A review of the nanoindentation's contribution for investigating the strain rate, ion irradiation, and environmental effects is provided. Finally, possible future avenues for further exploration of indentation of glasses are discussed.
\end{abstract}

Correspondence: $\quad$ Tanguy.rouxel@univ-rennes1.fr (ORCID iD: 0000-0002-9961-2458)

jijang@hanyang.ac.kr (ORCID iD: 0000-0003-4526-5355)

uram@ntu.edu.sg (ORCID iD: 0000-0002-0917-6497) 


\section{I able ol contents}

ABSTRACT

\section{INTRODUCTION}

\section{INORGANIC AND NON-METALLIC GLASSES}

2.1. Hardness and indentation plasticity

2.1.1. Physics and mechanics of the deformation process

2.1.2. Effect of composition

- Chalcogenide glasses

- Phosphate glasses

- Silicate glasses

- Silicon oxynitride glasses

\subsection{Indentation cracking}

2.2.1. Driving force and crack morphology

2.2.2. Crack initiation and cracking resistance

2.3. Effects of time, temperature, and pressure

\subsection{Nanoindentation studies}

2.4.1. Densification behaviour

2.4.2. Rates effects on hardness

2.4.3. Indentation size effect

2.4.4. Effect of irradiation on the mechanical properties

2.4.5. Topological constraints in chalcogenide glasses

2.5. Modeling and simulation of the indentation process

\section{METALLIC GLASSES}

3.1. Indentation-induced plasticity

3.1.1. Correlation between hardness and elastic properties

3.1.2. Discrete deformation during nanoindentation

3.1.3. Plasticity evolution and pressure sensitivity

3.1.4. Time-dependent deformation

3.1.5. Indentation plasticity and toughness correlation

3.2. Incipient plasticity

3.2.1. Onset of plasticity and its statistics

3.1.2. STZ volume estimation

3.3. Environmental effects on the indentation response

3.4. Modeling and simulation of the indentation behavior

\section{CLOSING REMARKS}




\begin{tabular}{|c|c|}
\hline A & Alkaline \\
\hline $\mathrm{AE}$ & Alkaline-earth \\
\hline $\mathrm{a}-\mathrm{SiO}_{2}$ & Amorphous (vitreous) silica \\
\hline $\mathrm{BMG}$ & Bulk metallic glass \\
\hline BMGC & Bulk metallic glass composite \\
\hline ECR & Electrical contact resistance \\
\hline FBG & Fiber Bragg gratings \\
\hline FE & Finite element \\
\hline FEM & Finite element method \\
\hline IP & Intermediate phase \\
\hline ISE & Indentation size effect \\
\hline KDE & Kernel density estimate \\
\hline LJ & Lennard-Jones \\
\hline MD & Molecular dynamics \\
\hline $\mathrm{MG}$ & Metallic glass \\
\hline PSR & Proportional specimen resistance \\
\hline RT & Room temperature \\
\hline SRO & Short-range ordering \\
\hline SRS & Strain-rate sensitivity \\
\hline STZ & Shear transformation zone \\
\hline UV & Ultraviolet \\
\hline$a$ & Radius of the circular imprint associated with the equivalent conical indenter \\
\hline$B$ & Brittleness index \\
\hline$C_{g}$ & Atomic packing density \\
\hline$C_{y}$ & A constant connecting $\tau_{\max }$ and $\tau_{y}$ \\
\hline$E$ & Elastic modulus \\
\hline$E_{\text {eff }}$ & Effective modulus \\
\hline$f$ & Cumulative probability \\
\hline$H$ & Hardness \\
\hline$H_{e l}$ & Equilibrium mean contact pressure (referred to as 'elastic hardness') \\
\hline$h$ & Depth of penetration in indentation test \\
\hline$h_{\max }$ & Maximum depth of penetration \\
\hline$K_{\text {Ic }}$ & Plane strain (mode I) fracture toughness \\
\hline$m_{i}$ & The molar mass of the $i^{\text {th }}$ element \\
\hline$N_{i}$ & Shear band number density around spherical indentations \\
\hline$N_{n}$ & Shear band number density ahead of a notch tip \\
\hline$P$ & Applied load in indentation test \\
\hline$\dot{P}$ & Loading rate \\
\hline$R^{2}$ & $\begin{array}{l}R \text {-squared, a statistical measure representing proportion of the variance in } \\
\text { the dependent variable that is predictable from the independent variable(s) }\end{array}$ \\
\hline$R_{i}$ & Indenter tip radius \\
\hline$r$ & Distance to the initial point of indentation contact \\
\hline$<r>$ & Average coordination number \\
\hline$r_{i}$ & Ionic radii \\
\hline$T$ & Absolute temperature \\
\hline$T_{g}$ & Glass transition temperature \\
\hline$t$ & Time \\
\hline$V^{*}$ & Activation volume \\
\hline$V_{0}$ & Corresponding effective volume of glass \\
\hline
\end{tabular}




\begin{tabular}{|l|l|}
\hline$V_{a}$ & Actual volume occupied by the constituent elements \\
\hline$x_{i}$ & The atomic fraction of the $i^{\text {th }}$ element \\
\hline$Y$ & Constrained factor \\
\hline$\alpha$ & friction coefficient \\
\hline$\dot{\varepsilon}$ & Indentation strain rate \\
\hline$\phi$ & Half apical angle of an equivalent conical indenter \\
\hline$\eta$ & Shear viscosity coefficient \\
\hline$\mu$ & Shear modulus \\
\hline$v$ & Poisson's ratio \\
\hline$\theta$ & $\begin{array}{l}\text { Angle to the loading axis, in spherical coordinates with origin on the surface } \\
\text { at contact point }\end{array}$ \\
\hline$\rho$ & Density of material \\
\hline$\sigma_{u}$ & Ultimate tensile strength \\
\hline$\sigma_{v}$ & Yield strength \\
\hline$\sigma_{r r}$ & Stress component along $r$ direction in spherical coordinates \\
\hline$\sigma_{\phi \phi}$ & Stress component normal to $r$ direction in spherical coordinates \\
\hline$\tau_{\max }$ & Maximum shear stress underneath the indenter \\
\hline$\tau_{y}$ & Shear yield strength for the onset of plasticity \\
\hline
\end{tabular}




\section{INI RUUUCIIUN}

The three key attributes that define the quasi-static mechanical behavior of a material at low temperature are its stiffness, strength, and toughness. They reflect the resistance offered by the material to elastic and plastic deformations, and to cracking, respectively, and are quantified through the properties: elastic modulus, $E$, yield strength, $\sigma_{y}$ (or tensile strength, $\sigma_{u}$ ), and fracture toughness, $K_{\text {Ic }}$. The first property, $E$ is often expressed in units of $\mathrm{Pa}$ and is the rate of change in the volume density of energy (that is stored in the material by virtue of the elastic deformation) with strain. Since the onset of plastic (or permanent) deformation occurs when the stored energy reaches a critical value (according to the widely used von Mises yield criterion), $\sigma_{y}$ is also expressed in units of Pa. The direct measurement of $\sigma_{y}$ requires some sophisticated instrumentation and specimen preparation; therefore, hardness, $H$, a measure of the mean contact stress required for the formation of a permanent indentation imprint, is often used as a simple and cost-effective alternative to estimate the plastic flow ability especially for quality control in manufacturing industries that deal with metals and alloys. Like $\sigma_{y}, H$ is also expressed in $\mathrm{Pa}$ and is defined as the ratio between the normal load applied on the indenter and the projected area (cross-section) of the impression made by it on the material being probed.

As soon as humans started using materials for cutting, shaping, or working matter in general, they imagined ways to compare their $H$, especially when relatively hard materials such as metals, ceramics and glasses became available. With the advent of industrialization, it has become the property that is routinely evaluated due to the relative ease with which it can be measured. Over the past century, various kinds of hardness measures that use different indenter tip geometries (such as Vickers, Brinell, Knoop, Rockwell) were proposed and widely adapted. Nevertheless, $H$ is a somewhat composite property, which reflects different elementary deformation processes that often occur concomitantly. Thus, hardness embodies the resistance offered by the material to both elastic and isochoric plastic deformations, as well as densification - in the case of glasses in which the atomic packing is inefficient or porous materials, as we shall see later - and micro-scale damage [1]. Moreover, the material deformation characteristics under contact loading, which results in severe gradients in stress and strain fields, are embodied in the hardness measure. Therefore, different deformation processes involving intrinsic as well as extrinsic properties may result in the same area of contact for a given load. All these factors can lead to considerable complexity in connecting $H$ to the underlying material physics.

A relatively more recent development in the field of hardness measurements is nanoindentation, in which the applied load, $P$, is continuously measured as a function of the depth of penetration, $h$, of the indenter into the material that is being probed [2]. Nanoindentation falls into the broad class of techniques known as 'instrumented indentation', through which $P-h$ data is acquired. 
The generated data can be analyzed not only to obtain $H$, but also to extract the effective elastic modulus of the specimen, $E_{\text {eff }}\left(=E /\left(1-v^{2}\right)\right.$, where $v$ is Poisson's ratio). In some specific instances, the shear viscosity coefficient, $\eta$, in the $10^{9}$ to $10^{14} \mathrm{~Pa} \cdot$ s range (i.e., through the glass transition) can also be estimated using this technique. Since $P$ and $h$ can be measured with high resolutions ( $\mu$ N for $P$ and $\mathrm{nm}$ for $h$ ) and with high accuracy, nanoindentation is particularly suited - and hence widely exploited - for probing materials that are only available in small volumes such as thin films and coatings [3]. It is also useful for measuring site-specific properties of surfaces, with high spatial and temporal resolutions.

Indentation technique can also be used for measuring the fracture resistance of a material. However, a necessary condition that needs to be fulfilled for measuring the toughness is that the indented material should crack in a controlled and well-defined manner [3-5]. Thus, all the three key mechanical attributes of a material can be measured, in principle, using indentation.

Indentation - whether it is for the simple measurement of $H$ or the more sophisticated nanoindentation - is the commonly used method for exploring the mechanical behavior of glasses, a class of materials of rapidly growing importance that are used extensively for both structural and functional purposes. Glasses at room temperature (RT) are generally brittle and hence tend to fail catastrophically under tension, i.e., they deform in a purely elastic manner before failing, and are highly sensitive to defects. It is possible, however, to induce a permanent deformation in them in a controlled manner via indentation and hence study their mechanical behavior.

The stress state underneath the indenter is complex, especially when a sharp indenter - such as Vickers indenter, which is the most common one for studying glasses - is used, and the deformation occurs with both reversible (elastic) and irreversible contributions; the latter stems either from shear plasticity, densification, or viscous flow, and is responsible for the permanent residual imprint from which $H$ is deduced $[3,6]$. With the nanoindentation technique, initiation of the incipient plasticity and the localized nature of plastic flow can be carefully monitored in quasi-brittle materials such as metallic glasses (MGs) [7]. The analysis of such features allows for a better understanding of the physics of deformation and fracture of glasses. In this paper, the indentation responses of inorganic glasses - both metallic and non-metallic - are reviewed, with emphasis on recent insights gained on the processes that glasses undergo during indentation. The behavior of non-metallic glasses during indentation are discussed first, which is followed by that on MGs.

\section{INORGANIC AND NON-METALLIC GLASSES}

In the absence of dislocation mediated plasticity, which is the main mechanism for permanent deformation in crystalline metals and alloys, two deformation processes were identified to occur during indentation of inorganic and non-metallic glasses, which are the following. (i) Densification 
$[8,9]$, which is dominant in glasses with a relatively low atomic packing density, $C_{\mathrm{g}}$, which is defined as the ratio of $V_{\mathrm{a}}$ to $V_{0}$, where $V_{\mathrm{a}}$ is the actual volume occupied by the constituent elements $\left(=\sum_{i}{ }_{3}^{4} \pi x_{i} r_{i}^{3}\right.$ , as estimated from the ionic radii, $r_{\mathrm{i}},[10]$ and the atomic fraction $x_{\mathrm{i}}$ of the $i^{\text {th }}$ element) and $V_{0}$ is the corresponding effective volume of glass $\left(=1 / \rho \sum_{i} x_{i} m_{i}\right.$, where $m_{\mathrm{i}}$ is the molar mass of the $i^{\text {th }}$ element); (ii) Volume conserving (isochoric) shear flow $[11,12]$ in those glasses with a high $C_{\mathrm{g}}$, and/or when $H$ is measured at temperatures, $T$, approaching the glass transition temperature, $T_{g}$ [13] It is important to recognize here that a major difference between the indentation of crystalline and amorphous materials is that plasticity in the former is volume conserving, whereas the volume of the material being deformed does not necessarily remain constant in glasses.

Non-metallic inorganic glasses such as the silicate glasses are brittle. Therefore, when the indentation load is sufficiently large, some microcracking events occur both on loading and on unloading $[14,15]$, which weaken the glass by leaving easy crack initiation sites at the surface.

The extent of the deformation, the physics behind it, and the microcracking patterns during indentation of glasses depend much on the composition, and more particularly on the atomic and molecular organizations (short to medium range order). In the context of glasses, $H$ is mostly found to correlate with the elastic moduli - especially the shear modulus, $\mu[1,16]-$ and is related to the average bond strength, the volume density of the bonds - and thus the free volume content - and the bond characteristics (especially directionality). Since composition and $T$ can independently influence $H$, it may be difficult to decouple the chemical and thermal effects. In other words, glasses with relatively low $T_{g}$ are likely to exhibit similar indentation features to the more refractory ones indented at higher $T$. Regardless of the specific chemical system, the general tendency is that $H$ scales with $T_{g}$. This is not surprising since $T_{g}$ is the boundary between the liquid state (above) and the supercooled liquid or glassy state (below), and since $H$ scales with the melting point for most materials.

The importance of the glass composition and atomic organization on the indentation deformation will be discussed in subsection $§ 2.1$, in light of the major mechanisms evidenced in noncrystalline materials, and of known features of the atomic structure. A quantitative analysis of the irreversible deformation process allows for an estimation of the driving force for indentation cracking, as well as for the crack pattern (morphology). This paves the way to the understanding of the contact damage behavior of glasses from different chemical systems and to the design of damage-resistant glasses, as discussed in subsection $§ 2.2$.

\subsection{Hardness and indentation plasticity}

\subsubsection{Physics and mechanics of the deformation process}


It is noteworthy that in the case of glasses with a large free volume content, such as vitreous silica (a$\mathrm{SiO}_{2}$ ), $H$ is predominantly controlled by the volume density of atomic bonds, regardless of the interatomic bond energy. This is the reason behind a- $\mathrm{SiO}_{2}(H=8.7 \mathrm{GPa})$ being considerably softer than its crystalline counterpart, quartz $(H=10-12 \mathrm{GPa})$, or than its high-density variant, stishovite (33 GPa) [17]. With an increase in the packing density, the bond strength becomes more dominant than the packing density itself, and $H$ is governed by the resistance offered by the glass to the shear flow. This is why MGs, which have a relatively high $C_{\mathrm{g}}$ of $\sim 0.6-0.8$ [18] that is reflected in their $v$ values being typically larger than 0.3 , can be stiffer and harder than oxide glasses, despite a much weaker interatomic bonding. The absence of dislocations in MGs, however, makes them considerably harder than their crystalline counterparts. Consequently, $\sigma_{y}$ and $H$ of MGs reflect the ease with which localized flow units and bands form, with transient local expansions, as will be further discussed in subsection $\S 3$.

Typical $H$ values for inorganic, non-metallic glasses range between 1 (chalcogenides) and 12 (silicon-oxynitrides) GPa. These are much larger than the stresses that glasses can withstand during classical mechanical testing (such as uniaxial tension or compression tests) and are sufficient to generate some densification in the process zone beneath the indenter imprint. Densification at the indentation sites was inferred from the refractive index measurements made optical interferometry [8,9], as well as by Raman spectroscopy [19,20]. A general property of glasses, densification could occur in a volume that is several times the indentation size and manifests through a persistent change of the atomic network structure ${ }^{1}$. Being displacive in nature, it results in packing of matter into a relatively-more close packed structure. The extent to which a glass can densify during indentation depends on its $C_{\mathrm{g}}$; a smaller $C_{\mathrm{g}}$ results in a larger shrinkage volume [20,21] Densification accounts for $80 \%$ of the indentation volume in $\mathrm{a}-\mathrm{SiO}_{2}[13,20]$. In contrast, it contributes to less than $10 \%$ of the deformed volume of a Zr-based MG due to the random close packed structure in it [20].

Shear flow, which is reconstructive in nature ${ }^{2}$, operates almost concomitantly to densification [13]. It results in the piling-up of matter around the indent edges while densification leaves a welldefined indent surrounded by a marginally distorted surface. A remarkable correlation was found

\footnotetext{
${ }^{1}$ Densification was demonstrated both by light scattering spectroscopy (Raman in particular) and by specific annealing treatments below $T_{g}$ that would 'recover' the densified zone. An axisymmetric boundary of the densified area exists, even if a sharp indenter is used, because the St-Venant principle is valid at a depth of about the indentation size [22].
}

${ }^{2}$ Densification becomes increasingly difficult with an increasing amount of the modifying cations in the glass. Both $C_{\mathrm{g}}$ and $v$ increase with this amount. Still, densification occurs, especially at $\mathrm{SiO}_{4}$ tetrahedral sites, but to a lesser extent. Details on the mechanistic variations upon densification in different glass chemical systems can be found in [21]. 
between the $v$ and the amount of densification or shear flow, which involve large strains ${ }^{3}$ [22]. This is because glasses with relatively open structures, such as those of amorphous silica and germania, are based on corner-sharing tetrahedra and usually come with a high degree of cross-linking. Hence, they offer a strong resistance to contraction in the transverse direction to tensile axis and have a low $v(0.15$ and 0.19 respectively). On the contrary, amorphous structures that are more efficiently packed are mostly associated with a smaller degree of atomic cross-linking (it is easier to pack rod- or sheetlike units than tetrahedra) so that local shear becomes easier and $v$ increases. In the extreme case of MGs with precious metal host elements $v$ reaches values as large as 0.45 [23]. In contrast to MGs, where significant progress toward the understanding of plastic flow was achieved thanks to the huge research efforts made during the last three decades, detailed understanding of the shear deformation mechanism of silicate glasses is still elusive. The observations of shear bands were reported in silicate glasses some decades ago $[11,24,25]$. However, it was not clear whether those were slip bands or shear microcracks. What we know is that shear flow in amorphous materials, which do not work harden, results in the pile-up of matter as a result of the volume conservative nature of it. The occurrence of both pile-up and sink-in crystalline metals and alloys, depending on their work hardening characteristics, has been extensively reported for crystals [26]. Shear flow occurs in a localized process zone beneath the indenter, and is more sensitive to $T$ than densification, with approximately an order of magnitude difference in their activation energies. As a matter of fact, shear flow takes over densification at $T$ from near - and above $-T_{g}$ but is much reduced at low $T$ [27,28]. Having relatively low $T_{g}$, chalcogenide and phosphate glasses experience significant shear flow at RT. Shear-thinning is favored in weakly polymerized network structures ${ }^{4}$; indeed both viscosity measurements and numerical simulation provide evidence for a sharp viscosity reduction at high stresses or strain- rates $[29,30]$. Hence, it is anticipated that for shear stresses of the order of GPa (comparable to $H$ values) viscosity may drop of orders of magnitude, so that viscous flow is plausible.

\footnotetext{
${ }^{3}$ The permanent deformation in glasses is reflected in $v$, and interestingly, this is consistent with the finding (phenomenological) that sink-in or pile-up is correlated to $H / E$. As the shear deformation becomes easier relative to the volume change, $H$ decreases while $E / \mu$ and $K / \mu$ increase $(K / \mu$ is better for a sound comparison of shear and volumetric deformations). Since both $E / \mu$ and $K / \mu$ scale with $v$, it turns out that examining $E / H$ or $v$ to anticipate sink-in or pile-up is about the same thing. Note that ductile materials, which show extensive pile-up, are comparatively soft and exhibit large $v$ values. ${ }^{4}$ In network glasses, the tetrahedra (or the basic units of the structure) form a mostly percolating network. The cross-linking decreases with an increasing content of alkaline or alkaline-earth cations in silicates, or chalcogen elements in chalcogenide glasses. This is often referred as a decrease in the polymerization degree.
} 

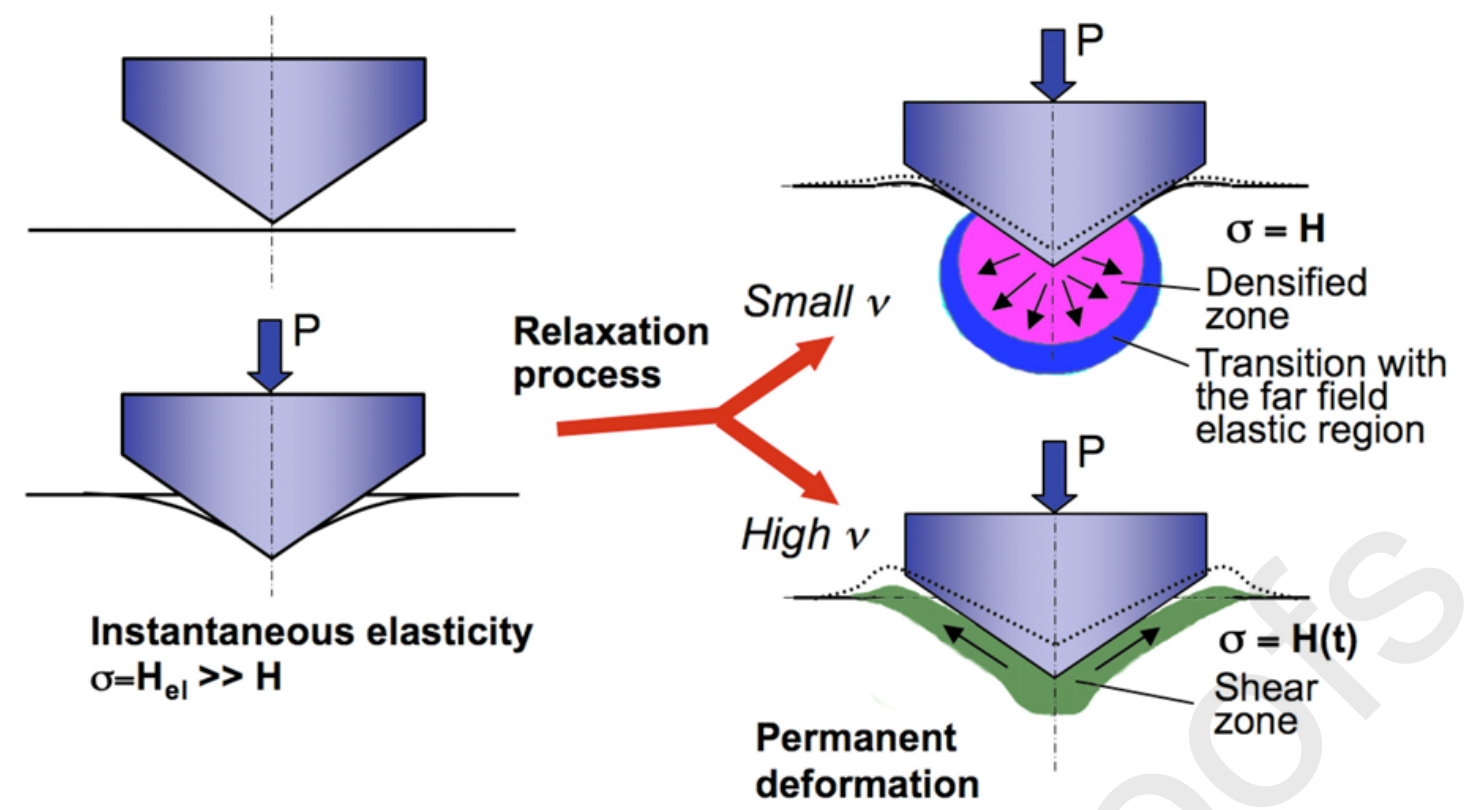

Fig. 1. Schematic drawings of different indentation deformation stages. The dashed lines indicate the indentation profile after unloading. Arrows indicate matter displacement. Hardness, $H$, is the mean contact pressure. (Reprinted with permission from Januchta and Smedskjaer [31]. Copyright (2019) Elsevier)

Deformation during indentation could involve three different processes, namely elastic deformation, densification, and shear flow (Fig. 1) [31]. If linear elasticity was to be the sole deformation mechanism, the equilibrium mean contact pressure (referred to as 'elastic hardness'), $H_{\mathrm{el}}$, for a rigid conical indenter of apical angle $2 \phi$ would be [32]:

$$
H_{\mathrm{el}}=\mu /[(1-v) \tan \phi] .
$$

For a Vickers indenter, which is the most widely used for measuring $H$ of glasses, $\phi=70.3^{\circ}$ such that the equivalent cone indenter produces the same projected area for a given penetration depth. Substituting typical values of $\mu$ and $v$ in Eq. (1), shows that $H_{\mathrm{el}}$ is about 2 to 3 times larger than $H$ measured on the same solid, which means that matter will tend to relax such highly constrained localized stress by means of densification and shear flow. If these mechanisms are not sufficiently active, microcracking damage occurs. Densification is supposed to occur first because it requires small local displacements in which the interatomic bond distances remain nearly unchanged, while inter-units (tetrahedra) angles are affected, which results in a change in the refractive index. Indeed, the refractive index of the pristine silica glass immediately surrounding the indentation was found to be different from that of the bulk [33]. 
Even in the cases where volume conserving flow is dominant, the pile-up volume remains considerably smaller than the indentation volume. For example, it is $34 \%, 61 \%$, and $75 \%$ of the total imprint volume for a $\mathrm{Zr}_{55} \mathrm{Cu}_{30} \mathrm{Ni}_{10} \mathrm{Al}_{5} \mathrm{MG}, \mathrm{GeSe}_{4}$ glass, and pure crystalline platinum, respectively [13]. The latter case of $\mathrm{Pt}$ demonstrates that even for a dense material, whose indentation behavior is essentially isochoric (plastic), the pile-up volume is significantly less than the imprint one. This is because a significant fraction of material moves downwards into the bulk, inducing post-unloading residual stresses. Such a stress field prevents complete recovery of the elastic strains induced during the loading stage and is responsible for the radial-median cracks observed at higher loads in brittle solids (see subsection $\S 2.3$ ).

\subsubsection{Effect of composition}

Composition affects glass $H$ in several different ways. Neither simple relationships nor efficient tools are available to predict $H$ of glasses from the stoichiometric formulae. At the local atomic scale of the short-range ordering (SRO), the cationic field strength, which accounts for both the valency and the ionic radius, and the bonding energy are important parameters. At the medium-range order scale, $H$ depends on $C_{\mathrm{g}}$, on the fraction of non-bridging anions, which can be viewed as 'loose ends', and possibly on the formation of weak channels within the network structures providing pathways for easy shear. These parameters are mostly coupled, making the understanding and prediction of $H$ complex. For example, as $T_{g}$ is raised, $C_{\mathrm{g}}$ is usually found to decrease, which results in a decrease of $H$ despite an increase of the molar dissociation energy, which scales with $T_{g}$. Conversely, upon annealing in the $T_{g}$ range, the fictive temperature (see reference [34] for a detailed description of this parameter) decreases whilst $C_{\mathrm{g}}$ increases as well as the density, so that $H$ increases upon structural relaxation. It is noteworthy that $C_{\mathrm{g}}$ is of primary importance in $H$ changes. Besides, phase separation is often reported (in barium silicates and in borates, for example) and makes the interpretation difficult. Mixed alkali effects, i.e., $H$ goes through an extremum as one alkali is substituted for another, are also reported in different chemical systems (in mixed alkali silicates and germanates for example [35-37]). Then, one must keep in mind that most compositional changes alter $T_{g}$ the same way changing $T$ affects the glass structure (as depolymerization occurs, especially above $T_{g}, H$ drops rapidly, and $v$ increases). Therefore, both chemical and $T$ effects need to be considered simultaneously in rationalizing the variation in $H$. 


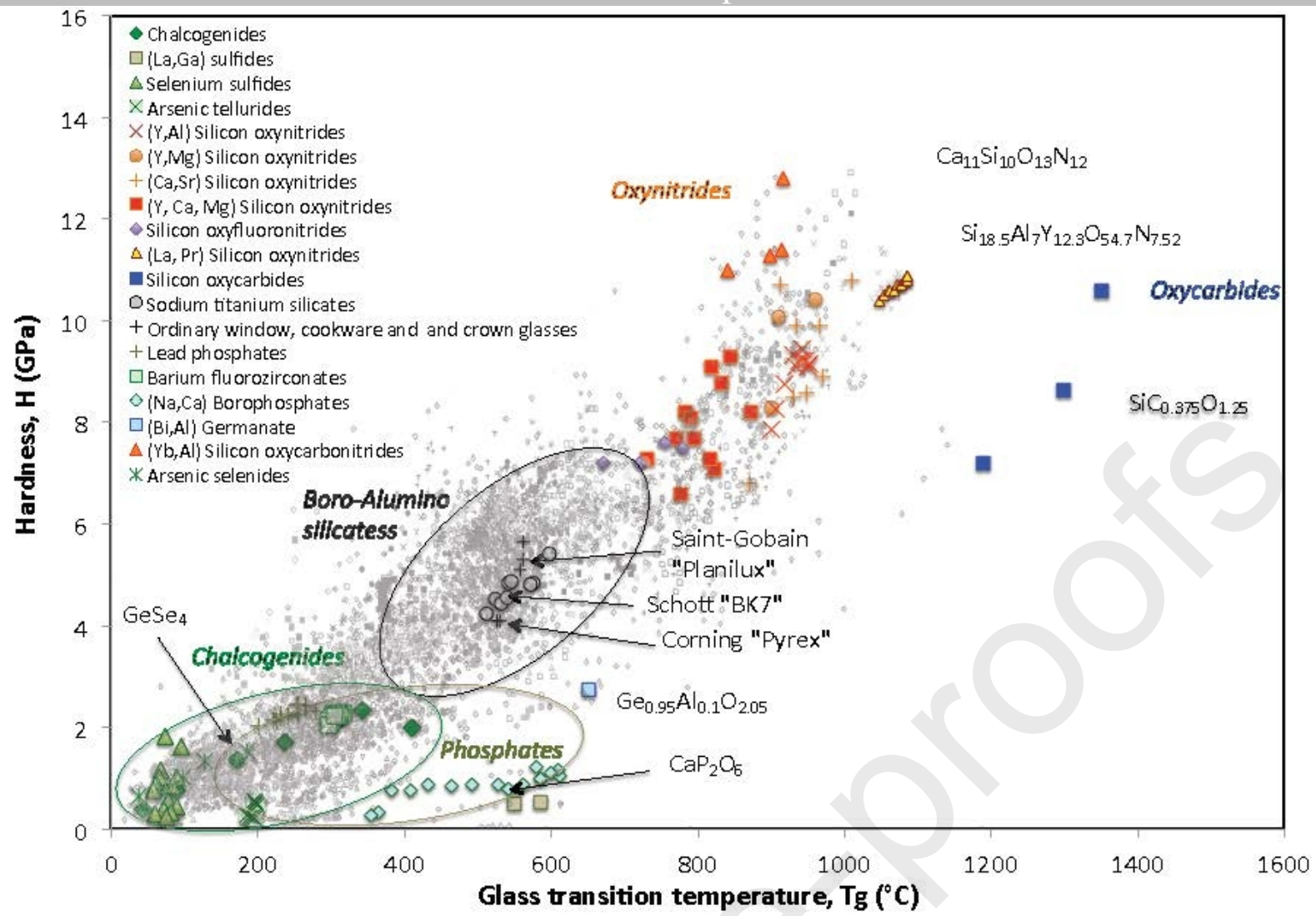

Fig. 2. Vickers hardness of glass as a function of the glass transition temperature. Background grey marks were extracted from the SciGlass database [38]. Data on chalcogenide and on halide glasses are from [39-43] and [44] respectively. Data for phosphate glasses are from [45] and [46]. Hardness values for silicon oxynitride are from [47-51] and those for silicon oxycarbide glasses are from [52]. Data for silicon-oxycarbonitride and -oxyfluoronitride materials are from [47] and [50] respectively. The germano-aluminate data are from [36].

The hardness of glasses from different chemical systems as a function of $T_{g}$ is plotted in Fig. 2, using the SciGlass database (background grey marks) [38]. Some peculiar series of glasses are highlighted with colored marks for discussion. Note in this diagram that $H$ is expected to drop to nearly zero at $T>T_{g}$, so that the data points are intersecting the $x$ axis at the ambient temperature in Fig. 2. A general observation from this representation is that as glasses become more refractory, they also become harder, and unfortunately more brittle. Nevertheless, there are several anomalies to these trends, where the chemical system providing the softest glasses is also the one resulting in the most brittle materials. For example, $H$ of chalcogen-rich chalcogenide glasses is mostly below 2 GPa while their toughness is typically smaller than $0.3 \mathrm{MPa} \sqrt{\mathrm{m}}$, and the most refractory glasses such as amorphous silica and silicon oxycarbides (with $T_{g}>1300^{\circ} \mathrm{C}$ ) are not as hard as the hardest oxynitride glasses, exhibiting $T_{g}$ ranging between $900-1000{ }^{\circ} \mathrm{C}$. This is where interesting fundamental aspects come into play. 
$H$ depends much on the glass composition, and more specifically on the atomic scale organization. Following the description of the physics of deformation that occurs during indentation deformation, it is anticipated that the sensitivity to densification will play a key role on $H$ in the case of glasses with low $C_{\mathrm{g}}$, whereas the ease for shear will be predominant in glasses with high $C_{\mathrm{g}}$. Indeed, $H$ is the result of a competition between the bond strength and $C_{\mathrm{g}}$. On the one side, $C_{g}$ depends very much on the relative size of the constituent elements - and thus on the valency - as well as on the average coordination and electronegativity difference. On the other side, an overall analysis of many chemical systems including metallic ones, shows that the average interatomic bonding energy scales with $T_{g}$ [18]. This is where the atomic bonding energy comes into consideration. We briefly discuss the key features of specific glass systems below.

- Chalcogenide glasses [39-43]: Despite the covalent nature of the interatomic bonding between adjacent chalcogen elements ( $\mathrm{Se}, \mathrm{S}, \mathrm{Te}$ ), $H$ of these glasses is relatively small (bottom left in Fig. 2) because they mainly consist of chain-like structural units, which are prone to relative sliding, owing to the weak inter-chain van der Waals interactions. In these systems, $H$ can be improved by replacing sulfur by selenium [20], which is more refractory, or more significantly by increasing the average coordination number, $<r>$. (For instance, in the Ge-Se system, $<r>$ for the $\mathrm{Ge}_{x} \mathrm{Se}_{(1-x)}$ composition is expressed as $4 x+2(1-x)=2(x+1))$, by incorporating 3 -fold coordinated pnictogen elements such as As or Sb, or even tetra-coordinated ones such as Ge or Si [40,41]. A linear correlation is often reported between $H$ and $\langle r>$ up to a maximum amount of 3-fold or 4-fold coordinated elements, beyond which some demixing occurs (formation of As-As cycling groups or Ge-rich clusters above $40 \mathrm{~mol} \%$ As or Ge for example). Barium fluorozirconate glasses exhibit $H$ values in the 2 to $2.5 \mathrm{GPa}$ range [44]. A major issue with these low $T_{g}$ glasses, especially on approaching the chalcogen rich or halide rich side of the chemical system is that $H$ becomes loading-time and rate dependent, as viscoelasticity becomes significant.

- Phosphate glasses [45,46,53-55]: These glasses exhibit $H$ and $T_{g}$ values in-between those of the chalco-halide and silicate glasses [45]. In regard of the low $T_{g}$ of pure $\mathrm{P}_{2} \mathrm{O}_{5}$ glass $\left(\sim 377^{\circ} \mathrm{C}\right)$, the incorporation of rare-earth elements or tetrahedrally coordinated glass forming cations such as $\mathrm{Si}$ and $\mathrm{Al}$ leads to a pronounced increase of $H$, as well as the substitution of divalent oxide $(\mathrm{CaO}$ or $\mathrm{ZnO}$ ) for monovalent ones $[46,53,54]$. The addition of $\mathrm{CaO}$ or the substitution of $\mathrm{P}_{2} \mathrm{O}_{5}$ for $\mathrm{B}_{2} \mathrm{O}_{3}$ is also found to increase both $H$ and $T_{g}$ in the series presented in Fig. 2 [45,55].

- Silicate glasses [36,56-59]: In view of the impressive quantity of data reported in the literature on these glasses (light grey marks in Fig. 2), largely due to the ease in performing Vickers indentation tests on them, we restrict our discussion to some particular cases, which bring to light the great diversity of the situations, to show that there is mostly no straightforward relationship between $H$ and the chemical composition in this glass system. Starting with alkaline (A) and alkaline-earth 
(AE) silicate glasses, it was noticed by Hand and Tadjiev [36] that as $\mathrm{Na}_{2} \mathrm{O}$ is replaced by $\mathrm{K}_{2} \mathrm{O}$, a bell curve is observed for both $T_{g}$ and $H$, with a maximum of $H$ at about $\mathrm{K}_{2} \mathrm{O} /(\Sigma \mathrm{A}) \approx 0.5$ (where $\Sigma \mathrm{A}$ is the sum of the alkaline oxide constituents). This is the so-called 'mixed alkali effect'. Replacing larger $\mathrm{AE}$ ions ( $\mathrm{Ca}$ or $\mathrm{Ba}$ ) by smaller $\mathrm{Mg}$ ions does not result in an improvement of $H$, $T_{g}$ and $C_{g}$, whilst $\mathrm{MgO}$ is more refractory than $\mathrm{CaO}$ and $\mathrm{BaO}$. Within the composition range studied in [36], $H$ of mixed $\mathrm{A}$ and $\mathrm{AE}$ oxides silicate glasses can be ranked as following: $H(\mathrm{Na}, \mathrm{Ca}, \mathrm{Ba})>$ $H(\mathrm{~K}, \mathrm{Ca}, \mathrm{Mg})>H(\mathrm{~K}, \mathrm{Ba}, \mathrm{Mg})$. Large ions such as $\mathrm{K}$ and $\mathrm{Ba}$ are found to make the glass softer even though the silica content is slightly increased. The same tendency was reported by Hermansen et al. [56], who concluded that $H(\mathrm{Na}, \mathrm{Ca})>H(\mathrm{~K}, \mathrm{Ca})>H(\mathrm{Na}, \mathrm{Ba})>H(\mathrm{~K}, \mathrm{Ba})$ for $(\mathrm{A}, \mathrm{AE})$ silicate glasses containing $75 \% \mathrm{SiO}_{2}$. Besides, an increase of $H$ was observed when up to $25 \%$ of $\mathrm{SiO}_{2}$ was replaced by a mixture of AE oxides, although the Si-O bond energy is much larger than the $\mathrm{Ca}-\mathrm{O}$ and the $\mathrm{Ba}-\mathrm{O}$ ones. This is because the corresponding increase of the atomic packing efficiency in comparison to a- $\mathrm{SiO}_{2}\left(C_{g} \sim 0.45\right)$ compensates for the decrease of the mean dissociation energy, which clearly reflects in the decrease of $T_{g}$. Hence, a horizontal line can be drawn in Fig. 2 through the point associated with a- $\mathrm{SiO}_{2}$ that intersects with many equally hard glasses containing $\mathrm{A}$ and $\mathrm{AE}$ oxides, and thus exhibiting much lower $T_{g}$ values. Focusing on $\mathrm{A}$ and AE silicates, Smedskjaer et al. [57] observed that replacing the A element by a smaller one $(\mathrm{Na} \rightarrow \mathrm{K} \rightarrow \mathrm{Rb} \rightarrow \mathrm{Cs}$ ) does not induce the same $H$ change as the substitution of the AE element by a smaller one $(\mathrm{Mg} \rightarrow \mathrm{Ca} \rightarrow \mathrm{Sr} \rightarrow \mathrm{Ba})$. Whilst both cases correspond to an increase of the cationic field strength, the A substitution leads to softening whereas the AE one results in hardening. It was suggested by the authors that large A cations, being weakly bonded to the silicate tetrahedra, promote a stronger atomic network skeleton $\left(\mathrm{SiO}_{4}\right.$ tetrahedra for example). In contrast, in the cases of cations with larger valency such as AE $(+2)$ or Rare-earth $(+3)$, the cationic field strength is directly affecting $\mathrm{H}$, and thus a decrease of the ionic radius induces an increase of $H$. The presence of elements with multiple coordination numbers such as $\mathrm{Al}(4,5,6), \mathrm{Ge}(4,5), \mathrm{B}(3,4)$, which enhance the atomic packing in comparison to tetrahedrally coordinated glass forming elements such as $\mathrm{Si}$, results in an increase of $H$. As was discussed by Morin et al. [58], in simple silicate glasses, where network-forming cation coordination is fixed, the fraction of non-bridging oxygens (NBO) per network cation is also fixed and thus structure-property effects are limited to structural details of network connectivity and bond strengths (other than network speciation). On the contrary, this constraint is relaxed in aluminoborosilicates in which B and Al coordination vary significantly.

Furthermore, when cations with the same valences and coordination numbers are present, smaller ionic radii lead to large cationic field strength - given by the valency of the cation divided by the square of its distance to a neighboring oxygen atom - and thus to a more efficient packing. 
For example, $H$ is significantly increased (from $\sim 6$ to $9 \mathrm{GPa}$ ) as La is replaced by $\mathrm{Y}$, or further by $\mathrm{Lu}$ and $\mathrm{Sc}$ in rare-earth aluminosilicate glasses with fixed $\mathrm{Al}_{2} \mathrm{O}_{3}$ and $\mathrm{SiO}_{2}$ contents [59]. A similar trend was observed ( $H$ increases from 5.6 to $6 \mathrm{GPa}$ ) in a series of phosphate glasses as La was substituted for $\mathrm{Nd}, \mathrm{Sm}, \mathrm{Gd}$, and finally Y [46].

In the sodium titanium silicate system [60], $v$ increases monotonically with the sodium and with the titanium contents, from 0.182 for the $\mathrm{Na}_{2} \mathrm{O}(10)-\mathrm{TiO}_{2}(4)-\mathrm{SiO}_{2}(86)$ composition to 0.245 for the $\mathrm{Na}_{2} \mathrm{O}(25)-\mathrm{TiO}_{2}(7)-\mathrm{SiO}_{2}(65)$ (numbers in brackets express the composition in mol. \%). Commensurately, the deformation mechanism evolves toward more volume conservative shear flow and less densification, as evidenced by the relative contribution of both processes to the indentation volume [61]. The transition in the deformation mechanism coincides with a significant change in the structure with the formation of $(\mathrm{Ti}, \mathrm{Na})$ rich clusters inducing local increases of $\mathrm{C}_{\mathrm{g}}$ and of the number of non-bridging oxygen atoms as well, in favor to shear flow, which becomes pronounced in glasses with more than $25 \mathrm{~mol} \% \mathrm{Na}_{2} \mathrm{O}$ and $10 \mathrm{~mol} \% \mathrm{TiO}_{2}(v>0.23)$. It is noteworthy that although $T_{g}$ increases, from 510 to $600{ }^{\circ} \mathrm{C}$, and $v$ decreases as the amounts of $\mathrm{TiO}_{2}$ and $\mathrm{Na}_{2} \mathrm{O}$ decrease to the benefit of the $\mathrm{SiO}_{2}$ content, $H$ remains nearly invariant. $H$ is about 4.7 and 4.6 GPa (10 N Vickers indentation load) for the $\mathrm{Na}_{2} \mathrm{O}(10)-\mathrm{TiO}_{2}(7)-\mathrm{SiO}_{2}(83)$ and $\mathrm{Na}_{2} \mathrm{O}(25)$ $\mathrm{TiO}_{2}(10)-\mathrm{SiO}_{2}(65)$ grades respectively, having $v$ values of 0.183 and 0.237 . But for the $\mathrm{Na}_{2} \mathrm{O}(15)-$ $\mathrm{TiO}_{2}(10)-\mathrm{SiO}_{2}(75)$ intermediate case, $H=5.4 \mathrm{GPa}$ and the smallest resistance to indentation cracking is recorded.

- Silicon oxynitride glasses [47-51]: These glasses are mostly obtained by conventional melting in either argon or nitrogen atmosphere, typically up to $1750^{\circ} \mathrm{C}$, adding some nitrided powders such as $\mathrm{AlN}$ and $\mathrm{Si}_{3} \mathrm{~N}_{4}$ in the powder mixture. Nitrogen is found to substitute for oxygen in the glass network leading to the formation of $\mathrm{Si}-(\mathrm{O}, \mathrm{N})_{4}$ tetrahedral units, where it is mostly connected to three $\mathrm{Si}-(\mathrm{O}, \mathrm{N})_{4}$ tetrahedra. A significant improvement of the cross-linking degree is achieved, which results in better mechanical properties in general. As some oxygen is replaced by nitrogen, the dissociation energy is not affected in a significant manner, but the $C_{\mathrm{g}}$ is much larger (from $\sim 0.5$ for most $\mathrm{A}$ and $\mathrm{AE}$-silicate glasses to $\sim 0.55-0.6$ for silicon oxynitride). Consequently siliconoxynitride glasses, and especially those containing rare-earth oxides, are among the hardest inorganic - and non-metallic - glasses. The substitution of some oxygen by tetrahedrally coordinated carbon to form silicon oxycarbide glasses results in an increase of the dissociation energy and thus in $T_{g}$ up to $\sim 1300^{\circ} \mathrm{C}$ for the $\mathrm{SiOC}$ grade (as compared to about $1070-1200{ }^{\circ} \mathrm{C}$ for a-SiO${ }_{2}$ ) [52]. However, these glasses suffer from a relatively open structure, with an $C_{\mathrm{g}}$ in the range of 0.41-0.43 [62]. Consequently, the permanent deformation in them stems essentially from densification and $H$ is not as large as the one reported for silicon oxynitride glasses. 


\subsection{Indentation cracking}

\subsubsection{Driving force and crack morphology}

As already mentioned, the indentation volume after complete unloading is still larger than the sum of the densification and the pile-up volumes: a significant amount of matter is radially displaced permanently during loading and is responsible for the development of the residual stresses. The stress field associated with the loading stage as well as the residual stress field give raise to a complicated microcracking pattern in the vicinity of the imprint. The way glass deforms beneath the sharp contact loading governs the microcracking features. It was long recognized $[63,64]$ that different crack morphologies occur depending on the glass composition and indenter geometry. For instance, surface ring cracks (corresponding to the Hertzian cone cracks that develop under the surface) are predominantly observed in amorphous silica and silica-rich glasses (as well as borates to a lesser extent), whereas radial (radial/median semi-elliptical under the surface) cracks are seen to extend from the indentation corners in the case of soda-lime-silica glasses (such as ordinary window and crown glasses) [65]. A binary classification was first proposed, where glasses exhibiting radialmedian cracking were considered as 'normal', as opposed to abnormal ones (exemplified by a-SiO${ }_{2}$ ). The ring crack formation at the surface of amorphous silica and silica-rich glasses (low $C_{g}$ glasses), and its development toward a cone crack with a steep angle was described in the pioneering work of Knight et al. [66]. It was proposed by them that the shear induced compaction of the region beneath a conical indenter extends to the contact area so that the propagation of ring cracks that nucleate in the contact zone occurs along shear stress trajectories. The truth is that all glasses are partially normal and abnormal, depending on the extent to which they densify during indentation. From residual-stress observations, it was noticed by Arora et al. [12] that reconstructive flow takes precedence over densification as the glass atomic structure becomes less and less open, or more closely packed. A mechanics analysis of this problem shows that $v, E$, and $H$ play key roles in this process. In particular, a large variation in $v$, when glasses from different chemical systems are compared, from 0.1 (SiOC and silica-rich glasses) to above 0.28 (oxynitride glasses), is primarily responsible for the dramatic changes in the indentation pattern, from ring/cone cracking at low $v$ to fully developed radial-median cracks at large $v$, until ductility shows up typically for $v>0.4$, where stress relaxation via plasticity or viscous flow becomes sufficient to suppress microcracking (for Pd based MGs for example, or as $T$ gets close to $T_{g}$ ) $[64,65]$. The dependence of the stress field at the periphery of the imprint on $E, H$ and $v$ is illustrated in Fig. 3 (see [6,64] for details regarding the calculations), in the case of the normal component $\sigma_{r r}$ (in spherical coordinates, with origin on the surface at contact point, $\theta$ being the angle to the loading axis, and $a$ the radius of the circular imprint associated with the equivalent conical indenter). This stress component is the driving force for the ring/cone cracking at $\theta=\pi / 2$ and for the subsurface lateral cracking (eventually resulting in chipping) at $\theta=0$. For $v<0.18, \sigma_{r r}(\theta=\pi / 2)$ is 
positive on loading, irrespective of the $E / H$ ratio $^{5}$. This means that ring/cone cracks are likely to form on loading in this range of $v$, which corresponds to silica-rich glasses for example. An examination of $\sigma_{r r}(\theta=0)$, shows that it is negative on loading for $v<0.2$, but becomes positive on unloading at higher $v$, with an intensity that goes up rapidly with the $E / H$ ratio, especially for $v$ between 0.25 and 0.35. In this latter case, lateral cracking can be expected upon unloading and more particularly for glasses with $v \sim 0.3$, such as silicon oxynitride ones.

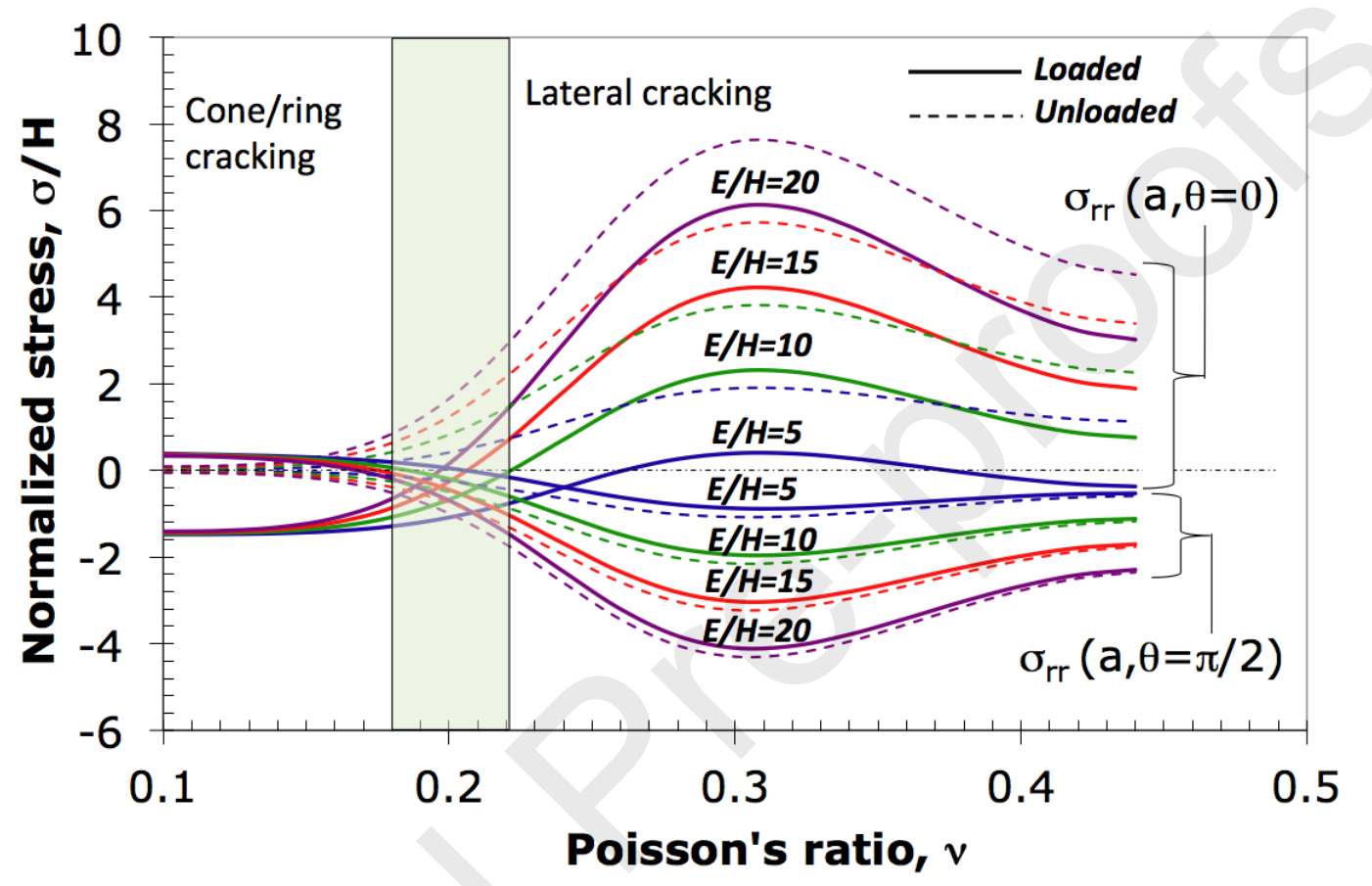

Fig. 3. Driving force for ring/cone cracking, $\sigma_{r}(r=a, \theta=\pi / 2)$, where $a$ is the radius of the equivalent cone, and subsurface lateral cracking, $\left.\sigma_{r}(r=a, \theta=0)\right)$ for different $E / H$ ratios as a function of the Poisson's ratio, v. (Reprinted with permission from Rouxel et al. [6]. Copyright (2019) Elsevier)

The $(E / H, v)$ regimes where radial/median cracks, which are governed by the $\sigma_{\phi \phi}(\theta=\pi / 2)$ stress component, and the ring/cone cracks are favored are illustrated in Figs. 4 (a) and (b), respectively, for different glass forming systems. In these figures, the thick red line shows the isostress contour where $\sigma_{\phi \phi}(\theta=\pi / 2)$ vanishes, i.e., where the driving force for cracking reaches its minimum. It is noteworthy that the 'less brittle' glass developed by Sehgal and Ito [67], with $E / H=$ 14.7 and $v=0.18$ stands precisely in the red contour for $\sigma_{r r}(\theta=\pi / 2)$ and in the compressive side for $\sigma_{\phi \phi}(\theta=\pi / 2)$. It is important to note, however, that the analysis of the driving force for indentation

\footnotetext{
${ }^{5}$ Whether cracks will actually show up in the glass under indentation does not solely depend on this driving force, but also on the fracture toughness of the glass, which ultimately controls the onset for crack initiation.
} 
cracking presented in Figs. 3 and 4 does not allow to conclude whether cracks will form or not; the occurrence of cracks is ultimately controlled by the fracture toughness of the material.
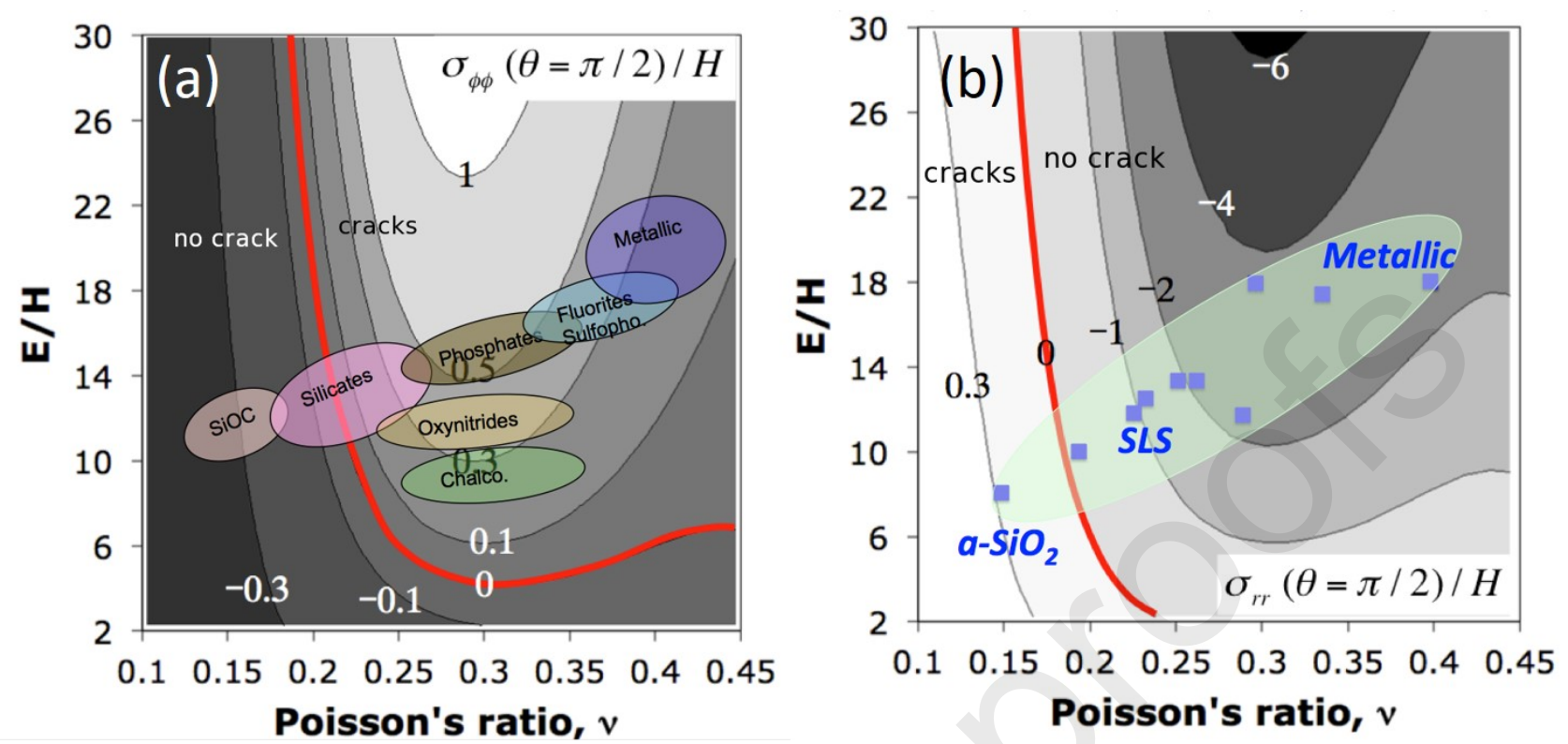

Fig. 4. Driving force for two common indentation cracking patterns, namely a) the radial-median crack system, as illustrated by $\sigma_{\phi \phi}$ at the surface $(q=p / 2)$ (left), and b) the ring-cone crack system occurring in loose packed atomic structures (silica-rich glasses for example) as given by $\sigma_{r r}$. The isostress contours were drawn by means of the expression of the stress components at the vicinity of the imprint provided in $[6,64]$. The thick red line corresponds to zero stress and separate domains where cracks are either unlikely to show up (negative stress) or favored (positive stress).

The Vickers indentation responses of different glasses, or of a given glass at different $T$, are illustrated in Fig. 5. As anticipated from the driving force, a-SiO${ }_{2}$ and borosilicate glasses are prone to cone cracking, whereas soda-lime-silicates and fluorite glasses exhibit the radial-median crack system, with some visible subsurface cracking when $v>0.24$, and even the formation of chips at $v>$ 0.26. Nevertheless, some critical load needs to be reached for the microcracking pattern to fully develop (this will be discussed in the next subsection), as illustrated for the case of a borosilicate indented at 1 and $98.07 \mathrm{~N}$ (Figs. $5(\mathrm{~g})$ and (h)). As $T$ is increased, both $E / H$ and $v$ change. Since $H$ decreases faster than $E[68,69], E / H$ increases, as well as $v$, especially in the case of 'fragile' glasses [52] (per Angell's concept). Consequently, in the case of an ordinary window glass, damage is more pronounced as $T$ is increased up to about $400{ }^{\circ} \mathrm{C}$ [70]. At higher $T$, the behavior becomes viscoelastic and a brittle to ductile transition occurs, such that cracking disappears at $480{ }^{\circ} \mathrm{C}$ [71]. 

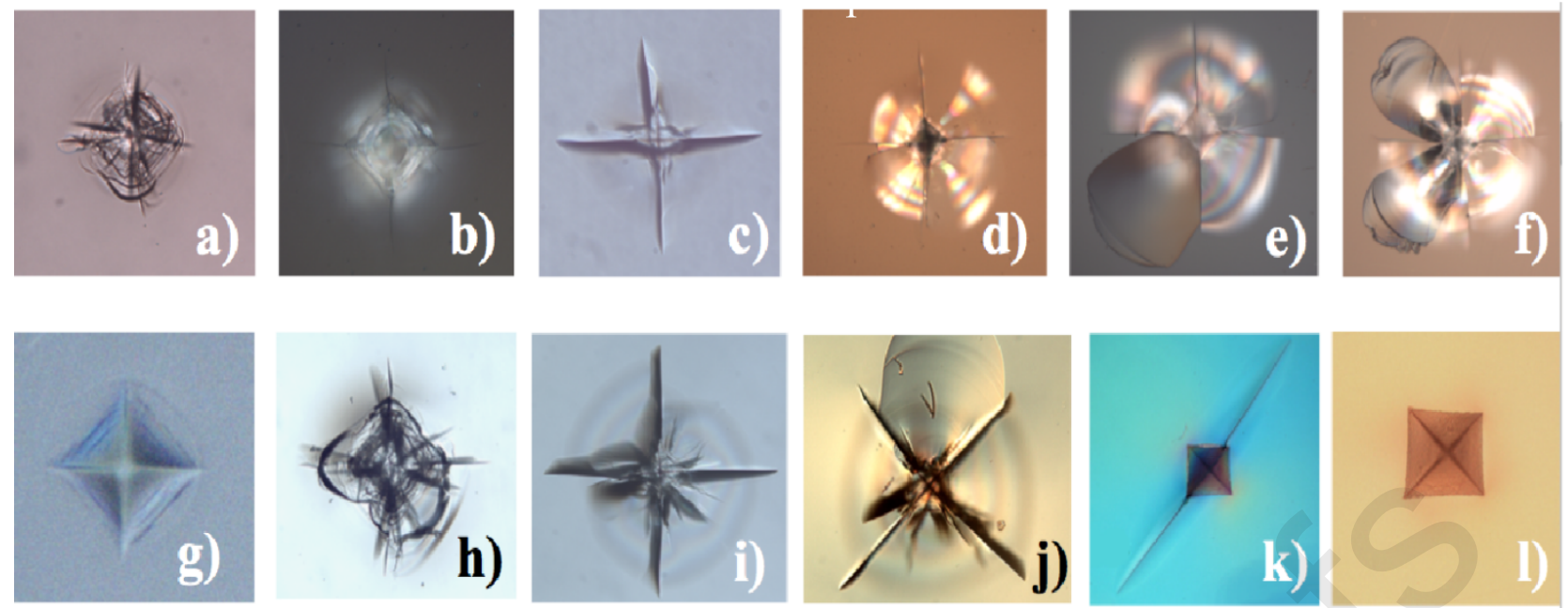

Fig. 5. Optical micrographs of different indentation cracking patterns produced by Vickers indentation. a) to $\mathrm{f}$ ): Indentation load of $9.81 \mathrm{~N}$ for $15 \mathrm{~s}$ for oxide glasses with different Poisson's ratio, from left to right: 0.15 (a-SiO2), 0.195 (borosilicate), 0.227 (soda-lime-silica: SLS), 0.248 (SLS), 0.264 (SLS), and 0.298 (fluorite) (after [64]). g) and h): borosilicate for $1 \mathrm{~N}$ and $98.07 \mathrm{~N}$ indentation load. i) to 1): SLS glass for $49 \mathrm{~N}$ load at 20, 200, 450 and $480{ }^{\circ} \mathrm{C}$ (after [70]).

\subsubsection{Crack initiation and cracking resistance}

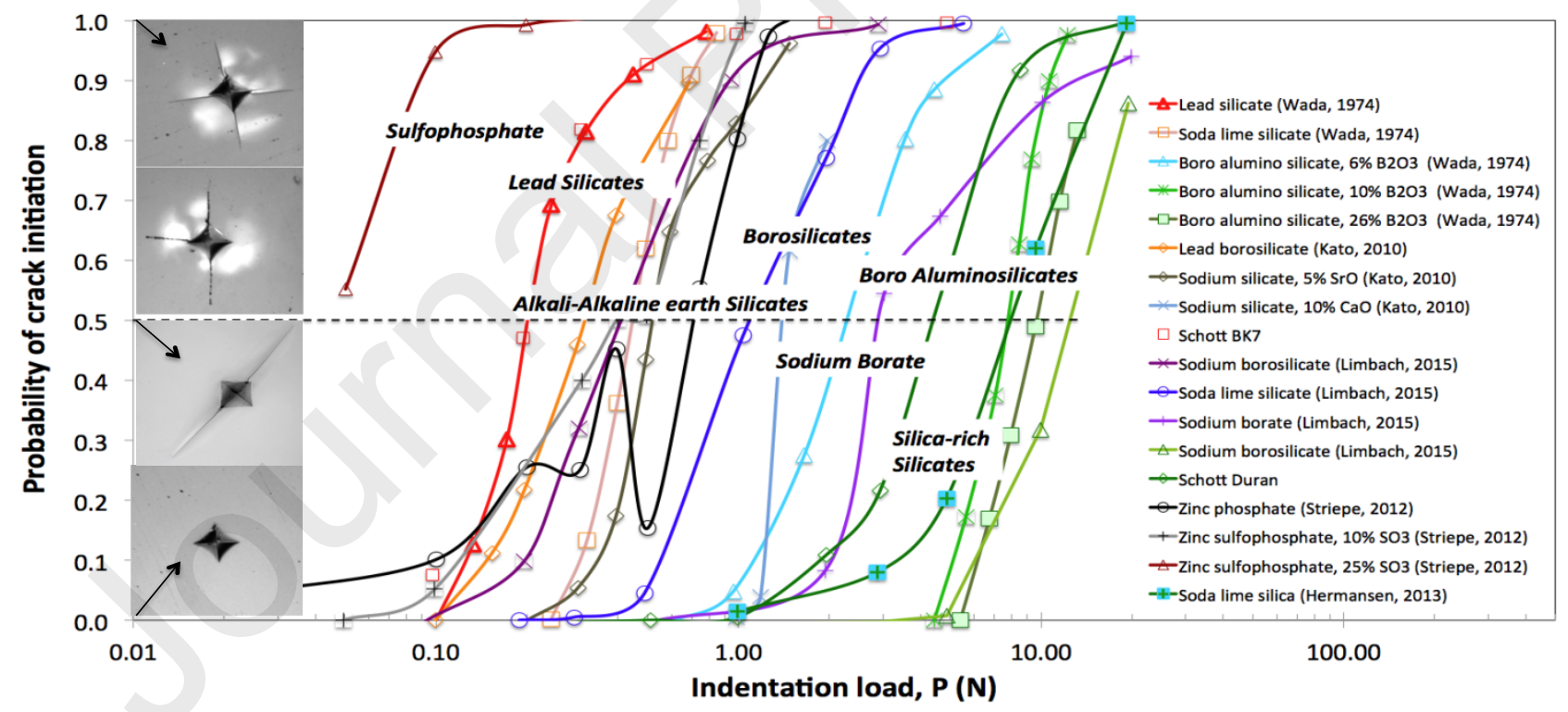

Fig. 6. The probability of crack initiation, determined as the average number of radial cracks per corner out of a series of indents performed at a given load (typically over 10), as a function of the indentation load, $P$. The crack resistance is the load at which the probability of crack initiation is equal to $50 \%$ (i.e., on average two corners out of four will contain cracks). Insets on the left show typical indentation cracking patterns corresponding to 0, 2, 3 and 4 well developed radial cracks. All results were obtained in ambient conditions, i.e., in humid air. Unfortunately, the accurate value of the water content in the air was not specified by most authors. 
Lawn et al. [72] suggested that the widely-used expanding cavity models for describing the deformation fields underneath indenter are then no longer valid when a material undergoes densification by compaction within the immediate contact zone of a sharp indenter. (This is also true when phase transformations occur underneath the indenter [73,74].) This is because of the intense hydrostatic compressive stresses that render the volume of the indentation to be more readily accommodated within the compaction zone, diminishing the intensity of any residual stresses. High pressure investigations conducted in the past twenty years on series of glasses from different chemical systems, either by isostatic loading or by sharp contact loading, uniformly concluded that densification contributes to over $40 \%$ of the indentation deformation [15,20,22,31,56,60,75-78]. Therefore, and in view of (i) the wide diversity in the glass deformation responses, and (ii) the lack of relevant universal constitutive law, methods based on the measurement of the indentation crack length are not recommended for the estimation of fracture toughness [5,79]. Nevertheless, sharp contact loading experiments, by means of cube-corner, Vickers, Knoop or Berkovich indenters, are still remarkably useful to characterize the onset for crack initiation, with the aim to reproduce what may happen in service conditions when the surface of a glass part is damaged by impacts, scratches, indents, etc. The crack resistance of a glass can be assessed by means of Vickers indentation tests, by indenting stepwise at increasing loads, and counting the number of radial cracks emanating from the corners of the residual imprints [80]. The probability of crack initiation is then defined as the ratio between the number of corners where a radial crack was formed and the total number of corners (4 for a Vickers test). When the occurrence of two radial cracks (optical microscope resolution) from two opposite corners of a Vickers indent (four cracks are observed when the indentation cracking pattern is fully developed) is considered as a criterion for the onset of indentation cracking, values of $\sim 0.3,0.7,1$, and $10 \mathrm{~N}$ are obtained for the critical indentation load for lead glasses, window glasses, E-glass (a low alkali boro-aluminosilicate glass) and the mother Vycor glass (silica-rich (96 mol.\%) borosilicate glass) respectively (Fig. 6). The so-called 'less brittle' glass ( $79 \mathrm{~mol} \% \mathrm{SiO}_{2}$ with alkaline and alkaline-earth) with a critical indentation load for crack initiation larger than $10 \mathrm{~N}$ was also proposed in the late $1990 \mathrm{~s}$, which represents a more than one order of magnitude improvement, in comparison to an ordinary window glass [80]. Nevertheless, there is no one to one relation between the onset load for crack initiation and mechanical properties such as $H, K_{I c}$, elastic moduli, strength, or any simple combination of those such as the brittleness index $\left(B=H / K_{I c}\right)[5,22,75,81]$. In an extensive comparison of German medieval and ancient Turkish glasses, Hasdemir et al. [81] reported a much better crack resistance for an ancient Turkish glass with $70.5 \mathrm{~mol} \% \mathrm{SiO}_{2}\left(C_{g} \sim 49.5\right)$ than for a medieval glass with $46.2 \mathrm{~mol} . \% \mathrm{SiO}_{2}\left(C_{g} \sim 53.6\right)$. The general trend, again confirming the crucial role of $C_{g}$, is that glasses with relatively open atomic structures, such as a-SiO 
toward crack initiation than glasses with large $C_{\mathrm{g}}$, such as lead-borate glasses for example [80], and indeed an increase in the critical crack initiation load with the densification contribution to the formation of the imprint (and thus with the decrease of the intensity of the residual stress field) was found (Fig. 7) [22,75,76,80,81]. It is interesting to note here that although silicate glasses are based on the same $\mathrm{SiO}_{4}$ tetrahedral units, the secondary cationic species, mostly alkaline and alkaline-earth ones, play a key role in determining the critical load for indentation cracking. The overall trend is that the more efficiently the atomic network space is filled, the smaller the critical load becomes. In general, enhanced levels of nano-porosity and free volume content are beneficial to the indentation cracking resistance.

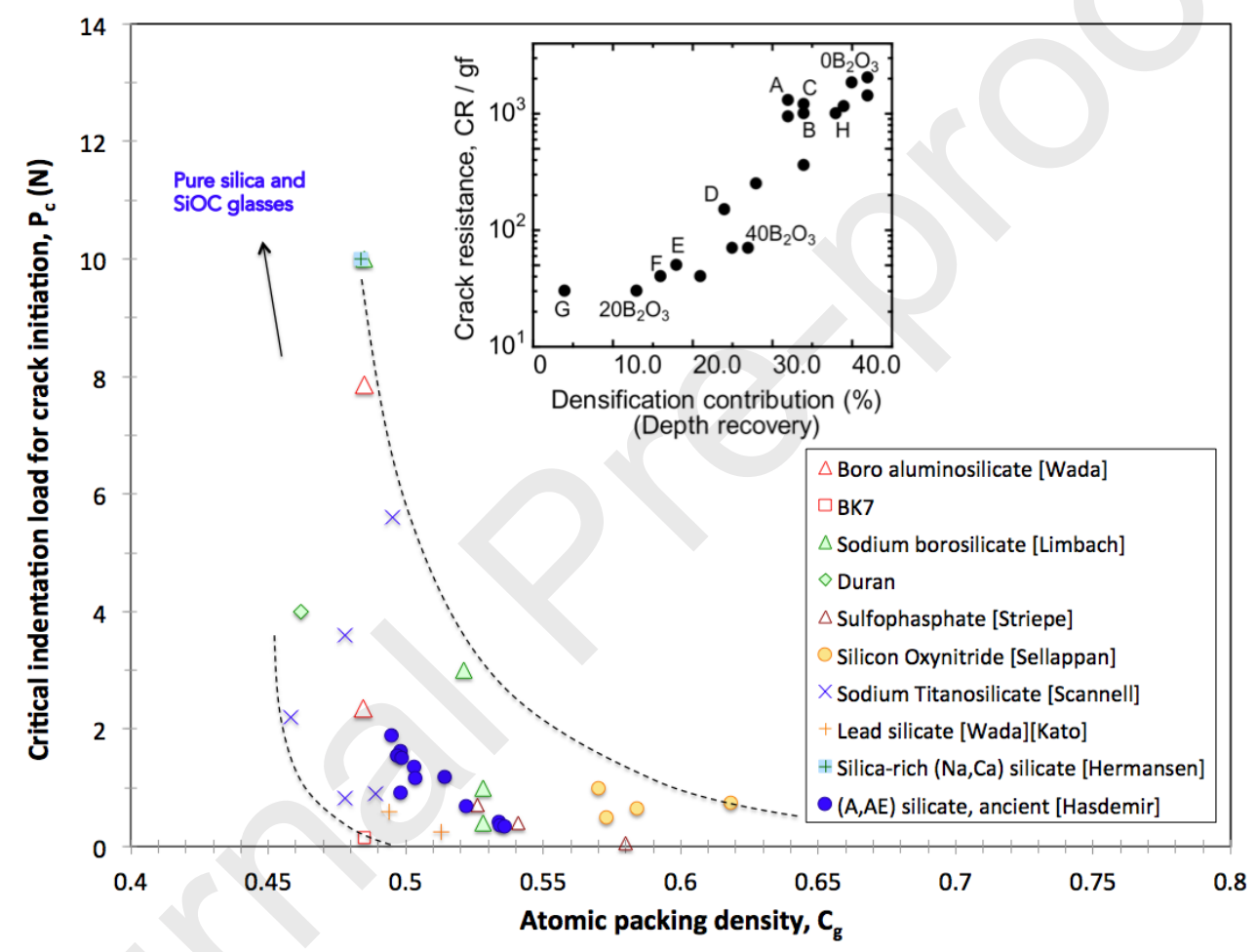

Fig. 7. The critical crack initiation load (associated with the formation of two corner radial cracks) as a function of the atomic packing density. The inset is reprinted with permission from Yoshida [15]. Copyright (2019) Elsevier.

\subsection{Effects of time, temperature, and pressure}

The indentation response of glasses is affected by time in several different ways. First, due to the exceptional stress intensity (GPa order) at the indentation site, creep cannot be excluded even at RT. Besides, time, especially during annealing at $T$ close to $T_{g}$, allows for the structural relaxation of the material, i.e., for a reduction of the free volume content, so that the indentation behavior slightly evolves toward a relatively lower contribution of densification and a larger amount of pile-up around the indent. The rate at which the glass is loaded is also, obviously, of paramount importance. Unlike 
densification, shear flow is not kinematically bounded. Consequently, its relative contribution can increase sharply with the loading time and with $T$. For glasses with different $T_{g}$ values, it tends to decrease with rising $T_{g}$. As a consequence of shear-thinning, which is favored in weakly polymerized network structures, viscosity may drop by orders of magnitude due to the fact that shear stresses are in the order of GPa in the regions that are immediately beneath the indenter. In addition, because of the large stress and strain rate levels at indentation site, the thermodynamics of the processes at play during sharp contact loading tend to be singular in character, and involves heat fluxes as well as entropy changes, and consequently local variations of the physical properties of the material. Nevertheless, considering a simple linear Maxwell model for the creep function, the following straightforward expression for the time-dependence of $H$ is obtained [82]:

$$
H(t)=\frac{2 \eta \mu}{(\mu t+\eta) \cdot \tan \varnothing}
$$

where the $\eta / \mu$ ratio gives the characteristic relaxation time, and $\phi$ is the apical angle of the axisymmetric indenter (equivalent cone for a Vickers indenter). In the case of a purely elastic materials $(\eta \rightarrow \infty)$, this expression reduces to the classical elasticity solution (Eq. 1).

Most glasses experience a decrease of their $H$ with increasing $T$. As discussed in subsection $\S 2.2$, this decrease is more dramatic than the corresponding decrease of the elastic moduli. Consequently, an increase of the intensity of the residual stress field, which is governed by the $E / H$ ratio, and thus the driving force for cracking, is expected. The increase of the $E / H$ ratio is particularly large when stiffening of the glass with increasing $T$ occurs (this is the so-called 'elastic anomaly' observed for a-SiO 2 ). Consequently, the formation of radial/median cracks, as opposed to the ring/cone cracking, becomes favored as $T$ increases from below $T_{g}$, at least based on a simple elastic approach of the far field stress. This was experimentally verified in a few cases, mostly for a-SiO and soda-lime-silicate glasses [68-70]. As the Vickers indentation testing $T$ is raised from ambient to $400{ }^{\circ} \mathrm{C}$, the ring/cone cracking system observed in a-SiO${ }_{2}$ disappears to the benefit of the $\mathrm{radial} / \mathrm{median}$ system. Conversely, as the testing $T$ is decreased from the $\mathrm{RT}, E / H$ as well as $v$ decrease and shear flow becomes less and less significant and eventually disappears at $-196{ }^{\circ} \mathrm{C}$ (liquid nitrogen) as observed by Kurkjian et al. [27] in the case of a-SiO${ }_{2}$ and a soda-lime-silica glass, for which the $E / H$ ratio decreases from 8 and 10 at RT to 3 and 6.3 , respectively at $-196{ }^{\circ} \mathrm{C}$.

Pressure, $P$, and $T$ have strong effects on the atomic network structure. In general, the $C_{\mathrm{g}}$ increases with $P$ while $T$ tends to de-structure or depolymerize the network. In both the cases, a rise of $v$ is noticed. High pressure experiments lead to denser materials (even after unloading), to an extent that was found to scale with $v$ of the glass because of the intimate relationship that exists between $v$ and the $C_{\mathrm{g}}[65,83]$. Hence, there is less room for further indentation densification after a high-pressure 
treatment. Both experiments [13] and molecular dynamics (MD) simulations [84] point to a shift to more pile-up of matter at the vicinity of the imprint and thus shear flow after high pressure treatments and, as a matter of fact, $v$ is mostly larger in the treated glass than in the pristine sample.

\subsection{Nanoindentation studies}

Most of the indentation studies performed on glasses up to the 1980s were conducted with conventional hardness tests in which the impression area is measured after the indenter is removed. Since this is an ex-situ measurement process, loss of some crucial information, which could otherwise be obtained from the real-time indentation response measurements (such as time- and load-dependent parameters), was a distinct possibility. The advent of the nanoindentation technique in the 1980 s and the widespread adaption of it for measuring mechanical properties (especially of 'small volume materials') made it possible to extract additional information during indentation, since the small-load instrumented test can provide real-time record of indentation responses obtained under precisely controlled conditions. Consequently, instrumented indentation in general, and nanoindentation in particular, is extensively employed to study a wide variety of physical phenomena in inorganic glasses. In this section, we briefly review some of them while nanoindentation studies on MGs are summarized in subsection $\S 3$.

\subsubsection{Densification behaviour}

The nanoindentation technique was utilized to gain intricate insights into the permeant deformation characteristics of various glasses. The fact that the areas under the loading and unloading parts of the $P-h$ curves give the work done during indentation and elastic recovery, respectively, was exploited by Suzuki et al. [85] to examine the energy spent for permanently indenting fused silica glass at RT with a Vickers tip for different maximum depths of penetration, $h_{\max }$. On the basis that the energy spent indenting the glass was similar to the reported activation energy required for the recovery of densification in it, they conclude that the main mechanism of permanent deformation during indentation is densification. Lee et al. [86] examined the effect of different indentation strains, varied by using different sharp-tipped indenters, on commercial window glass. By comparing the atomic force microscopy images of the indents before and after annealing (and through the process evaluating the volume of the recovery due to annealing), they revealed that the relative contribution of the shear flow to the total permanent deformation becomes larger with the indentation strain. They then employed a spherical indentation tip with which the indentation strain can be varied by changing $h_{\max }$ and concluded that the plastic deformation at the early stage of indentation is dominated by densification, and that the contribution of shear flow increases with strain. Their strain rate-based analysis shows that the latter's mechanism is shear transformation zone (STZ) mediated one. 
Niu et al. [87] employed nanoindentation to introduce surface defects in a controlled manner and then study the effect of such defects on the chemical dissolution rates of silica and soda-lime silicate glass surfaces through atomic force microscopy characterization. Their experimental results show indentation leads to enhanced dissolution rate, which was attributed to densification of the glass that occurs underneath the indenter. Such an enhancement completely 'disappears' upon postindentation annealing, proving that pressure-induced structural modifications are reversible. On this basis, they propose the study of dissolution rate can be utilized to probe the structural changes in glasses during indentation at the nanometer scale.

\subsubsection{Rates effects on hardness}

Due to the ready availability of polished disc samples, fused silica, i.e., a- $\mathrm{SiO}_{2}$, is commonly used as a reference material (or 'standard' sample) for the calibrations and verification of nanoindentation equipment and indenter tip. However, it is often overlooked that fused silica exhibits time-dependent plastic deformation during indentation, and creep can affect the unloading curve and should be minimized by a load-hold at the peak load [88]. While this serves as an example for highlighting the necessity of examining the time-dependent nanoindentation responses of glasses, the number of studies performed on this topic thus far are not many. The adopted approaches in these studies can be categorized into the following two groups: (1) directly examining the effect of the indentation rate (either loading rate or indentation strain rate) on the measured $H$ and (2) indirectly estimating the creep behavior.

The effect of the loading rate $(\dot{P} \sim \mathrm{d} P / \mathrm{d} t$ where $P$ is the load and $t$ is the time) on $H$ of sodalime-silica glass was investigated over a wide range of $\dot{P}$ [89-91]. A two-stage behavior can be seen from it; $H$ increases rapidly for up to some critical rate, whereafter the enhancement with $\dot{P}$ occurs less steeply (Fig. 8). In contrast, 'micro-indentation' experiments are inconclusive; the $H$ is increased [92], is decreased [93] or is almost rate-independent [94]. 


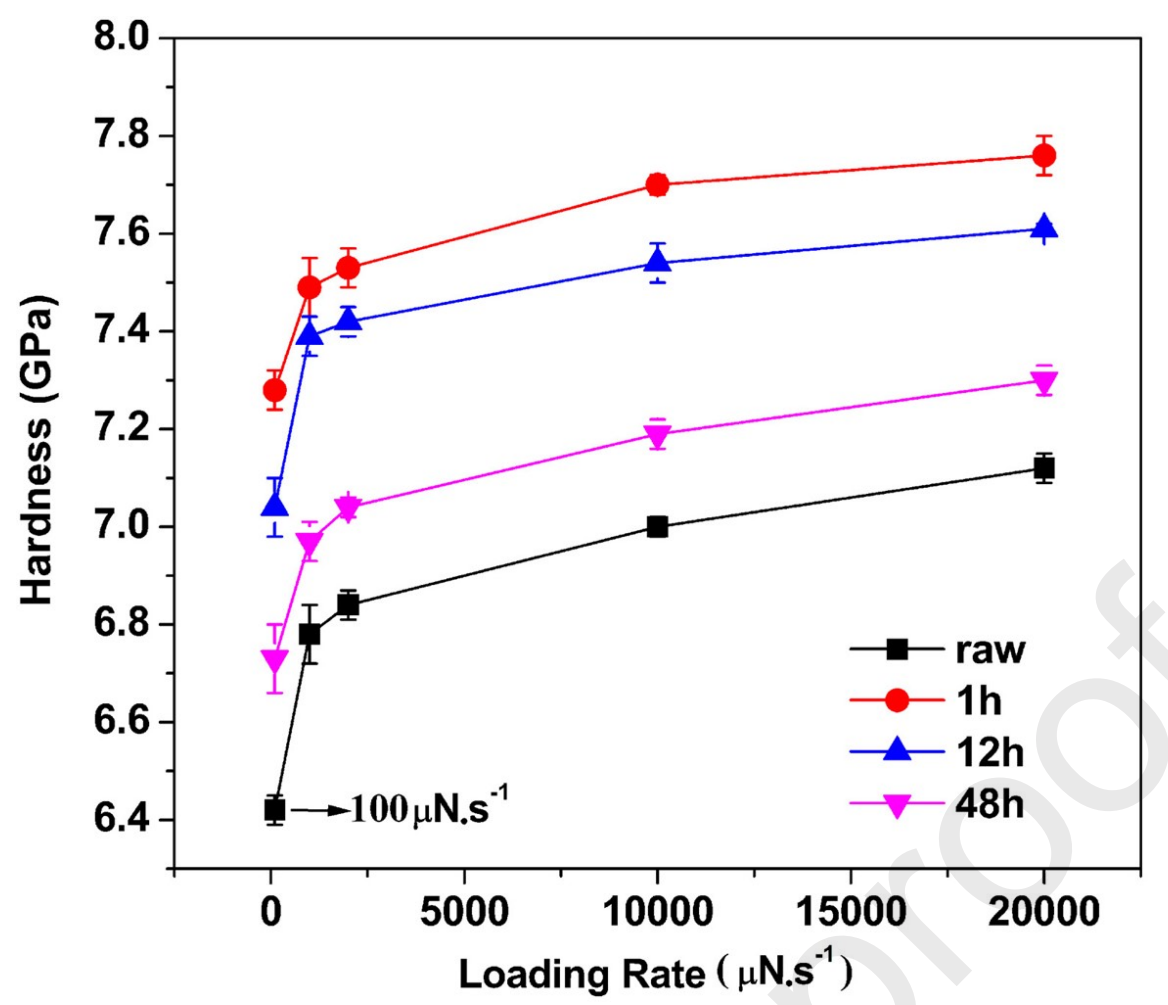

Fig. 8. Nanoindentation hardness variation as a function of loading rate performed on raw and ionexchanged (for different periods of time) aluminosilicate glasses. (Reprinted with permission from Li et al. [95]. Copyright (2018) Elsevier)

Studies on the influence of indentation strain rate $\left(\dot{\varepsilon} \sim h^{-1}(\mathrm{~d} h / \mathrm{d} t)\right)$ on $H$ can lead to an estimation of the strain-rate sensitivity (SRS), $\frac{\partial H}{\partial \dot{\varepsilon}}$, which is often accomplished by conducting strainrate jump tests. The SRS values of a wide variety of non-metallic glasses over a broad range of compositions including covalent, ionic, and superionic (typically containing Li, $\mathrm{Na}, \mathrm{S}, \mathrm{Ag}$ or I, with ionic conductivities better than $10^{-3} \mathrm{~S} \cdot \mathrm{cm}^{-1}$ ) glasses are investigated by Limbach et al. [96], who attempted to correlate them with the thermo-physical and structural properties such as reduced glass transition temperature ( $\left.T / T_{g}\right), C_{\mathrm{g}}$, average single bond strength, and $v$ (Fig. 9). As seen, SRS in glasses is relatively small (the maximum value is less than 0.1 ). While broad correlation could be found (for example, SRS increases with $T / T_{g}$, especially for $T / T_{g} \geq 0.6$ ), the trends are somewhat scattered. 

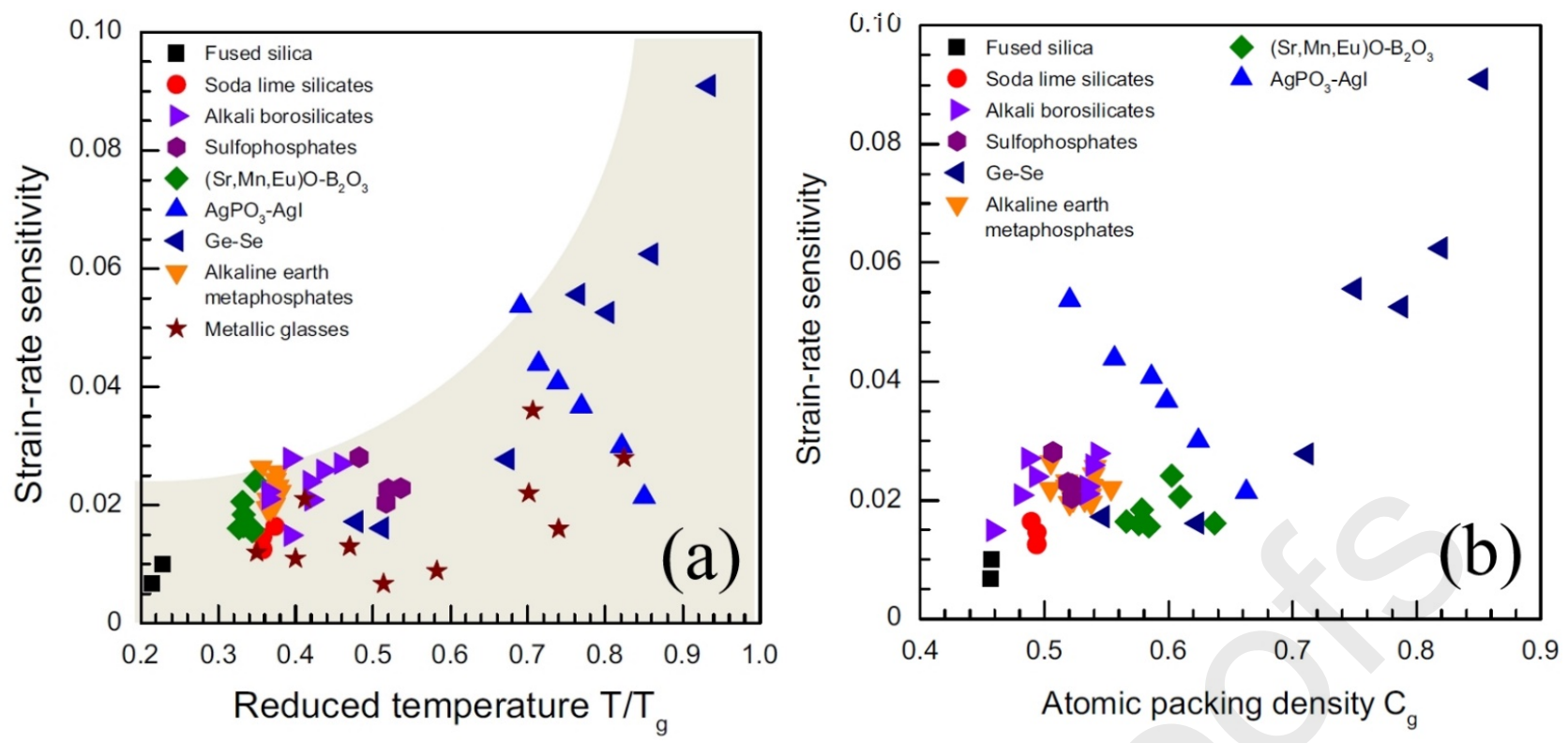

Fig. 9. Strain rate sensitivity data obtained using the nanoindentation tests on various glasses plotted as a function of (a) the reduced temperature, and (b) the atomic packing density. (Reprinted with permission from Limbach et al. [96]. Copyright (2014) Elsevier)

Early studies on the nanoindentation creep of non-metallic glasses were focused on a specific topic: the effect of water $\left(\mathrm{H}_{2} \mathrm{O}\right)$ on the degradation of the glass. Han and Tomozawa [97], who performed 'instrumented' micro-indentation, and Keulen [98] explored the influence of the water content in glass on the indentation creep. They found that water enhances the creep rate by promoting viscous flow [99]. To date, limited studies have been carried out on the nanoindentation creep behavior of non-metallic glasses (for instance, see [100]). However, detailed mechanisms that can explain how and why the nanoindentation parameters (including the peak load, $\dot{P}$, indenter type, and holding time) affect the indentation creep behavior of non-metallic glasses are not fully understood yet and hence require further exploration. Here, it is important to note that decoupling the creep effects from those of machine drift during nanoindentation, which could be substantial for some instruments, at various loading rates or hold times could pose a significant challenge.

\subsubsection{Indentation size effect}




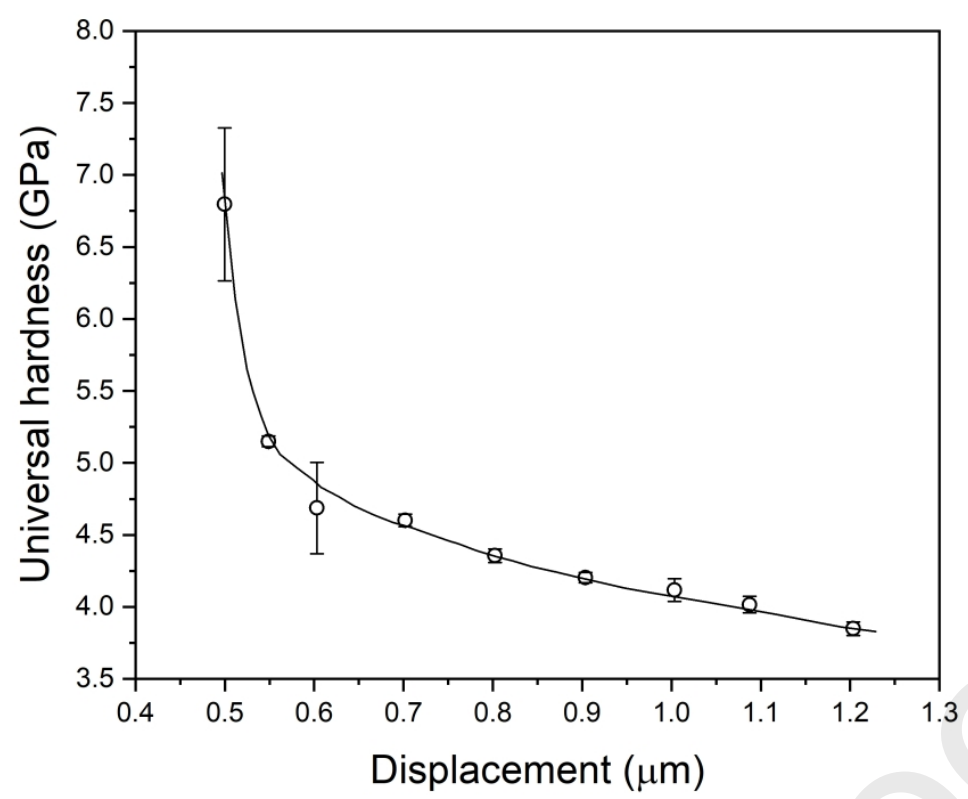

Fig. 10. Correlation between nanoindentation displacement and hardness for fused silica. (Reprinted with permission from Suzuki et al. [85]. Copyright (2004) John Wiley and Sons)

An interesting phenomenon that was confirmed using the nanoindentation on glasses is the indentation size effect (ISE), which manifests through a significant increase in $H$ upon decreasing the indentation load, that is with the reduction in the probed volume. As an example, data obtained on fused silica (with a density of $2.2 \mathrm{~g} / \mathrm{cm}^{3}$ ) is shown in Fig. $10^{6}$ [85]. ISE is widely reported in crystalline metals and alloys and is rationalized by recourse to the strain gradient plasticity models that postulate the necessity of certain density of dislocations to accommodate the imposed plastic strains purely from the geometrical considerations [101]. Hence, the observation of ISE in glasses is surprising, given that they lack long-range periodicity (and hence dislocations) [85,89,102,103]. There have been attempts to explain the origin of the ISE in non-metallic glasses such as the empirical model based on Meyer's law [102], the minimum specimen resistance model (Hays-Kendall model) [104], the proportional specimen resistance (PSR) model [105], and the modified PSR model [102]. All these approaches are focused on how to describe the experimental data of ISE by correlating $H$, peak load, and contact depth. An alternate explanation for ISE in ceramics, which is based on fracture mechanics, was given by Swain and Wittling [99]. Although the connection between ISE and the fundamental mechanisms of glass deformation (such as densification and shear flow) has not been established yet, some plausible explanation was proposed by Li et al. [105,106], based on the increase of the indentation surface to imprint volume ratio. With a reduction in the load both the contact area and the indentation volume decrease. Since the former scales with $a^{2}$, the latter with $a^{3}$ (where $a$ is

\footnotetext{
${ }^{6}$ The universal hardness displayed in this figure was estimated by the authors using the maximum applied load $(146 \mathrm{mN})$ and the penetration depth at the peak load.
} 
half the diagonal length of the projected imprint for the Vickers case), the surface to volume ratio increases with decreasing $P$. On this basis, Li et al. conclude that friction at the indenter-material interface is a major contributor to the observation of ISE. The role of friction in the load-independent high-load regime becomes negligible.

\subsubsection{Effect of irradiation on the mechanical properties}

The structure of the glasses is highly susceptible for change upon exposure to photonic and ionic irradiation and a detailed understanding of the effect of such changes on the properties are of paramount importance in a wide variety of contexts that range from nuclear waste disposal to optical communication technology. Since the irradiation effect is often confined to a thin surface layer (in the order of microns) of the material, nanoindentation is particularly useful to probe the properties of irradiated glasses and hence widely used. We summarize some such studies below.

Laser irradiation is frequently utilized for the scribing and welding of various glasses. For example, fiber Bragg gratings (FBG) in optical fibers, whose refractive index can vary markedly under exposure to ultraviolet (UV) radiation, are fabricated by modulating the refractive index via exposure to a patterned UV radiation. The mechanism of photosensitivity in the glasses used for optical fibers and the variation of it with UV exposure are rationalized by recourse to either the electronic models that rely on irradiation-induced defects affecting the electronic states, or the structural models that postulate changes to the intrinsic structure of the glass. The compactiondensification model, which belongs to the latter category, hypothesizes that the laser-irradiation induces compaction of the glass through internal structural rearrangements, and the resulting densification alters the index of refraction [107]. Aashia et al. [108] employed the nanoindentation technique to examine this, by studying germanosilicate preforms that were exposed to varying levels of UV irradiation. Their results show that while $H$ remains invariant with the exposure time, the $E$ increases first, indicating densification, before sharply decreasing due to internal dilation and damage accumulation that occurs in the glass, which is in accordance with the compaction-densification model. Likewise, Bellouard et al. [109] reported an increase in $E$ in the laser-affected zone of silica that was irradiated with low-energy femtosecond pulses, whereas high-energy pulses led to a reduction in both $E$ and $H$. The softening behavior in the latter was attributed to nonbridging oxygen hole centers formed in the regions exposed to femtosecond laser irradiation, especially in high pulse energy regime, which cause lower connectivity [110]. In addition, by measuring the radial crack lengths initiated from nanoindentation, Kongsuwan et al. [110] found out that the fracture toughness also decreases slightly $(<10 \%)$, which can be minimized by lowering the laser pulse energy or increasing the laser scanning speed. Sabapathy et al. [111] extended this work to GeGaS and GeGaSSb chalcogenide glasses whereas Ayiriveetil et al. [112,113] studied $\mathrm{Er}_{2} \mathrm{O}_{3}$-doped $\mathrm{GeGaS}$ and 
$\mathrm{GeS}_{2}$ glasses, wherein they examined the structural and mechanical characteristics of the glasses subjected to waveguide inscription using ultrafast lasers. The nanoindentation data reveled that the top region of the waveguide is considerably compliant and softer as compared to the other regions in the waveguide or the bulk. Micro-focus Raman spectroscopic studies that were performed in conjunction confirmed the existence of such distinct regions and support the notion of laser irradiation-induced structural modifications to the glass atomic network.

Borosilicate glasses are potential candidates for underground disposal of high-level radioactive waste owing to its radiation durability $[114,115]$. Nanoindentation has been widely used to investigate their ion or electron irradiation sensitivity. In general, ion irradiation causes a reduction in both $E$ and $H$, as compared to pristine glasses. Abbas et al. [116], who conducted nanoindentation experiments with complementary MD simulations on aluminoborosilicate glasses irradiated with He and $\mathrm{Kr}$ ions, attribute such property changes to an increase in the polymerization of the network structure due to irradiation. Peuget et al. [117] tried to decouple the relative influences of electronic and nuclear deposition energies from ion irradiation and suggested that the latter is predominant in the irradiation-induced softening. By comparing nanoindentation $H$ variations of borosilicate glasses irradiated with different ions, later studies also confirmed the dominated effect of nuclear energy in causing the ion irradiation induced variations in $H$ and $E$ [118-123] as well as unchanged or even reduced polymerization of the glass network $[118,124]$.

Alternatively, external irradiation means to simulate natural radioactivity and accelerate radiation experiments, were utilized and the resulting irradiated surface layers were evaluated using nanoindentation [125-127]. Yang et al. [125] reported that the $H$ reduction induced by He ion irradiation $(\sim 14 \%)$ is larger than the one by electron irradiation $(\sim 4 \%)$. It was suggested that the extended incubation dose and slower decreasing rate in the latter may be related to the survival and accumulation of point defects, since ionization and electronic excitation are the dominant mechanisms during electron irradiation. In addition, negligible compositional dependence was found in the $\mathrm{Au}$ ion irradiation induced variations in both $H$ and $E$ [127] whereas the changes by electron irradiation shows a certain level of dependence on the chemical compositions [128], which was attributed to the combination of several factors (transition of $\left[\mathrm{BO}_{4}\right]$ to $\left[\mathrm{BO}_{3}\right]$, the modification in polymerization, volume compaction, reduce in average ring size and point defects).

While a majority of the nanoindentation studies on ion/electron irradiated glasses are performed on borosilicates, a few investigations on other types of glasses that show distinct behavior are available. For example, Guan et al. [22], who compared the Xe ion irradiation susceptibility of borosilicate glass and a- $\mathrm{SiO}_{2}$, found that $H$ of silica decreases (only marginally) while $E$ increases upon irradiation. On this basis and some MD simulation results [23-26], it was suggested that the irradiation-induced softening of sodium borosilicate is not due to breaking of silicate network but to 
the breaking of boron-related network [124,129]. Interestingly, a binary potassium-silicate glass, which also does not contain boron like silica, was found to show a behavior similar to the one of a borosilicate glasses, that is both $H$ and $E$ decrease as the electron dose is increased [130]. Systematic nanoindentation studies on various types of glasses are required to further reveal the underlying reasons for the irradiation-induced mechanical property changes.

\subsubsection{Topological constraints in chalcogenide glasses}

As already mentioned in subsection $\S 2.1 .2$, chalcogenide glasses are the softest and most brittle amongst all the inorganic and non-metallic amorphous materials. They consist of covalently bonded networks of chalcogen atoms ( $\mathrm{S}, \mathrm{Se}, \mathrm{Te}$ ) connected to fourfold coordinated atoms such as Ge and Si. The degree of network connectivity in these glasses, which depends on the mean coordination number $\langle r\rangle$, can be varied by changing the composition [131]. At low connectivity, the number of degrees of freedom is more than the number of constraints, which leads to the glass being 'floppy'. When the number of constraints is larger than the degrees of freedom, the structure is 'rigid'. Thus, an increase in $\langle r\rangle$ can induce a floppy to a rigid transition [132-134] at the rigidity percolation threshold that refers to the critical average coordination number $\left\langle\mathrm{r}_{\mathrm{c}}>\right.$ at which the number of constraints is equal to number of degrees of freedom. For random covalent networks, $\left\langle\mathrm{r}_{\mathrm{c}}>=2.4\right.$. Various property anomalies that are observed at the rigidity percolation threshold of chalcogenide glasses are rationalized by recourse to the mean field constraint theory [132,133,135]. The floppy to rigid transition is usually not sharp and Boolchand et al. [136] proposed that the range of $<\mathrm{r}>$ over which it occurs (for some chalcogenides and oxide glasses as well) is associated with a so-called intermediate phase (IP) whose boundaries are labeled as rigidity and stress transitions. Over the IP region, the glass network is rigid but is unstressed due to optimum space filling $[137,138]$. Chalcogenide glasses with the compositions corresponding to this region are known to exhibit remarkable electrical, thermal, structural, and optical properties [136,139-141]. Since the mechanical behavior of glasses is sensitive to the atomic scale organization in them, the extended IP region should also get reflected in the mechanical properties, especially on the elastic modulus since it is a physical property that is highly sensitive to the connectivity and rigidity of the networks within the glass, which can be evaluated using nanoindentation. Das et al. [140] examined the variation of $E$ in bulk GeTeSi glasses and report a plateau in for $2 \leq x \leq 6$ in $\mathrm{Ge}_{15} \mathrm{Te}_{85-x} \mathrm{Si}_{x}$ glasses, for which $<\mathrm{r}>$ range between 2.34 and 2.42, see Fig. 11. In an earlier study on the same glass system, Anbarasu et al. [142], who examined the composition dependence of enthalpy change during glass transition obtained from non-reversing heat flow — a key attribute of IP that should have near-zero values — show a broad through in the same composition range, and hence identified it as IP formation range. A subsequent 
study by Varma et al. [137] on Ge-Te-In glass system also showed that the IP region can be identified with the aid of nanoindentation.

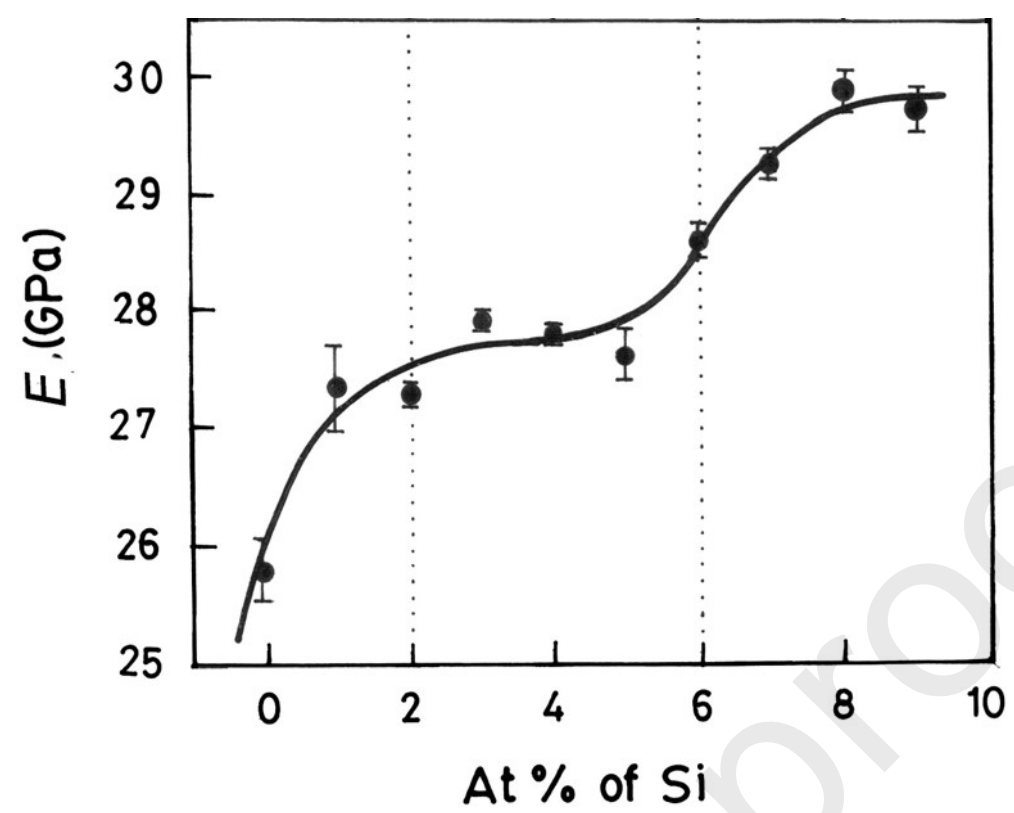

Fig. 11. Variation of $E$ in $\mathrm{Ge}_{15} \mathrm{Te}_{85-x} \mathrm{Si}_{x}$ glasses with composition. (Reprinted with permission from Das et al. [140]. Copyright (2012) Elsevier)

\subsection{Modeling and simulation of the indentation process}

Although many attempts to model the indentation behavior of non-metallic inorganic glasses were reported in scientific journals, several (very) serious problems remain. The elastic behavior can be modeled by means of approaches inspired by Boussinesq [143] (contact point loading) or Hertz (no deformation at the surface) [144], and then in the case of axisymmetric indenters, some solutions were provided by Sneddon [32] and Johnson [145]. Accounting for the irreversible deformation component is complicated; in particular, the force distribution along the contact area is usually not known, and so is the actual mechanical behavior of the material under such an intense stress field (stress is of the order of $H$ ), especially in the region close to the indenter and in the early stage of the imprint formation. Then time and temperature come into play. The slip-line field method [146] was applied to analyze the two-dimensional plane strain indentation of a rigid plastic material by an axisymmetric indenter $[11,145]$. In most of the approaches, a plastic zone is considered to develop beneath the indenter and to be confined by the surrounding elastic matrix. This zone expands and may eventually reach the surface on the sides of the indenter, allowing for matter to pile-up. This cavity expansion model is derived from Hill's spherical cavity solution [24]. As the core expands, due to the increasing indentation load, the stress increase in proportion to $\ln (r)$ in the cavity, and as $1 / r^{3}$ in the surrounding half-infinite elastic medium, where $r$ is the distance to the initial point of contact. A limitation of this model is that it does not consider the hoop stresses on the free surface of both half 
spaces. Besides, an exact analytical solution for this problem is out of reach inasmuch as the plastic yield stress of a glass is an unknown quantity, and how pressure contributes to the process. A field referred to as 'blister' field [14,147] was introduced to better describe the residual stress field that develops at the indentation site, especially on unloading, and is responsible for the microcracking events that occur during unloading in brittle materials such as silicate glasses and ceramics. By superposing the Boussinesq's stress field originating from a point-load normal to the surface of a semi-infinite elastic body and a blister field stemming from a strain nucleus built on three double forces of same intensity, Yoffe [147] proposed a field having the remarkable ability to provide an accurate description of the various indentation cracking features, especially in the case of materials experiencing densification (such as silicate glasses). This approach remains micro-mechanical and semi-empirical though. The strength of the blister fields is usually not known. Nevertheless, attempts to correlate the intensity of the blister field to the $C_{\mathrm{g}}$, and to the sensitivity of the glass to densification, were quite successful in the case of silicate glasses [64,148]. Another approach consists in implementing a yield criterion accounting independently for both shear and pressure effects (such as in the Drucker-Prager constitutive law) in a finite element (FE) analysis code, and further introducing some hardening to account for the fact that as densification proceeds, permanent deformation becomes more difficult $[149,150]$.

In the case of time- or rate-dependent materials, and especially for indentation experiment conducted from $0.9 T_{g}$ and to higher $T$ where creep and viscoelasticity become significant, the exact elasticity solutions provided by Sneddon were successfully extrapolated to the case of linear viscoelasticity $[151,152]$ using the Boltzmann's superposition principle. Using the finite element method (FEM) and remeshing techniques [153], discrete element method [154] or an X-FEM method [155], the geometrical characteristics of the Hertzian cone cracks observed in brittle materials could be reproduced well.

Recently, Luo et al. [156,157] conducted molecular dynamics (MD) simulations to gain a detailed understanding of the stress evolution and crack nucleation during indentation of oxide glasses. Their work revealed that the MD simulations can be a helpful tool for better understanding the underlying criteria for indentation cracking and its resistance of oxide glasses by providing the detailed information about principal stress fields and deformation morphology.

\section{METALLIC GLASSES}

In most common solidification conditions, metals and alloys crystallize upon cooling from the liquid state. However, it is possible to circumvent crystallization and obtain amorphous alloys by rapidly quenching the molten alloys of some specific compositions. Sixty years back, Klement et al. [158] first reported the synthesis of MGs (1960), which were achieved by imposing very high cooling rates 
$\left(>10^{6} \mathrm{~K} / \mathrm{s}\right)$ that allow the melt to bypass crystallization. Since this discovery, there has been extensive research into the structure and properties of MGs [23,159-163]. The critical requirement of high cooling rates for obtaining MGs in most alloy systems meant that they could only be produced in thin ribbon or powder forms, which limited their application potential. The discovery of bulk metallic glass (BMG) forming compositions, which do not crystallize even when cooled relatively slowly, in the 1990s [164,165], made these materials candidates for advanced structural applications in view of their extraordinary properties. Consequently, considerable research was conducted to understand their mechanical behavior, which is of interest from both technological and scientific viewpoints [23,160-163].

The basic mechanisms by which plastic deformation takes place in MGs are distinctly different from those in crystalline metals and alloys in which the character and mobility of lattice line defects (namely dislocations) dictates plasticity. After extensive research over the past two decades, it is now widely accepted that the fundamental unit processes of plastic deformation in glasses occurs via the collective shuffling of clusters of atoms to accommodate the applied shear strain; these are termed as shear transformation zones (STZs). At the more macroscopic scale and when the applied stresses are sufficiently high, plastic deformation of MGs at low $T$ occurs inhomogeneously through localization of flow into narrow bands with typical thickness of $\sim 10 \mathrm{~nm}[160,166]$. Since amorphous alloys lack long range atomic order, they offer a relatively weak resistance to the propagation of these 'shear bands'. This is because the atomic network consists of relatively stiff clusters embedded in a softer and weaker matrix (per the random modified network proposed by Greaves [167]). After propagating a characteristic distance, the shear bands become shear cracks and, in turn, lead to failure of the MG. Consequently, negligible plasticity beyond the elastic limit is often noted when MGs are tested in tension. Therefore, indentation techniques are widely employed to understand the mechanical behavior of MGs [168-170]. Since many reviews on this topic are already available in literature $[7,171,172]$, only the aspects that are not covered hitherto, are briefly reviewed below. Before doing so, it is worth reiterating that the indentation plasticity in MGs is almost exclusively isochoric, just as in crystalline metals and alloys, and densification during indentation of MGs is negligible due to the random close packing in these 'atomic glasses'. Therefore, the following summary of indentation behavior of MGs will exclusively be in terms of shear flow in them.

\subsection{Indentation-induced plasticity}

\subsubsection{Correlation between hardness and elastic properties}

While the packing density is a key factor for understanding the elastic moduli and $H$ of oxide glasses, the bond energy and character predominate in the case of MGs due to the high $C_{\mathrm{g}}$. A direct consequence of the near-ideal close random packing efficiency in MGs is that there is little room for 
densification during indentation and the formation of an indentation imprint is almost solely due to shear flow. The macroscopic stress-strain response remains elastic and yield occurs at a considerably large strain, and the RT $H$ of MGs is almost linearly correlated to the shear modulus (Fig. 12), with $H=0.151 \mu$ [173]. A similar expression relating $H$ with the $E, H=E / 20$, was proposed, despite the relatively wide range of $v$ of MGs [174]. The presence of light elements in the glass composition results in strong directional bonds, but to the detriment of the packing, and to the ease for isochoric shear. In contrast, heavy elements improve the atomic packing of the MG but lead to weaker bonds and thus to softer glasses. Non-transition metal host elements such as $\mathrm{Ce}, \mathrm{Ca}$, and $\mathrm{Mg}$, impart more directional bonding through better localized ' $f$ ' (for $\mathrm{Ce}$ ) and ' $s p^{\prime}$ ( $\mathrm{Ca}, \mathrm{Mg}$ ) electrons giving rise to a relatively inefficient packing (and low v). As a consequence, rare-earth-based MGs as well as Caand $\mathrm{Mg}$-based ones are relatively soft, although they behave in a more brittle manner than harder glasses such as the Zr-based ones for example. So soft does not mean ductile in the context of MGs, and the same holds for chalcogenide glasses, which are very soft (pure Se glass can be even deformed by hand at RT), but are extremely brittle ( $K_{I c}$ is less than $\left.0.3 \mathrm{MPa} \cdot \sqrt{ } \mathrm{m}\right)$. MGs based on precious metal elements such as $\mathrm{Pt}, \mathrm{Au}$ or $\mathrm{Pd}$ also exhibit relatively small $H$ values because of the ease for shear deformation in such glasses thanks to the large atomic number and weak interatomic bonding directionality. The addition of $\mathrm{Cr}$ or Mo to Fe-based glasses containing metalloid elements such as carbon and boron provide metal-metalloid bonds, which are stronger than the $\mathrm{Fe}-(\mathrm{Cr}, \mathrm{Mo})$ bonds, while the packing density is almost unchanged. In such a situation, $H$ is increased. The highest $H$ reported so far for BMGs are those reported on Co-based glasses, and in particular for the $\mathrm{Co}_{43} \mathrm{Fe}_{20} \mathrm{Ta}_{5.5} \mathrm{~B}_{31.5}(H=14.5 \mathrm{GPa})$ [175] and for the $\left(\mathrm{Co}_{0.535} \mathrm{Fe}_{0.1} \mathrm{Ta}_{0.055} \mathrm{~B}_{0.31}\right)_{98} \mathrm{Mo}_{2}(H=16.6 \mathrm{GPa})$ [176] compositions and approaches the value for a $\mathrm{W}_{46} \mathrm{Ru}_{37} \mathrm{~B}_{17}$ ribbon $(H=16.8 \mathrm{GPa})$ reported by Ohtsuki et al. [177]. Replacing Fe with $\mathrm{Ni}$, or (Cr, Mo) by Ti reduces the bond strength and makes the glass softer. Ni-based amorphous alloys have about the same $H$ as $\alpha-\mathrm{SiO}_{2}$, despite much smaller interatomic bonding energies. This example illustrates that efficient packing can easily compensate for the weaker interatomic bonding. Of course, the formation of clusters and of chemical heterogeneities in BMGs prevents a detailed case by case discussion at this stage, but the general trend is illustrated in Fig. 12. Most MGs, which include Cu-, Zr-, Ti-, and Fe-based ones, exhibit similar values, much larger than those reported for oxide glasses. The fact that the efficient atomic packing in MGs leaves little room for volume change in comparison with oxide glasses, and is conducive to isochoric shear flow, gives a great importance to the bond character. The volume density of energy (reflected in the elastic moduli) then almost scales with the dissociation energy, or with $T_{\mathrm{g}}$ (as the melting $T$ is an ill-defined concept for a glass). 


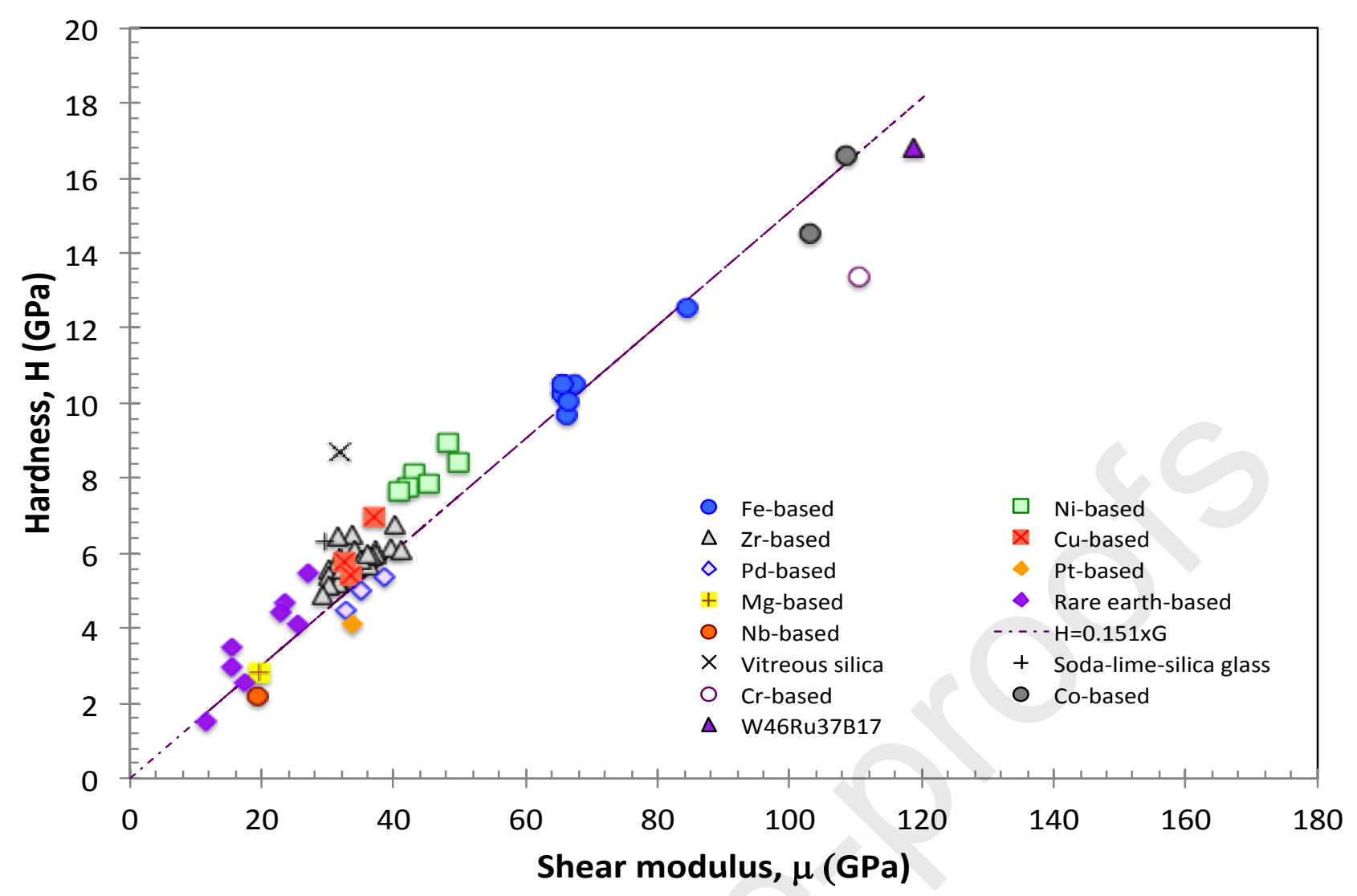

Fig. 12. Hardness, $H$, plotted as a function of the shear modulus, $\mu$, illustrating the influence of the chemical system.

\subsubsection{Discrete deformation during nanoindentation}

Unlike the conventional hardness tests, the nanoindentation testing technique makes it possible to explore the mechanical response during the entire loading and unloading sequence. The $P-h$ responses measured on MGs using sharp indenters often exhibit small and discrete displacement bursts at constant loads (when the tests are performed under load control) that are often referred to as 'pop-ins', which are attributed to the shear band nucleation, propagation, and arrest in a 'stick-slip' manner $[160,166]$. Such a serrated flow, which is more clearly observed when a sharper tip like the cube-corner indenter is used, is known to be affected by various factors. Schuh and Nieh [178] asserted that the nature of pop-ins depends not only on the composition of the MG being tested but also on the $\dot{P}$; the serrations on the $P-h$ curves are more pronounced at lower $\dot{P}$ and gradually disappear with increasing rate. Since then, there have been extensive studies investigating the 'apparent' rate dependency of the inhomogeneous-to-homogeneous transition (e.g., see [179-182]). The following are the two major hypotheses offered for this transition. First (and mostly accepted) hypothesis is that the absence of pop-in events in 'fast' indentation was caused by kinetic limitations on the nucleation of shear bands. In the low-rate regime, a single shear band operates in isolation leading to a large pop-in. At high rates of loading, simultaneous nucleation of multiple shear bands causes each one to propagate only shorter distances, making it appear as if the flow is homogeneous 
overall. The second hypothesis is that the apparent absence of serrations at high indentation rate is just an artifact due to the lack of instrumental resolution including the limited data acquisition rate as well as the limited response time of the indentation equipment.

Temperature is another factor that affects the serrated flow behavior in a marked manner, which was revealed through high temperature nanoindentation experiments. For example, Schuh et al. [183] showed that increasing $T$ leads to the gradual emergence of homogeneous flow, as thermal relaxations allow dissipation of strain localization into general viscous flow. Another critical factor is the indenter angle [184]; as shown in Fig. 13, sharper the indenter, more pronounced are the popin events. Additionally, factors like sub- $T_{\mathrm{g}}$ annealing [185], shot peening [186] and residual stress [187] may also affect the serrated flow of MGs.
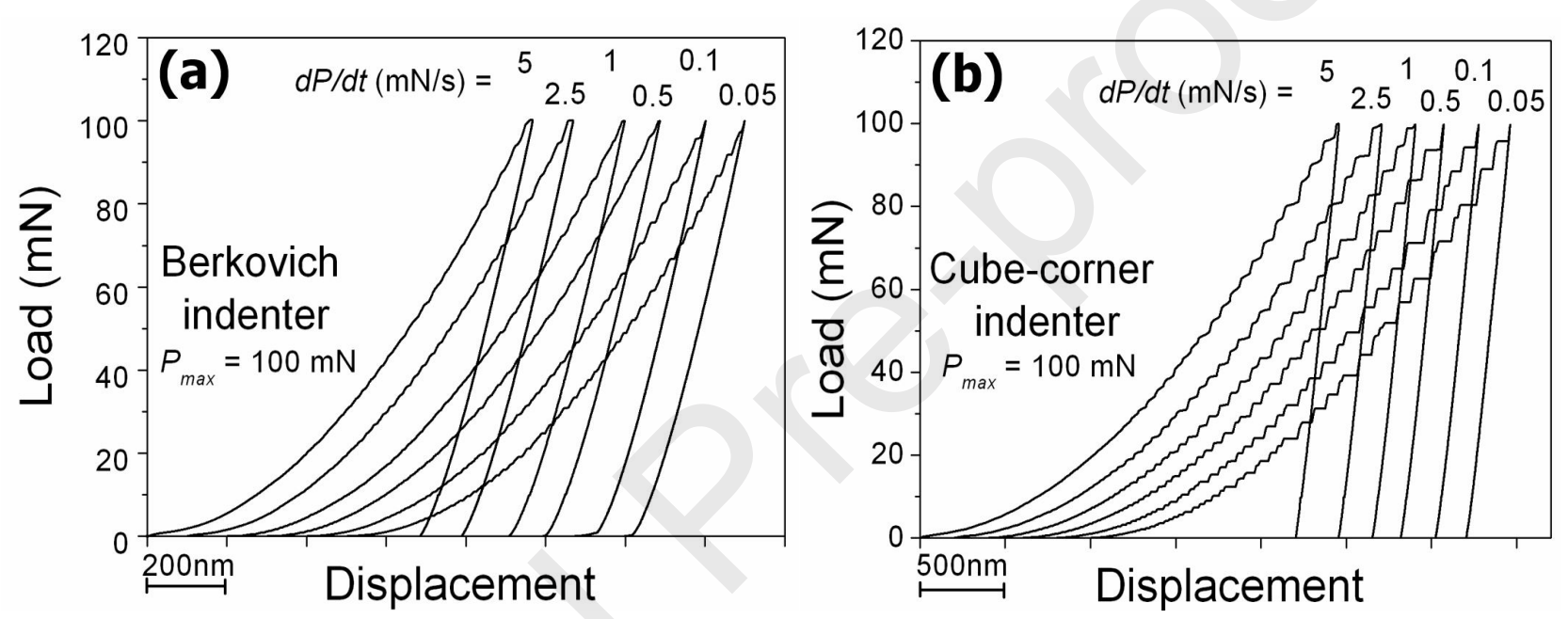

Fig. 13. Representative examples of the nanoindentation load-displacement responses illustrating different extents of serrated flow obtained with (a) Berkovich and (b) cube-corner indenters at different loading rates. (Reprinted with permission from Yoo et al. [184]. Copyright (2007) The Japan Institute of Metals and Materials)

Recently, coupling of nanoindentation with electrical contact resistance (ECR) measurement such that both electrical and mechanical responses can be measured simultaneously became possible [188-190]. Yang et al. [191] performed nanoindentation in elastic regime on a Zr-based MG and revealed what triggers local inelastic atomic shuffling using ECR. It was inferred from the results obtained that deformation events take place cooperatively and exhibit a self-organized behavior. Singh et al. [192] investigated further the relationship between plastic deformation and current output in a Pd-based MG using ECR, and reported that the pop-in behavior in the $P-h$ curve can be directly linked to the discrete surges in current measurement, implying the current excursions may be attributed to the formation of shear band offsets. 


\subsubsection{Plasticity evolution and pressure sensitivity}

It is relatively straightforward to find the evidence that 'shear banding' is responsible for the serrations in the loading segments of the $P-h$ responses. For example, shear bands can be observed on the surface around hardness impression, which is clearer when indentations are made with a sharper indenter [181]. However, imaging the entire shape of shear bands development, to develop 'structureproperty' correlations, is difficult since most of the shear bands usually form underneath the indenter and do not manifest often on to the free surface [184]. To overcome this, the 'bonded interface' technique, which was pioneered by Mulhearn and Van Der Zwaag et al. for metals and brittle materials, respectively $[193,194]$, was utilized to study the subsurface deformation characteristics (especially, the shear band patterns) in a plane along the indentation axis [195-203]. In it, macroscopic indentation imprint is made on the bonded interface such that a well-defined plastic flow zone is generated on a cross-section underneath the indenter, which can later be probed for deformation morphology as well as for performing nanoindentation tests on the shear bands. Although the flow constraint is somewhat relaxed in the interface-bonded samples, and hence the stress and strain fields differ from those during indentation on samples without interface, it provides a rather unique opportunity to gain insights into the governing deformation mechanism during indentation, especially in the case of opaque materials [195].

One of the important features that have been successfully captured through interface-bonded technique and which was investigated by means of nanoindentation experiments on the shear banded region, is the strain softening behavior of MGs. Such softening is a consequence of the large local and transient dilatation of the surrounding matrix (required for the activation of STZs), which, in turn, enhances the structural disorder within the amorphous packing and, consequently, makes the structure more readily amenable for subsequent plastic flow [160]. This was demonstrated by Bhowmick et al. [198], who employed the bonded interface technique to generate a large and well-defined plastic zone decorated with profuse shear bands, as shown in Fig. 14(a), which was subsequently probed by nanoindentation. Analyses of the nanohardness data obtained from an extensively deformed regions [185], as illustrated in Fig. 14(b), showed that the deformed region is always softer than the undeformed region. 

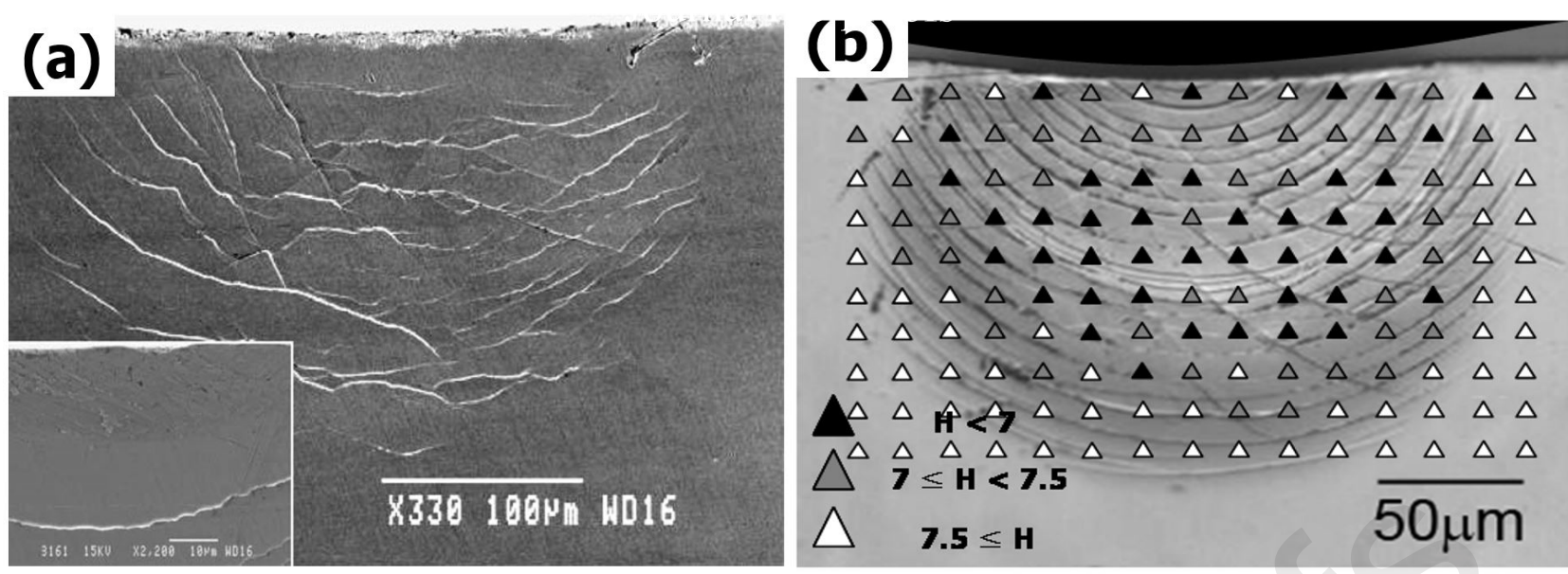

Fig. 14. Indentation-induced subsurface deformation of BMGs. (a) The subsurface deformation morphology of $\mathrm{Zr}_{41} \mathrm{Cu}_{14} \mathrm{Ti}_{12} \mathrm{Ni}_{10} \mathrm{Be}_{23} \mathrm{BMG}$ under a spherical indenter with the inset showing elastic zone immediately beneath the indenter (Reprinted with permission from Bhowmick et al. [198]. Copyright (2006) Elsevier): (b) The hardness distribution underneath a spherical indenter made on $\mathrm{Zr}_{52.5} \mathrm{Cu}_{17.9} \mathrm{Ni}_{14.6} \mathrm{Al}_{10} \mathrm{Ti}_{5}$ BMG. (Reprinted with permission from Yoo et al. [202]. Copyright (2008) IOP)

Although plasticity in MGs is volume conserving at the macroscopic scale, the yield condition was found to be sensitive to the normal stress or pressure [183,186,204]. This sensitivity stems from the requirement of dilatation associated with STZ activation [205]. To account for this, instead of Tresca or Von Mises yield criteria that are routinely used for describing the yield loci in crystalline alloys, pressure-modified criteria such as Mohr-Coulomb [205,206], Drucker-Prager [207-209], modified Tresca [210], and a cooperative-shear process based shear plane criteria [211] have been proposed in the literature and have been validated to varying extent. Indentation can be also used to examine the pressure sensitivity of plastic flow in MGs. Vaidyanathan et al. [206], who employed both Berkovich nanoindentation experiments and their 3-dimensional FE simulations, reported that the experimental $P-h$ curves are consistent with FE simulations when the Mohr-Coulomb criterion (instead of von Mises criterion) was used, and that the shear band traces around the hardness impression follow the contours of effective Mohr-Coulomb stress (as illustrated in Fig. 15). 

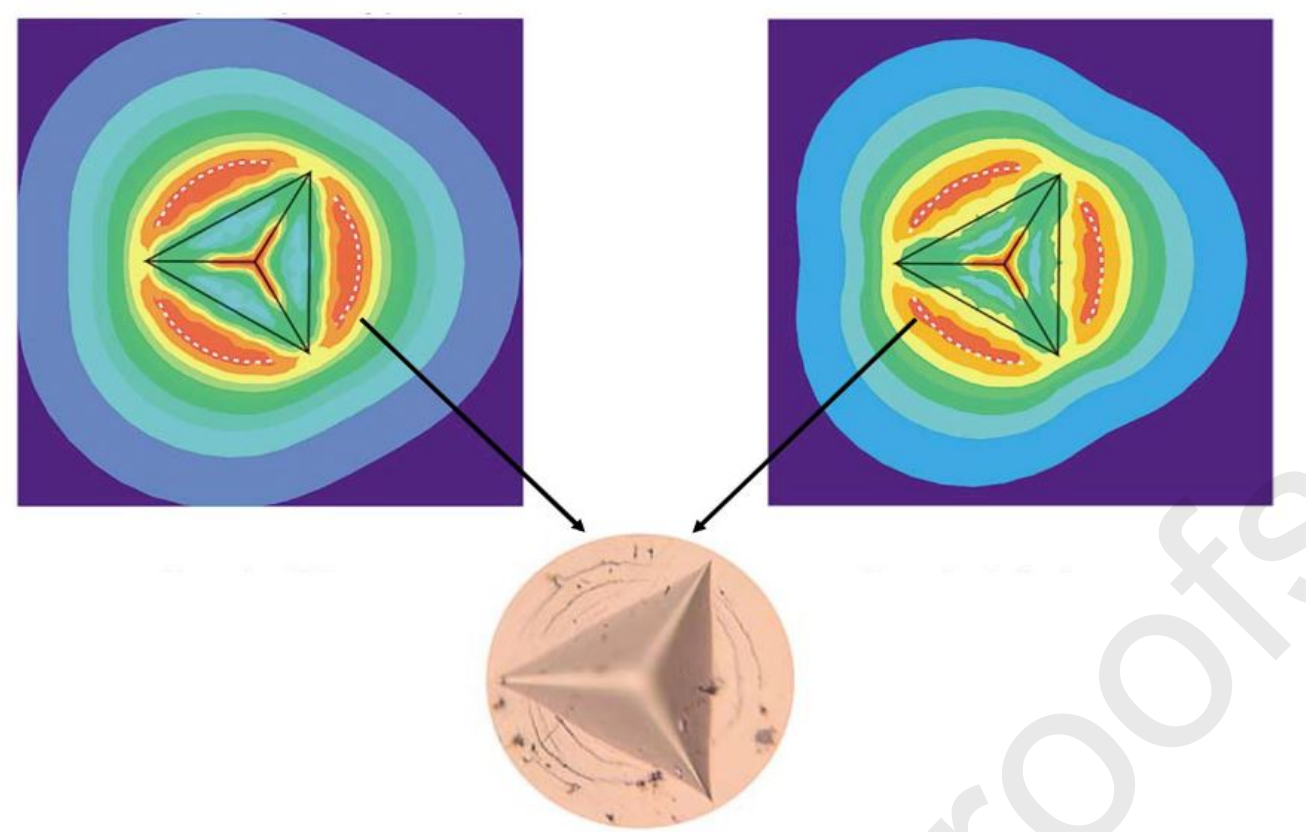

Fig. 15. Plain view of contours indicating the Mises equivalent stress (top left) and the MohrCoulomb effective stress where the part with dark orange represents the areas of greatest stress, obtained from the finite element analyses using two different constitutive responses. An experimentally obtained image of the Berkovich indent made on a Zr-based BMG, scaled to the size of the simulation, is shown below; it agrees well with the simulated result obtained with the MohrCoulomb yield criterion, implying pressure sensitivity of plastic flow. (Reprinted with permission from Vaidyanathan et al. [206]. Copyright (2001) Elsevier)

The shear bands emanating from the edge of the spherical indentation impression resemble the slip lines around circular holes under pressure. The intersection angle between the shear bands can be utilized to infer the friction angle associated with the Mohr-Coulomb yield condition and hence examine the pressure sensitivity of plastic flow [186,207,212]. An included angle of $90^{\circ}$ means the flow is pressure-insensitive; a deviation from it implies pressure-sensitivity. For example, Dubach et al. [186] examined the effect of structural state, and in turn, the free volume content in the MG on the pressure sensitivity of plastic flow in MGs through experiments on a $\mathrm{Zr}_{41.2} \mathrm{Ti}_{13.8} \mathrm{Cu}_{12.5} \mathrm{Ni}_{10} \mathrm{Be}_{22.5}$ (composition in at.\%) MG in the as-cast, shot-peened and structurally relaxed conditions. Their results show $H$ to be highly sensitive to the structural state whereas the uniaxial compressive $\sigma_{y}$ remains invariant. Significant variations in the shear band morphology around the indenter impressions was noted as well (see the left panel on Fig. 16). The observed variations in the intersection angles of the slip lines emanating from the periphery of the conical indents (right panel on Fig. 16) indicate that while structural relaxation, which reduces the free volume content in the glass, leads to a marginal reduction in the friction angle (compared with the as-cast state) and hence 
an enhanced pressure sensitivity. In comparison, prior-plastic deformation via shot peening makes the MG pressure-insensitive.
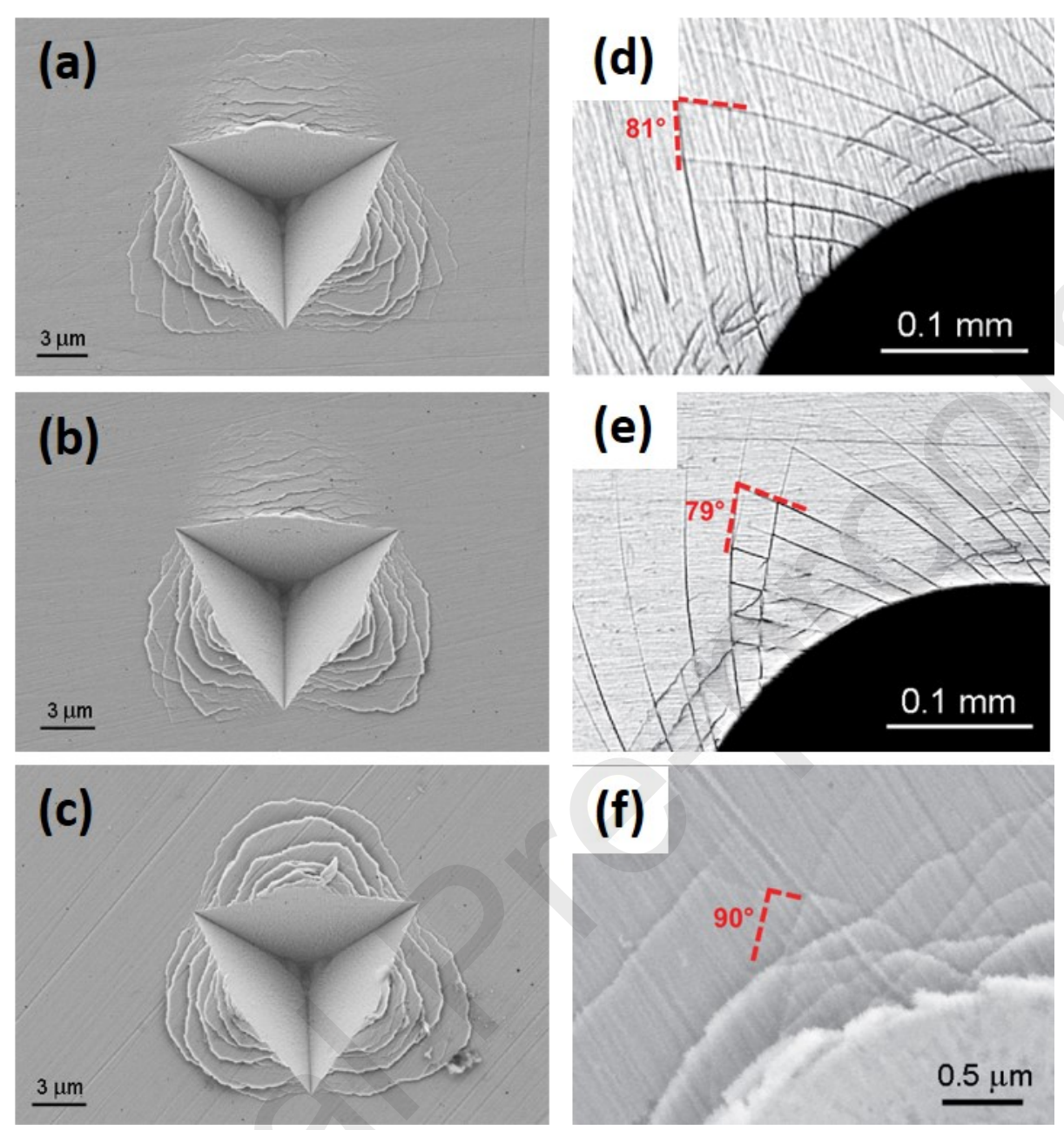

Fig. 16. [Left column] Scanning electron micrographs of the cube corner indents showing the appearance of shear bands in the form of surface steps for the (a) as-cast, (b) structurally relaxed, and (c) shot-peened Zr-based bulk metallic glass. [Right column] Optical micrographs and SEM image, respectively, showing the intersecting slip lines (with the intersection angle a) emanating from the edge of a conical indent, performed on the (d) as-cast and (e) structurally-relaxed material, and (f) on the cross-section of the shot-peened layer. (Reprinted with permission from Dubach et al. [186]. Copyright (2011) Materials Research Society)

A major consequence of the pressure sensitivity, in the context of indentation is an enhancement in $H$ since the deforming volume of material underneath the indenter experiences a large hydrostatic compression. This is captured through the constraint factor, $Y$, which is given by the ratio of $H$ to $\sigma_{y}$, measured in uniaxial compression. The value of $Y$ depends on the geometry of the indenter as well as the mechanical properties of the material being indented. Based on the modified of expanding cavity model developed by Narasimhan [213], it was first shown by Patnaik et al. [207] 
that the pressure sensitivity of plastic flow in MGs leads to high $Y$, which ranges between 3 and 4.5 in the fully plastic regime of indentation, whereas it is always below 3 for crystalline metals; see Fig. 17(a) [145].

Below $T_{g}$, the plastic flow characteristics, in terms of shear band nucleation rate and the amount of strain each of them carries, vary significantly with $T$ even though the strength of a MG is only weakly $T$ dependent. Through nanoindentation experiments on the $\mathrm{Pd}_{40} \mathrm{Ni}_{40} \mathrm{P}_{20}$ (in at.\%) BMG at 20,100 , and $150{ }^{\circ} \mathrm{C}$ coupled with analytical modeling, Schuh et al. [183] showed that the pressure sensitivity increases with increasing $T$ as diffusive activation of the STZs prevents easy shear localization. Since shear band initiation is relatively more pressure-sensitive, Prasad et al. [199] and (then) Keryvin et al. [214] have shown that $Y$ increases monotonically with $T$, confirming enhanced pressure sensitivity with $T$; see Fig. 17(b). Surprisingly, similar $T$ dependence of $Y$ was also reported for an amorphous polymer, poly(methyl methacrylate), suggesting an universal trend [215].
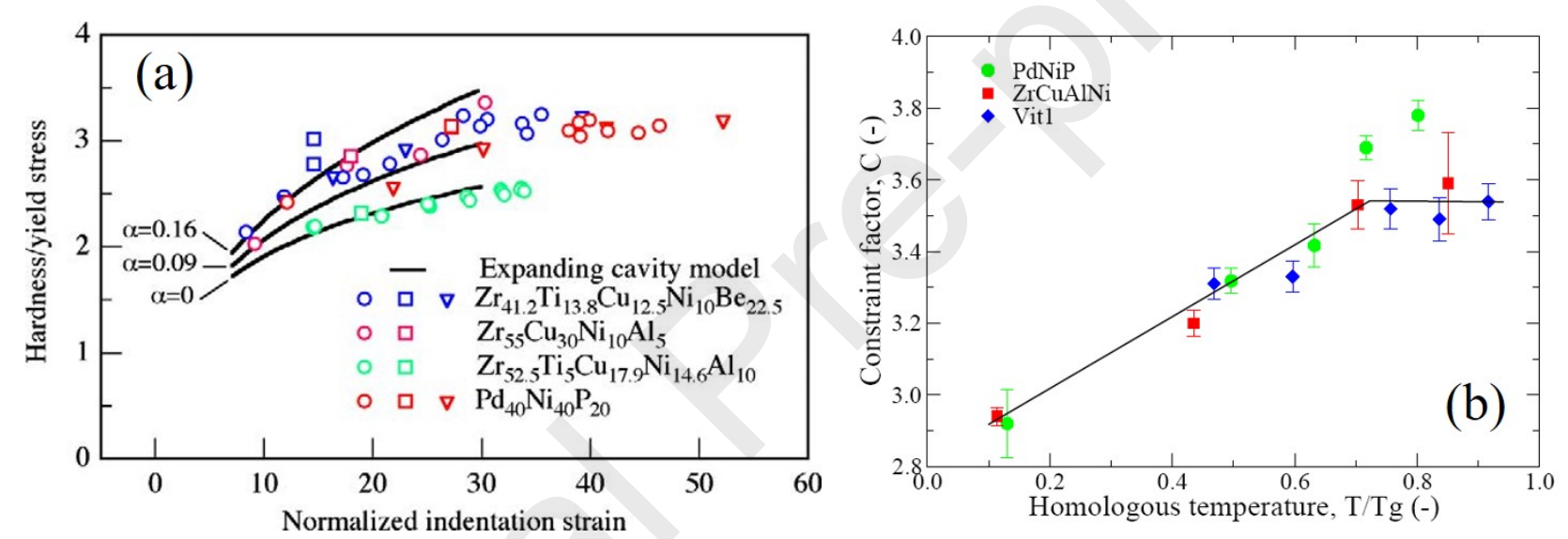

Fig. 17. Variation of the constraint factor, given by the ratio of the hardness to the yield strength in compression, in various BMGs (a) as a function of the indentation strain (normalized with the respective yield strains) at room temperature (Reprinted with permission from Schuh et al. [160]. Copyright (2007) Elsevier), and (b) as a function of homologous temperature $T / T_{g}$ (Reprinted with permission from Keryvin et al. [214]. Copyright (2008) Taylor \& Francis)

\subsubsection{Time-dependent deformation}

Although localized plastic flow mediated by shear bands dominates the deformation of MGs at relatively low $T$ and sufficiently high stresses, it was demonstrated that at sufficiently long loading periods, homogeneous deformation can be observed even when the applied stresses are well below the nominal yield strength at RT [216,217]. While atomistic simulations have suggested that such loads can produce irreversible changes in the glass structure [216], creep-like behavior at RT was experimentally observed through uniaxial elastostatic compression tests in mm-sized MG samples $[217,218]$. Hence, time-dependent plastic deformation, or creep, at RT in a wide variety of MGs has 
been investigated using nanoindentation [219-227]. Results show that creep occurs at RT irrespective of whether $T_{g}$ is low or high, and the measured response is sensitive to both intrinsic material features such as the chemical composition [228] and the nature of initial structural defects [223,225], as well as external testing conditions such as the $\dot{P}[223,226]$ and imposed strain [224,227]). For example, the influence of structural state on the RT indentation creep of BMG was studied by comparing the nanoindentation responses of the as-cast and annealed BMGs [222,223]. The results show that both anelastic and viscoplastic deformations were much more pronounced in the as-cast sample than in the annealed one [223]; this difference was attributed to the fact that the structurally relaxed glass contained relatively less free volume [229] and hence was more creep resistant.

\subsubsection{Indentation plasticity and toughness correlation}

Unlike oxide, chalcogenide or fluoride glasses, most MGs are 'ductile' when indented, which implies that they are susceptible to extensive shear band mediated plasticity. Although such shear band activity does not result in any tensile ductility, the fracture initiation toughness of MGs can be considerable. For some BMGs, exceptional values, as high as $\sim 150 \mathrm{MPa} \sqrt{\mathrm{m}}$ (for $\mathrm{Zr}_{61} \mathrm{Ti}_{2} \mathrm{Cu}_{25} \mathrm{Al}_{12}$ BMG [230,231]), of mode I fracture initiation toughness, $K_{\text {Ic }}$, were reported. This is due to the occurrence of extensive plasticity ahead of crack/notch tips during tensile loading of cracked/notched specimens. When indented with sufficiently large loads, distinct shear band morphology forms around indents, but corner cracks are rarely seen (unless otherwise the MG in question is severely embrittled). Narayan et al. [231], who examined the shear band morphology in the plastic zones ahead of notch tips in a number of notched BMGs, found that $K_{\mathrm{Ic}}$ is proportional to the square root of the shear band number, $N_{n}\left(K_{I c}=16.95 \sqrt{N_{n}}\right)$, as displayed in Fig. 18(a). By recourse to elasto-plastic fracture mechanics and recognizing that the critical energy release rate is directly proportional to the area of the notch-tip plastic zone (and since shear bands of discretized carriers of plasticity in MGs), Narayan et al. [231] rationalized the observed square root dependency between $N_{n}$ and $K_{I c}$. It is interesting to note here that Shao et al. [232], who examined a broad range of 13 BMGs from different alloy systems, found this exact relation to hold. Narayan et al. [231] also found an excellent correlation between $K_{\mathrm{Ic}}$ and $N_{i}$, which is the number of shear bands around spherical indentation impressions that are made to predetermined indentation strain of 10\%; see Fig. 18(b). (The choice of $10 \%$ indentation strain was made on the basis of the 'ductile fracture criterion,' which postulates that fracture initiates upon the attainment of a critical strain over a characteristic length, identified by Tandaiya et al. [233] through their mixed-mode fracture studies.) The critical examination of the possible connection between $N_{i}$ and $N_{n}$ performed by Narayan et al. [231] suggests that it is possible to use indentation as a quick (and easier way) to estimate the fracture toughness of BMGs. 

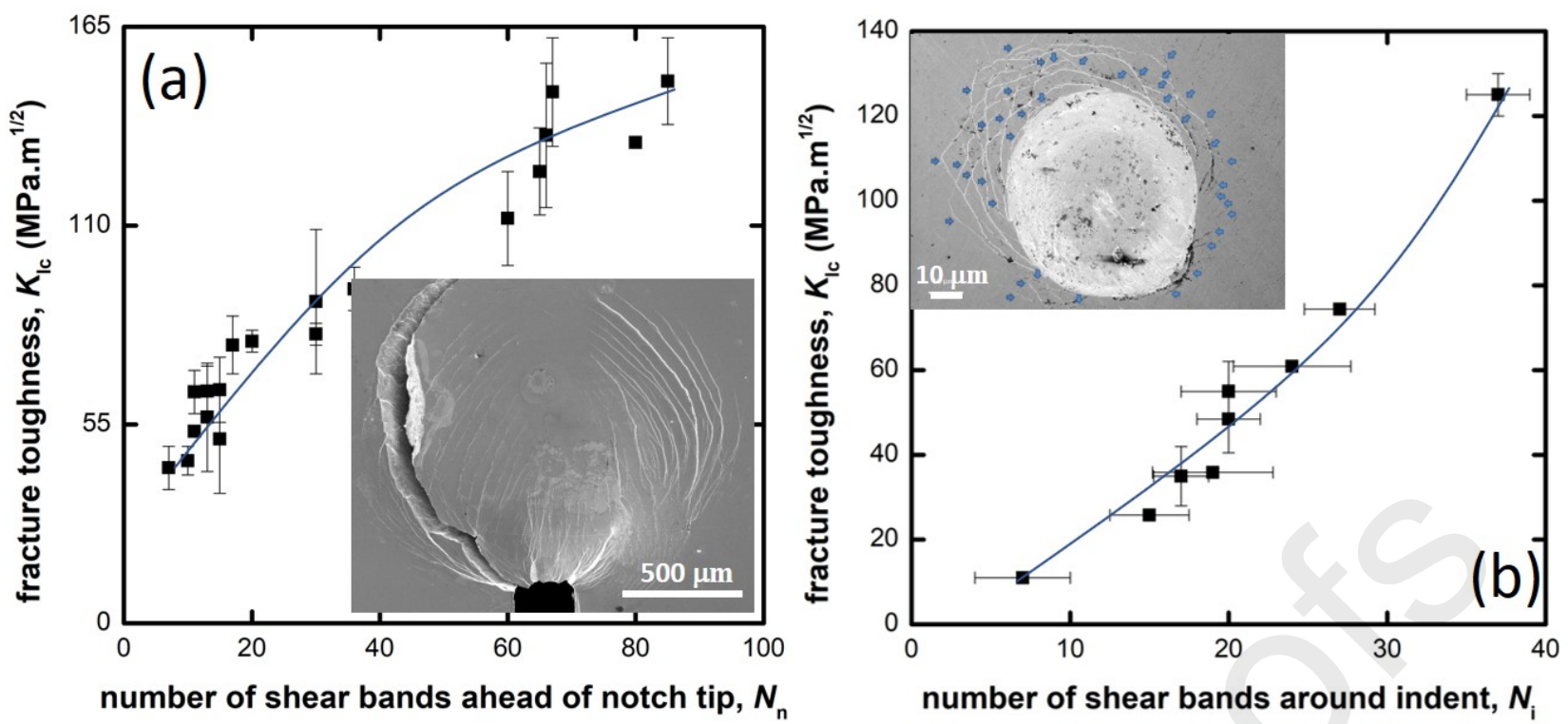

Fig. 18. Variations in the mode I fracture initiation toughness, $K_{I c}$, with the number of shear bands (a) in the notch tip plastic zone, $N_{n}$, and (b) around the spherical indents (made with an indentation strain of $10 \%$ ), $N_{i}$, illustrating the power law relationship between $K_{I c}$ and both $N_{n}$ and $N_{i}$. (Reprinted with permission from Narayan et al. [231]. Copyright (2018) Elsevier)

Since BMGs lack tensile ductility, several routes are being investigated to remedy this problem; the most common one being the composites approach. Early efforts in this direction are either to introduce crystalline second phases, either by means of a controlled thermal treatment of the BMG to induce nanocrystalline phases [234] or via infiltration of the MG matrix in a preform of fibers (the most common being tungsten crystalline fibers) [235]. Vickers micro-indentation studies on nanocrystalline BMG composites (BMGCs) by Basu et al. [236] show that the embrittlement associated with the nanocrystallization of the BMG can easily be studied by examining the indents; the very observation of a shear band morphology around the indents made on the BMG in the as-cast state indicates that it is tough. Annealing the alloy first leads to the absence of such shear bands, with further annealing causing corner cracks, which indicates that the BMG became brittle. Recognizing the limitations of such composites, Hofmann et al. [237] have designed BMGCs with crystalline dendritic phases that are ductile, and hence enhance the BMG's fracture toughness significantly. Narayan et al. [238] employed the nanoindentation technique to evaluate the $E$ and $H$ of the constituent phases and Vickers microindentation to examine the shear band interactions between the amorphous matrix and the crystalline dendrites. Their results show that the modulus of the BMGC is in agreement with the 'rule of mixtures' prediction whereas $H$ corresponds to that of the matrix. They rationalized the latter result as due to the constraint imposed by the matrix for the flow of (otherwise) softer second phases. Recently, Gentile et al. [239] have employed the bonded interface technique, which was coupled with the strain-field mapping to examine the yield condition's dependence on the 
volume fraction and size of the dendritic phases, to show a cross-over in the mechanism to nearhomogeneous one at about 60 vol.\% of the crystalline phase.

\subsection{Incipient plasticity}

\subsubsection{Onset of plasticity and its statistics}

It has been widely demonstrated that nanoindentation on well-prepared surface can capture the onset of plasticity in crystalline materials when spherical or blunt indenters are used [240-242]. On the $P-h$ response, the transition from elastic to elastoplastic deformation is observed as a sudden displacement burst (or pop-in). The first pop-in for crystalline materials originates from the nucleation or movement of dislocations; for MGs it is generally thought to mark the completion of shear band nucleation and the onset of its propagation [172,243,244]. Fig. 19 shows an example of the pop-in behavior in the loading segment of the $P-h$ curve obtained through nanoindentation with a spherical tip on the $\mathrm{Zr}_{52.5} \mathrm{Cu}_{17.9} \mathrm{Ni}_{14.6} \mathrm{Al}_{10} \mathrm{Ti}_{5} \mathrm{BMG}$. The maximum shear stress underneath the indenter at the first pop-in, $\tau_{\max }$, usually represents the shear yield strength for the onset of plasticity, $\tau_{\mathrm{y}}$, in the crystalline material. In MGs, however, $\tau_{\max }$ value may not be the exact $\tau_{\mathrm{y}}$ due to pressure sensitivity of plastic flow. Nevertheless, $\tau_{\mathrm{y}}$ can always be written in the form $\tau_{\mathrm{y}}=C_{\mathrm{y}} \tau_{\max }$, where the constant $C_{y}$ depends on the yield criterion [211,245], for spherical indentation. Producing large pop-in data sets and statistical analyses of them can provide insights into the physics of deformation. First example is that despite the absence of dislocations, the average value of the first pop-in stress in MGs is dependent on the indenter radius, $R_{\mathrm{i}}$, which was reported for single crystal $\mathrm{Ni}$ as a new kind of 'spherical' ISE: the smaller $R_{\mathrm{i}}$, the higher pop-in load/stress [246]. Bei et al. [245] reported that the upper bound of the $\tau_{\max }$ is almost constant for indenter radii smaller than a critical value (for example, $\sim 90 \mu \mathrm{m}$ for a $\mathrm{Zr}$ based MG [246], but the lower bound of this $\tau_{\max }$ decreases with increasing $R_{\mathrm{i}}$. They argued that this size effect is probably due to the increased probability of finding defects underneath larger indenters. Packard et al. [247], who made first pop-in statistical measurements on both crystalline metals as well as on MGs, suggest that at the nanoscale, the strength distributions in crystalline metals are governed by thermal fluctuations (and hence are $\dot{\varepsilon}$ and $T$ sensitive) whereas in MGs, the measured variance is due to the intrinsic statistical nature of the atomic packing and is both $T$ and $\dot{\varepsilon}$ insensitive. The nanoscale structural heterogeneity in the disordered atomic structure, which also reflects in significant variability (up to $30 \%$ ) in the local $E$ values was independently confirmed by atomic force acoustic microscopy measurements [248], dynamic modulus mapping [249] and dynamic force microscopy [250]. 


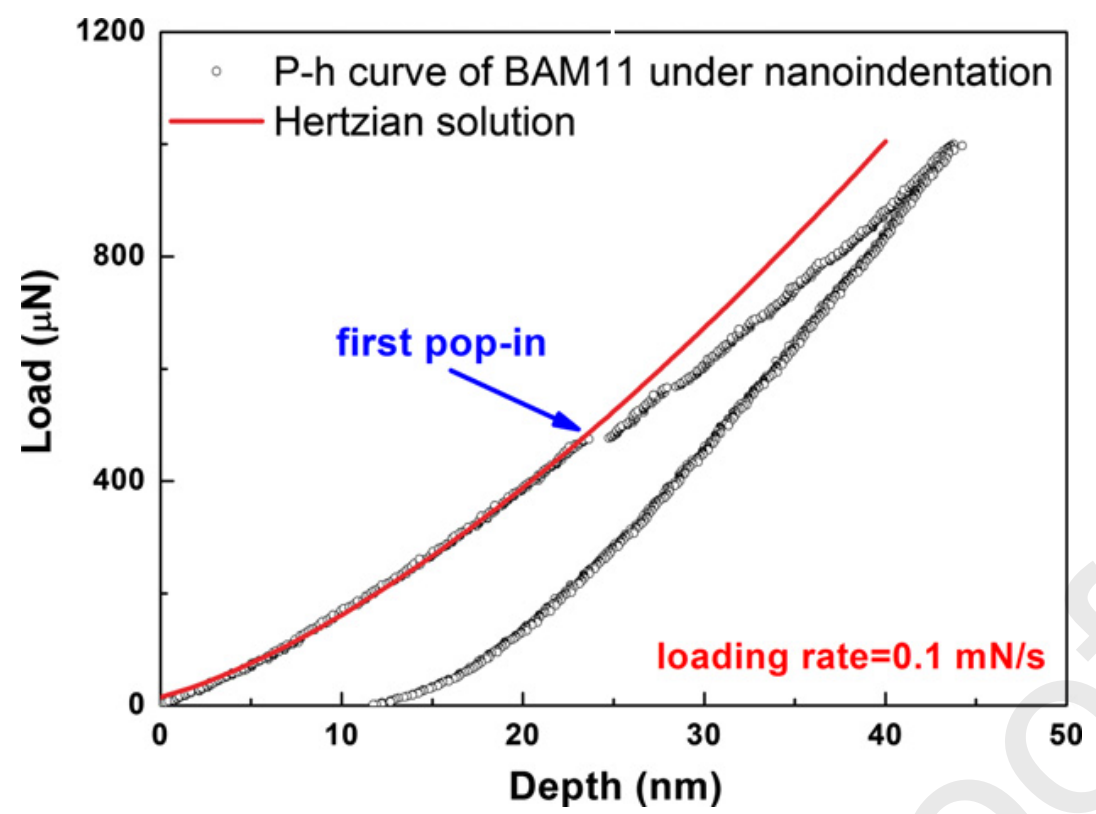

Fig. 19. Representative $P-h$ response obtained from spherical nanoindentation (tip radius: $780 \mathrm{~nm}$ ) on a $\mathrm{Zr}_{52.5} \mathrm{Cu}_{17.9} \mathrm{Ni}_{14.6} \mathrm{Al}_{10} \mathrm{Ti}_{5}$ metallic glass sample showing pop-ins and Hertzian contact model fit for the elastic part of the response. (Reprinted with permission from Wang et al. [244]. Copyright (2011) Elsevier)

Subsequent to the work of Packard et al., a number of such studies [228,251,252] were performed on a wide variety of MGs. In most of these, the analysis performed by Packard et al. (but for crystalline metals) was used for obtaining activation volume associated with the incipient plasticity. However, neither Packard et al. nor those who followed them examined the nature of the statistical distributions of first pop-in strength in detail and routinely used the Gaussian distribution function to describe the dispersions. Perepezko et al. [253], who critically examined such datasets generated on four different MGs, observed that the statistical distribution of $\tau_{y}$ in MGs is bimodal in nature. On this basis, they assert the existence of a bimodal distribution of intrinsic defect sites and justify it as following: (a) The yield event underneath the indenter is triggered by the formation of an incipient shear band. (b) A shear band can be nucleated by activating one of two families of defects, one which operates at a lower load and another at higher load. Such distinct defect morphology results in an overlapping normal distributions of yield events. The above conjecture is supported by the observation of a shoulder at higher loads in the probability density distribution of their $\tau_{y}$ data. This observation also prompted the authors to arbitrarily fit two Gaussian distributions to the kernel density estimates (KDEs) of their data [254], which they validate with an adjusted- $R^{2}$ test. Then, using a hazard function to model this distribution, individual shear band nucleation rates were calculated for the families of low load and high load defect sites.

The data sets that Perepezko et al. have analyzed were obtained with only one combination of $\dot{P}(=20 \mu \mathrm{N} / \mathrm{s})$ and $R_{\mathrm{i}}(=5 \mu \mathrm{m})$ [253]. Recently, Nag et al. [255] performed detailed statistical analyses 
on a total of $13 \tau_{y}$ distributions, each containing at least 100 data points, that are obtained on two different Zr-based MGs with varying structural states and are probed with different combinations of $R_{\mathrm{i}}$ and $\dot{P}$. By employing the maximum likelihood estimates and the Akaike information criterion, Nag et al. [255] critically examined the suitability of the uni- and bi-modal (or mixture) versions of Gaussian, lognormal, and Weibull statistical models to examine which one of those best describes the experimental data. Results show that the 3-parameter bimodal Weibull distribution best captures the stochastic nature of the incipient plastic strengths in MGs. Interestingly, they noted that the bimodality is significant only when either large indenters or high $\dot{P}$, or both, were employed; see Fig 20. Based on the analyses of the stress distributions and their gradients, which shows that the stress required to nucleate a shear band along a particular shear trajectory depends on both $R_{\mathrm{i}}$ and $\dot{P}, \operatorname{Nag} e t$ al. [255] rationalize the bimodality observed under specific experimental conditions by postulating that the stress required for shear band nucleation must exceed a critical value over a characteristic distance over which the stress gradients are minimum. It is interesting to note that Gao and Perepezko [256] reported a trimodal pop-in strength distribution in a Gd-based MG that was probed with four different $\dot{P}$. Nevertheless, a comprehensive and detailed understanding on the nature of incipient plasticity in MGs is still elusive.
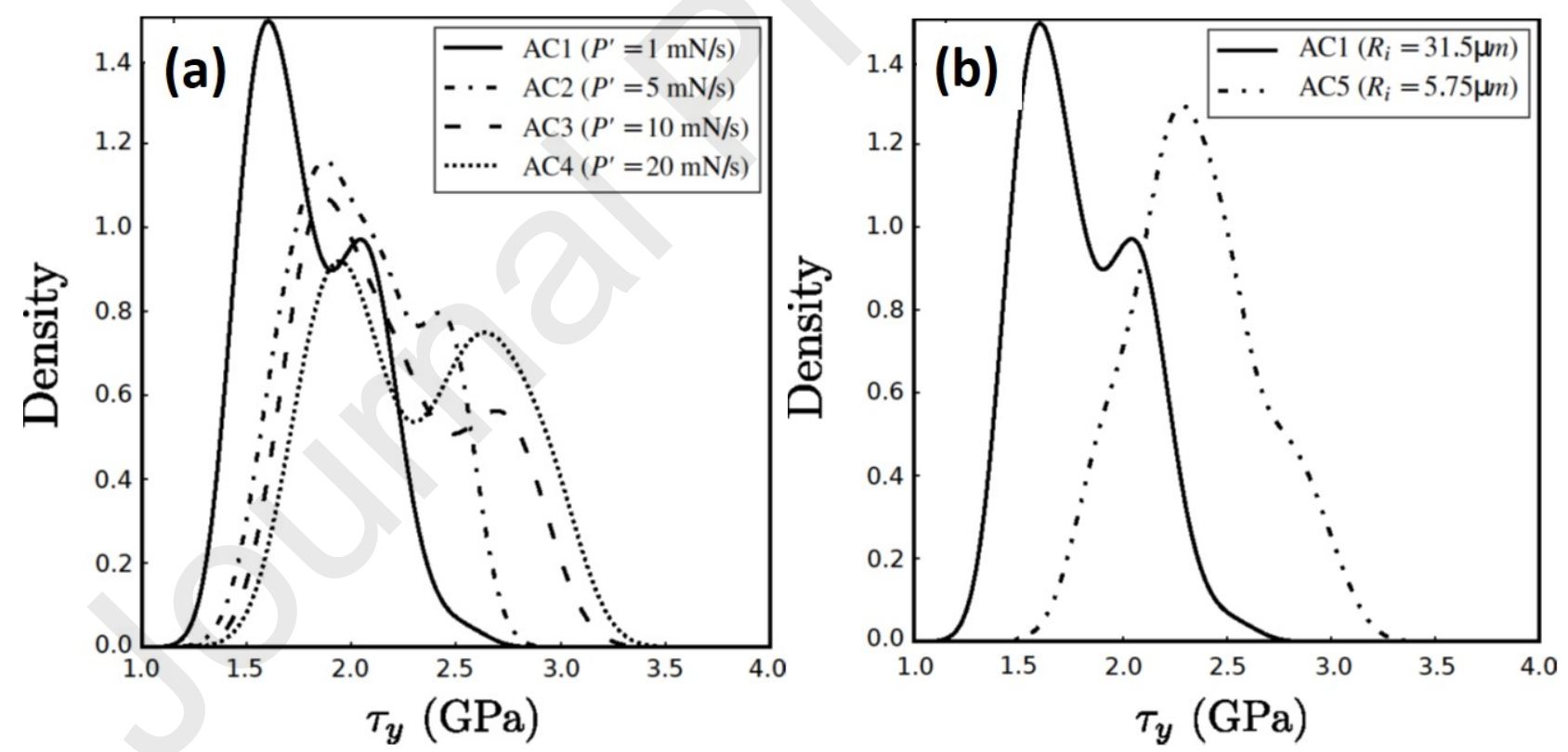

Fig. 20. Strength distribution represented as KDE of $\tau_{y}$ in different MGs demonstrating the individual effects of (a) loading rate, $\dot{P}$, and (b) indenter tip radius, $R_{\mathrm{i}}$. (Reprinted with permission from Nag et al. [255]. Copyright (2020) Elsevier)

\subsubsection{STZ volume estimation}

An important application of nanoindentation studies of MGs is the estimation of STZ volume through a statistical analysis of the first pop-in data [257-260]. According to the cooperative shear model 
proposed by Johnson and Samwer [261], yielding is determined by the cooperative shearing of STZs and, hence, intrinsically depends on the activation volume $V^{*}$ (which generally ranges from $\sim 0.01$ to $0.05 \mathrm{~nm}^{3}$ for various MGs [258-260]), whose value can be estimated from $\ln \left[\ln (1-f)^{-1}\right]$ versus $\tau_{\max }$ plots, where $f$ is the cumulative probability of the thermally assisted and stress-biased pop-in events, as illustrated in Fig. 21 [262]. The measured STZ volume would be independent of the spherical tip $R_{\mathrm{i}}$ [258] but influenced by $\dot{\varepsilon}$ (see Fig. 21 [257]), $v$, and structural state of MG [258,260]. It should be noted that although $\tau_{\max }$ was used to denote yielding here, it is possible to use other yield criteria to mark the elastic-plastic transition. However, this does not change the cumulative property of pop-in event, because all the nonzero stresses can be written in terms of the $\tau_{\max }$ as discussed above [245].

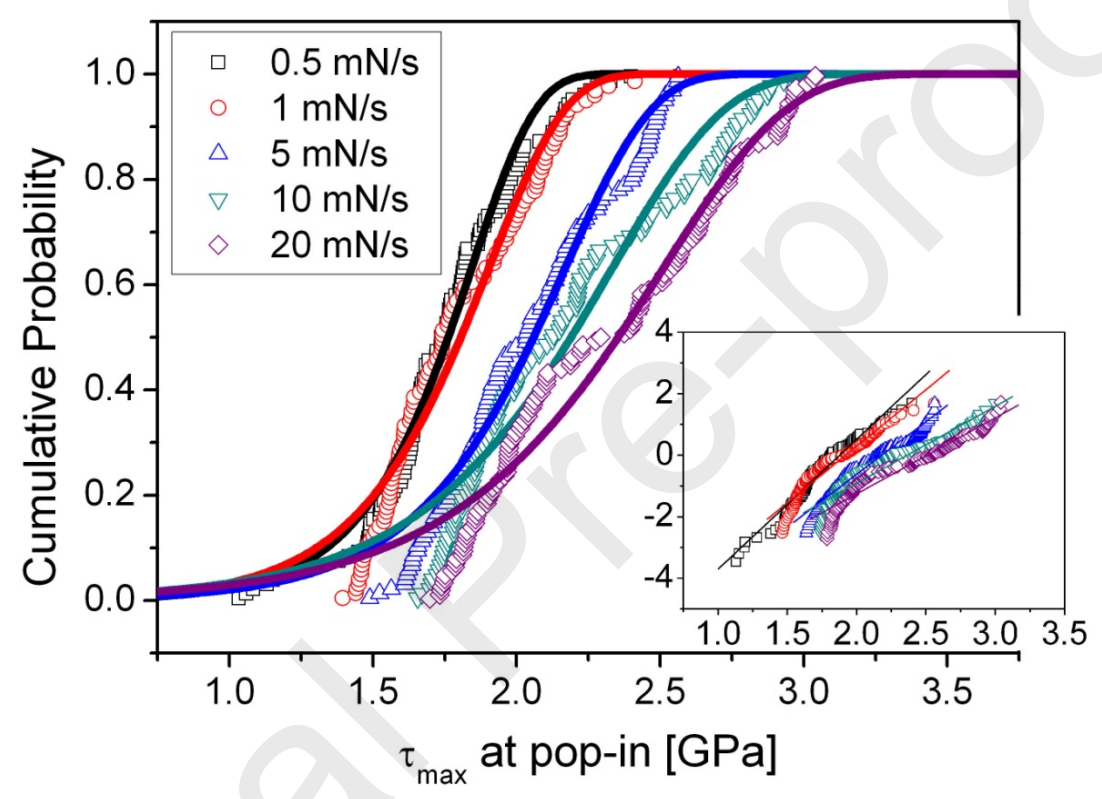

Fig. 21. The distributions of cumulative probability, $f$, of the maximum shear stress, $\tau_{\max }$, at various loading rates. Inset shows the linear fits to the $\ln [\ln (1-f)-1]$ vs. $\tau_{\max }$ data. (Reprinted with permission from Choi et al. [257]. Copyright (2012) Elsevier)

The rate-jump method, which is a commonly used method to evaluate SRS and, in turn, estimate the activation volume, was also utilized via nanoindentation to estimate the STZ volume [263]. However, the results obtained based on such tests are valid if and only if the SRS obtained is a positive quantity. Since the strain softening nature of MGs imparts negative SRS to them [264267], i.e., the flow stress decreases when the strain-rate is increased, rate-jump methods are unlikely to be useful for this purpose. Significant material pile-up around indenter that occurs during nanoindentation of BMGs, can lead to an overestimation of $H[184,264,268]$. Since pile-up volume would also depend on the rate of loading, a higher rate of deformation can lead to larger pile-up, which, in turn, could lead to a larger divergence between estimated and actual $H$ values. 


\subsection{Environmental effects}

Since MGs have potential for hydrogen storage or hydrogen separation [269,270], understanding the effects of hydrogen on their mechanical behavior is of paramount importance. As already discussed, deformation mechanisms in MGs are much different from those in crystalline alloys. It is thus anticipated that the physics behind the hydrogen effects in BMGs might differ from the one in crystalline metals. By performing nanoindentation on the subsurface region of a macroscopic spherical indentation made on a $\left(\mathrm{Zr}_{52.5} \mathrm{Ni}_{13.6} \mathrm{Cu}_{18} \mathrm{Al}_{10.4}\right) \mathrm{Nb}_{2}$ BMG, Yoo et al. [271] found that hydrogen charging enhances the nanohardness and decreases both the plastic zone size and the corresponding shear band density. Zhao et al. [259] applied nanoindentation with a spherical tip to investigate the influence of dissolved hydrogen on $\tau_{\mathrm{y}}$ and $\mathrm{STZ}$ volume of $\mathrm{Ni}_{45} \mathrm{Nb}_{30} \mathrm{Zr}_{25}$, $\mathrm{Ni}_{33} \mathrm{Nb}_{22} \mathrm{Zr}_{40} \mathrm{Co}_{5}, \mathrm{Ni}_{27} \mathrm{Nb}_{18} \mathrm{Zr}_{50} \mathrm{Co}_{5}$, and $\mathrm{Ni}_{35} \mathrm{Nb}_{30} \mathrm{Zr}_{15} \mathrm{Ti}_{10} \mathrm{Fe}_{5} \mathrm{Co}_{5}$ MG membranes through pop-in analyses. While no clear trend was seen across all MGs, $\tau_{\max }$ increases and the STZ volume decreases in the high-Zr alloys $\left(\mathrm{Ni}_{33} \mathrm{Nb}_{22} \mathrm{Zr}_{40} \mathrm{Co}_{5}\right.$ and $\left.\mathrm{Ni}_{27} \mathrm{Nb}_{18} \mathrm{Zr}_{50} \mathrm{Co}_{5}\right)$, whereas opposite effects were observed in the low-Zr alloys $\left(\mathrm{Ni}_{45} \mathrm{Nb}_{30} \mathrm{Zr}_{25}\right.$ and $\left.\mathrm{Ni}_{35} \mathrm{Nb}_{30} \mathrm{Zr}_{15} \mathrm{Ti}_{10} \mathrm{Fe}_{5} \mathrm{Co}_{5}\right)$. Similarly, Zhao et al. [272] also observed softening in low-Zr alloys and hardening in high- $\mathrm{Zr}$ ones during nanoindentation with a sharp tip as shown in Fig. 22 [272]. These variations were attributed to the mobile-hydrogen-assisted softening and immobile hydrogen trapped inside Zr-rich interstitial sites that results in a densely packed structure, respectively [273,274].

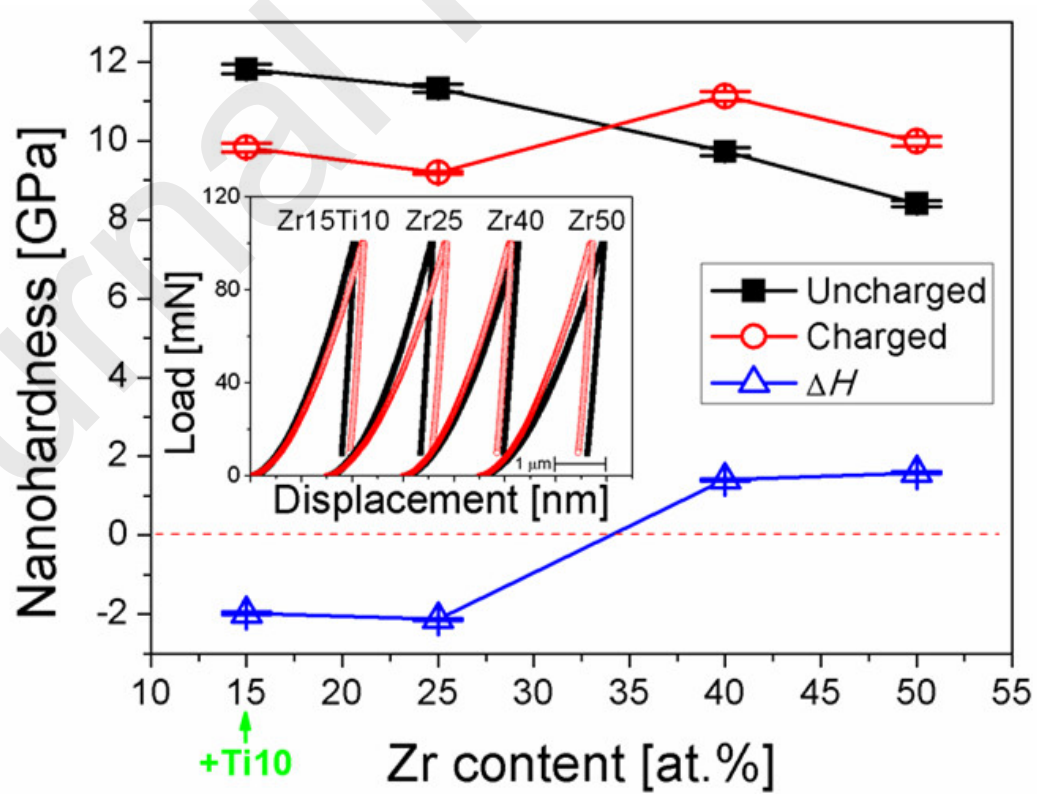

Fig. 22. Variation in hardness with $\mathrm{Zr}$-content and the $\mathrm{H}$-induced hardness change of MGs, $\Delta H$ (= $H_{\text {Charged }}-H_{\text {Uncharged }}$ ). Inset shows representative $P-h$ responses. (Reprinted with permission from Zhao et al. [272]. Copyright (2014) Elsevier) 
Irradiation can tailor the amorphous structure, since the bombardment of MGs with energetic particles such as electrons, neutrons, and ions induce structural heterogeneities [275,276]. Irradiation effects on the mechanical behavior of MGs was also examined via nanoindentation [276-278]. Raghavan et al. [278] observed an irradiation-induced hardening behavior and a transition from serrated flow in the as-cast region to homogeneous flow in the ion-irradiated regions, which were attributed to the densification of the material (that dilated during irradiation) underneath the indenter in the irradiated regions. Their work clearly demonstrated that irradiation makes MGs more plastic, whereas it hardens and embrittles crystalline metals, due to the increased free volume content in MGs upon ionic irradiation.

\subsection{Modeling and simulation of indentation response of MGs}

The state of stress underneath the indenter is complex, especially when a sharp tipped indenter is used, with steep gradients in stress, strain, and displacement fields. This invariably makes the deciphering of the experimental results difficult. To overcome this limitation, several studies focused on the inelastic deformation behavior of MGs during indentation by means of numerical simulations. These can be classified into two broad classes: continuum-level FEM and atomic-scale MD simulations. For FEM, the choice of appropriate constitutive laws that reflect the modeled material's intrinsic mechanical response is critical. For MGs, which are pressure sensitive and are prone to discrete plasticity through shear banding, constitutive descriptions that are routinely used for crystalline metals would result in inaccurate simulated results. The first elastic-plastic FE analysis on the indentation of MGs by Vaidyanathan et al. [206] revealed that the predicted $P-h$ curve using Mohr-Coulomb criterion (with friction coefficient $\alpha$ of 0.13 for the examined Zr-based MGs) is in a good agreement with the experimental results whereas the classical von Mises criterion over-predicts $h$ at any given $P$.

While the Mohr-Column yield criterion (that is the most widely used for describing plasticity in granular materials in soil mechanics as well as amorphous polymers) was found to be valid for predicting the yield locus of MGs [205], there was no agreement for the elastic-plastic constitutive model for the criterion. In this light, Anand and Gu [279] generalized the existing two-dimensional 'double shearing' model to develop a three dimensional rate-independent elastic-plastic model, and Anand and $\mathrm{Su}$ [280] further generalized it to formulate a thermodynamically consistent, finitedeformation macroscopic constitutive model for the rate-dependent elastic-viscoplastic deformation of pressure-sensitive, plastically-dilatant materials. They implemented this constitutive model in a commercial FE software (ABAQUS) to simulate the plane-strain wedge indentation (whose wedge half-angle was chosen to be $68^{\circ}$ to approximate a Vickers indenter) of a Zr-based MG. The simulated shear band patterns around indent (i.e., slip steps on the free surface) and the serrations in $P-h$ curves 
were in reasonable agreement with those of the complementary experimental results; see Fig. 23. In a follow-up paper [281], a number of (approximately plane-strain) wedge indentation experiments were performed on a Zr-based MG with a cylindrical indenter tip. By direct comparison of the predicted shear-band pattern and equivalent plastic strain contours from FE simulations with the corresponding experimental data, it was suggested that their constitutive model and simulation procedures are capable of not only quantitatively predicting $P-h$ curves, but also capable of approximately estimating the inelastic strain distribution and its evolution during indentation.

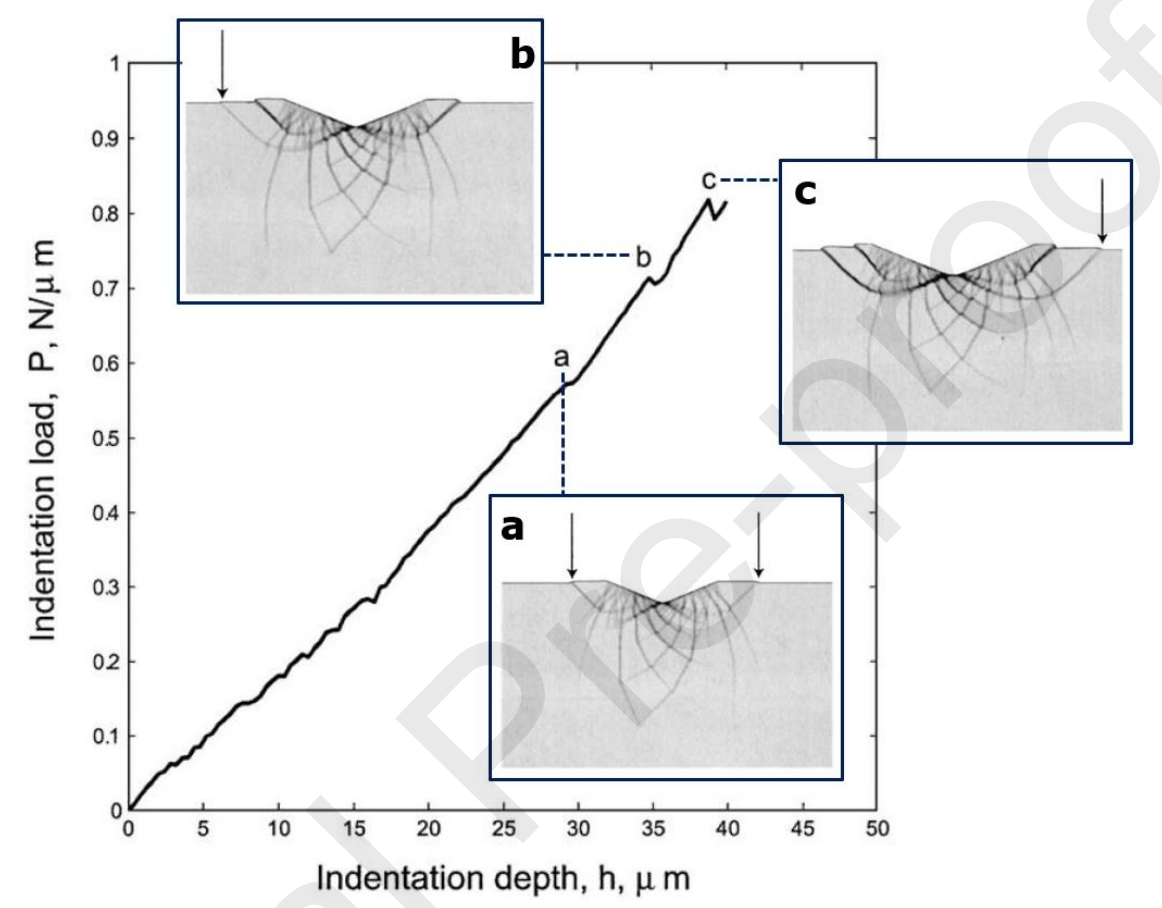

Fig. 23. Simulated $P-h$ response using finite element modeling. Distinct 'load-drops' marked as events $a, b$, and $c$ on the $P-h$ curve occur when the shear bands (indicated by arrows in the inset figures) initiate. (Reprinted with permission from Anand and Su [280]. Copyright (2005) Elsevier)

In addition to continuum FE simulations, atomistic MD simulations were conducted for analyzing the nanoindentation behavior of MGs. During the MD simulation (where the equation of motion is solved for all the atoms to retrace their trajectories during indentation), $P$ and $h$ are calculated by the sum of the forces acting on the atoms of the indenter and the relative displacement of the indenter tip to the initial surface of the indented material [282].

Atomistic simulation for nanoindentation of MGs is useful for understanding of their atomicscale deformation mechanism but is somewhat challenging. The unique nature of MGs (e.g., the inhomogeneities are frozen into the entire solid and the macroscopic plastic deformation is intensely localized into shear bands) makes it difficult to identify the nanoindentation damage by computational techniques used for a crystalline solid. 
Early works on atomistic simulation of MG were performed by Lund and Schuh [205]. While they are not on nanoindentation, their molecular static simulations of a $\mathrm{Cu}-\mathrm{Zr} \mathrm{MG}$ showed the asymmetry in the plane-stress yield surface (i.e., uniformly stronger in net compressive stress state than in net tension) and it can be well-described using the Mohr-Coulomb yield criterion, which can be linked to the fundamental criterion for STZ activation.

By performing a series of MD simulations on nanoindentations of three-dimensional binary (i.e., non-specific) MG, Shi and Falk [283] proved the usefulness of the atomistic simulations in exploring the atom-scale subsurface deformation morphology and stress field pattern that can characterize the incipient plasticity of a MG during nanoindentation. From their simulations controlling various parameters (such as quenching rate and $\dot{\varepsilon}$; see Fig. 24), they proposed that the short range ordered (SRO) domains provide a significantly greater signal-to-noise response than the free volume. While the Lennard-Jones (LJ) model system employed by Shi and Falk gives some hints about the deformation in a $\mathrm{MG}$, its description of the atomic interactions may be too simple to realistically describe a 'specific' MG. Thus, MD simulations with many-body potentials instead of LJ potential were performed. For example, Păduraru et al. [284] used the effective medium theory potentials to describe $\mathrm{CuZr}$ and $\mathrm{Mg}_{85} \mathrm{Cu}_{15}$ MGs, and reported a clear signature of shear band formation under the indenter, though shear bands are less clearly developed in comparison with the LJ-based simulations. To overcome the scale hurdle of each simulation and to capture the actual features of the deformation during indentation of MGs, combined FE and MD simulations, as for crystalline materials, appears promising (e.g., see for example, Ref. [285] for the simulations performed on crystalline $\mathrm{Cu}$ ). 

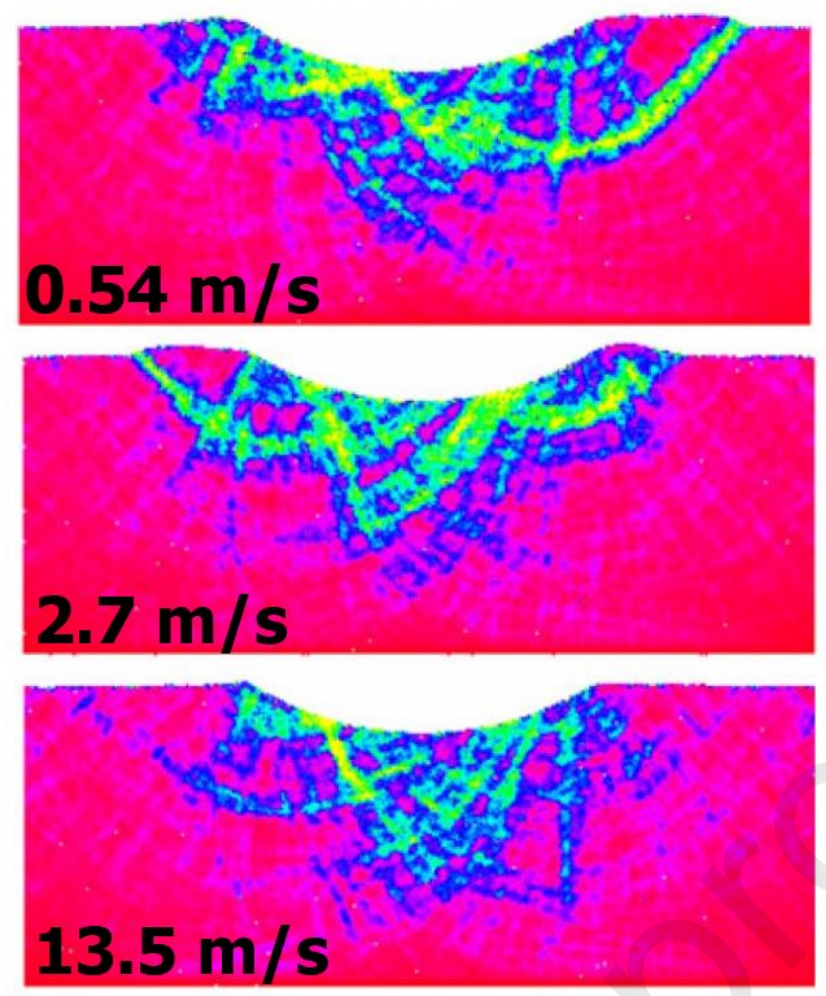

Fig. 24. Visualization of the magnitude of the net local deviatoric shear strain underneath the indenter at the maximum depth under three indentation rates, obtained using MD simulations. The simulations were performed for the spherical indentations (with tip having the radius of $40 \mathrm{~nm}$ ) until the maximum displacement reaches $5 \mathrm{~nm}$. (Reprinted with permission from Shi and Falk [283]. Copyright (2007) Elsevier)

\section{CLOSING REMARKS}

On one hand, glass is a generic word which covers a great diversity of materials with stunning mechanical and physical properties. These materials have in common the lack of long range atomic ordering and their complex structures still raise numerous fundamental questions. On the other hand, indentation is a unique mechanical testing method, where extraordinary stress levels (order of magnitude of hardness) with steep gradients and spatial variations develop, leading to complicated physical phenomena, such as densification, localized shear flow through shear transformation zone activation, shear band formation, and cracking. Hence, deciphering the experimental data generated through such tests requires cutting edge developments in physics, mechanics and modelling tools even for crystalline materials whose deformation mechanisms are well understood. Therefore, indentation of glasses, while relatively easy to perform and perhaps the most convenient method to probe properties, is considerably more challenging in terms of understanding the results obtained. As this review highlights, considerable progress was made over the years and insights continue to be gained by means of innovative indentation techniques in conjunction with image analysis and 
modelling. While indentation remains a useful and suitable tool for the study of glasses ${ }^{7}$ and is increasingly being used, several unsolved issues remain. Especially, direct experiments that would reveal fundamental unit deformation processes and mechanisms of fracture at the nanoscopic length scales would not only advance this field of research further, but also will enable design of stronger and tougher glasses. Further advances in instrumentation complemented with sophisticated theoretical models and simulations are required for such an objective to be accomplished. Towards former, one can expect coupled experiments performed in situ, involving for example indentation and electric conductivity through the contact area, or indentation and optical spectroscopy (Raman, IR), etc. can shed new insights into the extraordinary physics that takes place at the indentation site. That way, indentation can become a more and more as a unique and powerful tool to fill the connection between the nanoscale glass structural scale to its macroscale response. Besides, there are great expectations for a better understanding of environmental effects using indentation investigations, as indentation testing is particularly suitable for environment-controlled set-up.

\section{Acknowledgements}

We thank Dr. Yakai Zhao for the assistance he rendered during the preparation of this manuscript. T. Rouxel is very grateful to Institut Universitaire de France for the support he received. The work at Hanyang University was supported by the National Research Foundation of Korea (NRF) grants funded by the Korea government (MSIT) (No. 2020R1A2B5B01001446 and No. 2020R1A5A6017701). The work at the Nanyang Technological University was supported by the funding from A*STAR via the Structural Metals and Alloys Programme (No. A18B1b0061).

\section{References}

[1] Tabor D. The Hardness of Metals. Oxford: Oxford University Press; 1952.

[2] Oliver WC, Pharr GM. An improved technique for determining hardness and elastic modulus using load and displacement sensing indentation experiments. J Mater Res 1992;7:1564-83. https://doi.org/10.1557/JMR.1992.1564.

[3] Ramamurty U, Jang J. Nanoindentation for probing the mechanical behavior of molecular crystals-a review of the technique and how to use it. CrystEngComm 2014;16:12-23. https://doi.org/10.1039/C3CE41266K.

[4] Sebastiani M, Johanns KE, Herbert EG, Pharr GM. Measurement of fracture toughness by nanoindentation methods: Recent advances and future challenges. Curr Opin Solid State

\footnotetext{
${ }^{7}$ Indentation techniques are also employed to study glassy polymers. However, they were not covered in this review, due in part to the lack of necessary expertise amongst the authors of this paper on that specific area. While the plastic deformation phenomenology in glassy polymers is significantly different from those of the inorganic glasses examined in this review, indentation studies on glassy polymers (which are not many, compared to those on the inorganic glasses) indicate some common features, such as pressure sensitivity of plastic flow [286], indentation size effect [287], strain rate sensitivity [288], etc. Interested reader is referred the papers listed here [289-298].
} 
Mater Sci 2015;19:324-33. https://doi.org/10.1016/j.cossms.2015.04.003.

[5] Rouxel T, Yoshida S. The fracture toughness of inorganic glasses. J Am Ceram Soc 2017;100:4374-96. https://doi.org/10.1111/jace.15108.

[6] Rouxel T, Sellappan P, Célarié F, Houizot P, Sanglebœuf JC. Toward glasses with better indentation cracking resistance. Comptes Rendus - Mec 2014;342:46-51. https://doi.org/10.1016/j.crme.2013.10.008.

[7] Schuh CA, Nieh TG. A survey of instrumented indentation studies on metallic glasses. J Mater Res 2004;19:46-57. https://doi.org/10.1557/jmr.2004.19.1.46.

[8] Ernsberger FM. Role of Densification in Deformation of Glasses Under Point Loading. J Am Ceram Soc 1968;51:545-7. https://doi.org/10.1111/j.1151-2916.1968.tb13318.x.

[9] Peter KW. Densification and flow phenomena of glass in indentation experiments. J Non Cryst Solids 1970;5:103-15. https://doi.org/10.1016/0022-3093(70)90188-2.

[10] Shannon RD. Revised effective ionic radii and systematic studies of interatomic distances in halides and chalcogenides. Acta Crystallogr Sect A 1976;32:751-67. https://doi.org/10.1107/S0567739476001551.

[11] Marsh DM. Plastic flow in glass. Proc R Soc London Ser A Math Phys Sci 1964;279:42035. https://doi.org/10.1098/rspa.1964.0114.

[12] Arora A, Marshall DB, Lawn BR, Swain MV. Indentation deformation/fracture of normal and anomalous glasses. J Non Cryst Solids 1979;31:415-28. https://doi.org/10.1016/00223093(79)90154-6.

[13] Rouxel T, Ji H, Guin JP, Augereau F, Ruffí B. Indentation deformation mechanism in glass: Densification versus shear flow. J Appl Phys 2010;107:094903. https://doi.org/10.1063/1.3407559.

[14] Cook RF, Pharr GM. Direct Observation and Analysis of Indentation Cracking in Glasses and Ceramics. J Am Ceram Soc 1990;73:787-817. https://doi.org/10.1111/j.11512916.1990.tb05119.x.

[15] Yoshida S. Indentation deformation and cracking in oxide glass -toward understanding of crack nucleation. J Non-Crystalline Solids X 2019;1:100009. https://doi.org/10.1016/j.nocx.2019.100009.

[16] Pugh SF. XCII. Relations between the elastic moduli and the plastic properties of polycrystalline pure metals. London, Edinburgh, Dublin Philos Mag J Sci 1954;45:823-43. https://doi.org/10.1080/14786440808520496.

[17] Léger JM, Haines J, Schmidt M, Petitet JP, Pereira AS, da Jornada JAH. Discovery of hardest known oxide. Nature 1996;383:401-401. https://doi.org/10.1038/383401a0.

[18] Rouxel T, Yokoyama Y. Elastic properties and atomic bonding character in metallic glasses. J Appl Phys 2015;118:044901. https://doi.org/10.1063/1.4926882.

[19] Perriot A, Vandembroucq D, Barthel E, Martinez V, Grosvalet L, Martinet CH, et al. Raman microspectroscopic characterization of amorphous silica plastic behavior. J Am Ceram Soc 2006;89:596-601. https://doi.org/10.1111/j.1551-2916.2005.00747.x.

[20] Yoshida S, Sanglebœuf JC, Rouxel T. Quantitative evaluation of indentation-induced densification in glass. J Mater Res 2005;20:3404-12. https://doi.org/10.1557/jmr.2005.0418.

[21] Rouxel T, Ji H, Hammouda T, Moréac A. Poisson's ratio and the densification of glass under high pressure. Phys Rev Lett 2008;100:225501.

https://doi.org/10.1103/PhysRevLett.100.225501.

[22] Sellappan P, Rouxel T, Celarie F, Becker E, Houizot P, Conradt R. Composition dependence of indentation deformation and indentation cracking in glass. Acta Mater 2013;61:5949-65. https://doi.org/10.1016/j.actamat.2013.06.034.

[23] Wang WH, Dong C, Shek CH. Bulk metallic glasses. Mater Sci Eng R Reports 2004;44:4589. https://doi.org/10.1016/j.mser.2004.03.001.

[24] Hill R. The Mathematical Theory of Plasticity. Oxford: Oxford University Press; 1950.

[25] Hagan J., Van Der Zwaag S. Plastic processes in a range of soda-lime-silica glasses. J Non Cryst Solids 1984;64:249-68. https://doi.org/10.1016/0022-3093(84)90221-7. 
[26] Tolansky S. Surface microtopography. New York: Interscience Publishers; 1960.

[27] Kurkjian CR, Kammlott GW, Chaudhri MM. Indentation Behavior of Soda-Lime Silica Glass, Fused Silica, and Single-Crystal Quartz at Liquid Nitrogen Temperature. J Am Ceram Soc 1995;78:737-44. https://doi.org/10.1111/j.1151-2916.1995.tb08241.x.

[28] Ji H, Robin E, Rouxel T. Compressive creep and indentation behavior of plasticine between 103 and 353K. Mech Mater 2009;41:199-209.

https://doi.org/10.1016/j.mechmat.2008.10.014.

[29] Heyes DM, Kim JJ, Montrose CJ, Litovitz TA. Time dependent nonlinear shear stress effects in simple liquids: A molecular dynamics study. J Chem Phys 1980;73:3987-96. https://doi.org/10.1063/1.440624.

[30] Simmons JH, Ochoa R, Simmons KD, Mills JJ. Non-Newtonian viscous flow in soda-limesilica glass at forming and annealing temperatures. J Non Cryst Solids 1988;105:313-22. https://doi.org/10.1016/0022-3093(88)90325-0.

[31] Januchta K, Smedskjaer MM. Indentation deformation in oxide glasses: Quantification, structural changes, and relation to cracking. J Non-Crystalline Solids X 2019;1:100007. https://doi.org/10.1016/j.nocx.2018.100007.

[32] Sneddon IN. The relation between load and penetration in the axisymmetric boussinesq problem for a punch of arbitrary profile. Int J Eng Sci 1965;3:47-57. https://doi.org/10.1016/0020-7225(65)90019-4.

[33] Hillig WB. Advances in Glass Technology. In: Matson FR, Rindome GE, editors. Adv. Glas. Technol. Part 2, New York: Plenum; 1963, p. 51.

[34] Mauro JC, Loucks RJ, Gupta PK. Fictive Temperature and the Glassy State. J Am Ceram Soc 2009;92:75-86. https://doi.org/10.1111/j.1551-2916.2008.02851.x.

[35] Kjeldsen J, Smedskjaer MM, Mauro JC, Yue Y. Hardness and incipient plasticity in silicate glasses: Origin of the mixed modifier effect. Appl Phys Lett 2014;104:051913. https://doi.org/10.1063/1.4864400.

[36] Hand RJ, Tadjiev DR. Mechanical properties of silicate glasses as a function of composition. J Non Cryst Solids 2010;356:2417-23. https://doi.org/10.1016/j.jnoncrysol.2010.05.007.

[37] Hirao K, Yoshimoto M, Soga N, Tanaka K. Densification of magnesium and calcium metaphosphate glasses. J Non Cryst Solids 1991;130:78-84. https://doi.org/10.1016/00223093(91)90158-3.

[38] SciGlass 3.5. SciGlass Database n.d. http://www.akosgmbh.de/sciglass/sciglass.htm.

[39] Ivanova ZG, Vassilev VS. Glass phases based on the Se-S-X ( $\mathrm{X}=\mathrm{Cu}, \mathrm{Zn})$ system. Phys Chem Glas 1992;33:105-7.

[40] Hach C., Cerqua-Richardson K, Varner J., LaCourse W. Density and microhardness of AsSe glasses and glass fibers. J Non Cryst Solids 1997;209:159-65. https://doi.org/10.1016/S0022-3093(96)00544-3.

[41] Guin J-P, Rouxel T, Sanglebœuf J-C, Melscoët I, Lucas J. Hardness, Toughness, and Scratchability of Germanium-Selenium Chalcogenide Glasses. J Am Ceram Soc 2002;85:1545-52. https://doi.org/10.1111/j.1151-2916.2002.tb00310.x.

[42] Vassilev V, Hristova-Vasileva T, Petkov K. Glass formation in the As-Te-Cd system. Chalcogenide Lett 2008;5:51-7.

[43] Flahaut J, Guittard M, Loireau-Lozac'h AM. Rare earth sulfide and oxysulfide glasses. Glas. Technol., 1982, p. 149-56.

[44] Lebullenger R, Poulain M. Influence of barium substitution on the physical characteristics of ZBLA glass. J Non Cryst Solids 1997;213-214:353-7. https://doi.org/10.1016/S00223093(97)00016-1.

[45] Hadj Youssef N, Belkhiria M., Videau J., Ben Amara M. Investigation of the physicochemical properties of calcium borophosphate glasses. Effect of the substitution of sodium for calcium. Mater Lett 2000;44:269-74. https://doi.org/10.1016/S0167-577X(00)00043-4.

[46] Liang X, Li H, Wang C, Yu H, Li Z, Yang S. Physical and structural properties of calcium iron phosphate glass doped with rare earth. J Non Cryst Solids 2014;402:135-40. 
https://doi.org/10.1016/j.jnoncrysol.2014.05.021.

[47] Murakami Y, Yamamoto H. Properties of Yb-Si-Al-O-C-N oxycarbonitride glasses and liquid-phase sintering of SiC. J Ceram Soc Japan 1997;105:21-5.

https://doi.org/10.2109/jcersj.105.21.

[48] Sellappan P, Sharafat A, Keryvin V, Houizot P, Rouxel T, Grins J, et al. Elastic properties and surface damage resistance of nitrogen-rich ( $\mathrm{Ca}, \mathrm{Sr})-\mathrm{Si}-\mathrm{O}-\mathrm{N}$ glasses. J Non Cryst Solids 2010;356:2120-6. https://doi.org/10.1016/j.jnoncrysol.2010.07.043.

[49] Hakeem AS, Ali S, Jonson B. Preparation and properties of mixed La-Pr silicate oxynitride glasses. J Non Cryst Solids 2013;368:93-7. https://doi.org/10.1016/j.jnoncrysol.2013.03.013.

[50] Greene K, Pomeroy MJ, Hampshire S, Hill R. Effect of composition on the properties of glasses in the $\mathrm{K} 2 \mathrm{O}-\mathrm{BaO}-\mathrm{MgO}-\mathrm{SiO} 2-\mathrm{Al} 2 \mathrm{O} 3-\mathrm{B} 2 \mathrm{O} 3-\mathrm{MgF} 2$ system. J Non Cryst Solids 2003;325:193-205. https://doi.org/10.1016/S0022-3093(03)00337-5.

[51] Lemercier H, Rouxel T, Fargeot D, Besson J-L, Piriou B. Yttrium SiAlON glasses: structure and mechanical properties - elasticity and viscosity. J Non Cryst Solids 1996;201:128-45. https://doi.org/10.1016/0022-3093(96)00147-0.

[52] Rouxel T, Soraru GD, Vicens J. Creep Viscosity and Stress Relaxation of Gel-Derived Silicon Oxycarbide Glasses. J Am Ceram Soc 2001;84:1052-8. https://doi.org/10.1111/j.1151-2916.2001.tb00789.x.

[53] Salama SN, El-Batal HA. Microhardness of phosphate glasses. J Non Cryst Solids 1994;168:179-85. https://doi.org/10.1016/0022-3093(94)90134-1.

[54] Grabco DZ, Shikimaka OA, Elisa M, Sava BA, Boroica L, Pyrtsak K, et al. Features of the mechanical properties of phosphate glasses doped with rare earth elements under indentation. Surf Eng Appl Electrochem 2012;48:365-74. https://doi.org/10.3103/S1068375512040072.

[55] Hartmann M, Bintzer-Schmidt S, Heinz Frischat G. Low-Tg phosphate glasses with improved water resistance for the coating of fluoride glass fibers. Glas Sci Technol Frankfurt 1995;68:352-9.

[56] Hermansen C, Matsuoka J, Yoshida S, Yamazaki H, Kato Y, Yue YZ. Densification and plastic deformation under microindentation in silicate glasses and the relation to hardness and crack resistance. J Non Cryst Solids 2013;364:40-3.

https://doi.org/10.1016/j.jnoncrysol.2012.12.047.

[57] Smedskjaer MM, Jensen M, Yue Y. Effect of thermal history and chemical composition on hardness of silicate glasses. J Non Cryst Solids 2010;356:893-7.

https://doi.org/10.1016/j.jnoncrysol.2009.12.030.

[58] Morin EI, Wu J, Stebbins JF. Modifier cation (Ba, Ca, La, Y) field strength effects on aluminum and boron coordination in aluminoborosilicate glasses: The roles of fictive temperature and boron content. Appl Phys A Mater Sci Process 2014;116:479-90. https://doi.org/10.1007/s00339-014-8369-4.

[59] Stevensson B, Edén M. Structural rationalization of the microhardness trends of rare-earth aluminosilicate glasses: Interplay between the RE3 + field-strength and the aluminum coordinations. J Non Cryst Solids 2013;378:163-7. https://doi.org/10.1016/j.jnoncrysol.2013.06.013.

[60] Scannell G, Laille D, Célarié F, Huang L, Rouxel T. Interaction between Deformation and Crack Initiation under Vickers Indentation in Na2O-TiO2-SiO2 Glasses. Front Mater 2017;4:6. https://doi.org/10.3389/fmats.2017.00006.

[61] Peng M, Wang C, Chen D, Qiu J, Jiang X, Zhu C. Investigations on bismuth and aluminum co-doped germanium oxide glasses for ultra-broadband optical amplification. J Non Cryst Solids 2005;351:2388-93. https://doi.org/10.1016/j.jnoncrysol.2005.06.033.

[62] Rouxel T. Elastic Properties and Short-to Medium-Range Order in Glasses. J Am Ceram Soc 2007;90:3019-39. https://doi.org/10.1111/j.1551-2916.2007.01945.x.

[63] Hagan JT. Micromechanics of crack nucleation during indentations. J Mater Sci 1979;14:2975-80. https://doi.org/10.1007/BF00611482.

[64] Rouxel T. Driving force for indentation cracking in glass: composition, pressure and 
temperature dependence. Philos Trans R Soc A Math Phys Eng Sci 2015;373:20140140. https://doi.org/10.1098/rsta.2014.0140.

[65] Greaves GN, Greer AL, Lakes RS, Rouxel T. Poisson's ratio and modern materials. Nat Mater 2011;10:823-37. https://doi.org/10.1038/nmat3134.

[66] Knight CG, Swain M V, Chaudhri MM. Impact of small steel spheres on glass surfaces. J Mater Sci 1977;12:1573-86. https://doi.org/10.1007/BF00542808.

[67] Sehgal J, Ito S. A new low-brittleness glass in the soda-lime-silica glass family. J Am Ceram Soc 1998;81:2485-8. https://doi.org/10.1111/j.1151-2916.1998.tb02649.x.

[68] Le Bourhis E, Rouxel T. Indentation response of glass with temperature. J Non Cryst Solids 2003;316:153-9. https://doi.org/10.1016/S0022-3093(02)01948-8.

[69] Michel MD, Serbena FC, Lepienski CM. Effect of temperature on hardness and indentation cracking of fused silica. J Non Cryst Solids 2006;352:3550-5. https://doi.org/10.1016/j.jnoncrysol.2006.02.113.

[70] Kese K, Sangleboeuf J-C, Rouxel T. Effect of high-temperature ambience during sharp indentation on the residual contact site properties. J Phys D Appl Phys 2008;41:074025. https://doi.org/10.1088/0022-3727/41/7/074025.

[71] Rouxel T, Sanglebœuf JC. The brittle to ductile transition in a soda-lime-silica glass. J Non Cryst Solids 2000;271:224-35. https://doi.org/10.1016/S0022-3093(00)00109-5.

[72] Lawn BR, Cook RF. Probing material properties with sharp indenters: a retrospective. J Mater Sci 2012;47:1-22. https://doi.org/10.1007/s10853-011-5865-1.

[73] Anuja J, Narasimhan R, Ramamurty U. A numerical study of the indentation mechanics of shape memory alloys in different temperature regimes. Mech Mater 2019;139:103212. https://doi.org/10.1016/j.mechmat.2019.103212.

[74] Anuja J, Narasimhan R, Ramamurty U. An Expanding Cavity Model for Indentation Analysis of Shape Memory Alloys. J Appl Mech 2020;87. https://doi.org/10.1115/1.4045397.

[75] Kato Y, Yamazaki H, Yoshida S, Matsuoka J. Effect of densification on crack initiation under Vickers indentation test. J Non Cryst Solids 2010;356:1768-73. https://doi.org/10.1016/j.jnoncrysol.2010.07.015.

[76] Limbach R, Winterstein-Beckmann A, Dellith J, Möncke D, Wondraczek L. Plasticity, crack initiation and defect resistance in alkali-borosilicate glasses: From normal to anomalous behavior. J Non Cryst Solids 2015;417-418:15-27. https://doi.org/10.1016/j.jnoncrysol.2015.02.019.

[77] Barlet M, Delaye J-M, Charpentier T, Gennisson M, Bonamy D, Rouxel T, et al. Hardness and toughness of sodium borosilicate glasses via Vickers's indentations. J Non Cryst Solids 2015;417-418:66-79. https://doi.org/10.1016/j.jnoncrysol.2015.02.005.

[78] Januchta K, Youngman RE, Goel A, Bauchy M, Rzoska SJ, Bockowski M, et al. Structural origin of high crack resistance in sodium aluminoborate glasses. J Non Cryst Solids 2017;460:54-65. https://doi.org/https://doi.org/10.1016/j.jnoncrysol.2017.01.019.

[79] Quinn GD, Bradt RC. On the vickers indentation fracture toughness Test. J. Am. Ceram. Soc., vol. 90, 2007, p. 673-80. https://doi.org/10.1111/j.1551-2916.2006.01482.x.

[80] Wada M, Furukawa H, Fujita K. Crack resistance of glass on Vickers indentation. Proc Int Congr Glas 10th 1974;11:39-46.

[81] Hasdemir I, Striepe S, Deubener J, Simon K. A 2000-year perspective on indentation crack resistance and brittleness of glass. J Non Cryst Solids 2015;408:51-6. https://doi.org/10.1016/j.jnoncrysol.2014.10.012.

[82] Shang H, Rouxel T. Creep behavior of soda-lime glass in the 100-500 K temperature range by indentation creep test. J Am Ceram Soc 2005;88:2625-8. https://doi.org/10.1111/j.15512916.2005.00464.x.

[83] Makishima A, Mackenzie JD. Calculation of bulk modulus, shear modulus and Poisson's ratio of glass. J Non Cryst Solids 1975;17:147-57. https://doi.org/10.1016/00223093(75)90047-2. 
[84] Yuan F, Huang L. Brittle to Ductile Transition in Densified Silica Glass. Sci Rep 2015;4:5035. https://doi.org/10.1038/srep05035.

[85] Suzuki K, Benino Y, Fujiwara T, Komatsu T. Densification Energy during Nanoindentation of Silica Glass. J Am Ceram Soc 2004;85:3102-4. https://doi.org/10.1111/j.11512916.2002.tb00590.x.

[86] Lee D-H, Choi I-C, Seok M-Y, Zhao Y, Lee J-A, Jang J. Strain-Dependent Plasticity Evolution of Window Glass. J Am Ceram Soc 2015;98:186-9. https://doi.org/10.1111/jace.13266.

[87] Niu Y-F, Han K, Guin J-P. Locally Enhanced Dissolution Rate as a Probe for NanocontactInduced Densification in Oxide Glasses. Langmuir 2012;28:10733-40. https://doi.org/10.1021/la300972j.

[88] Fischer-Cripps AC. Nanoindentation. New York, NY: Springer New York; 2011. https://doi.org/10.1007/978-1-4419-9872-9.

[89] Chakraborty R, Dey A, Mukhopadhyay AK. Loading Rate Effect on Nanohardness of SodaLime-Silica Glass. Metall Mater Trans A 2010;41:1301-12. https://doi.org/10.1007/s11661010-0176-8.

[90] Dey A, Chakraborty R, Mukhopadhyay AK. Nanoindentation of Soda Lime-Silica Glass: Effect of Loading Rate. Int J Appl Glas Sci 2011;2:144-55. https://doi.org/10.1111/j.20411294.2011.00046.x.

[91] Dey A, Chakraborty R, Mukhopadhyay AK. Enhancement in nanohardness of soda-limesilica glass. J Non Cryst Solids 2011;357:2934-40. https://doi.org/10.1016/j.jnoncrysol.2011.03.036.

[92] Fairbanks CJ, Polvani RS, Wiederhorn SM, Hockey BJ, Lawn BR. Rate effects in hardness. J Mater Sci Lett 1982;1:391-3. https://doi.org/10.1007/BF00724848.

[93] Yoshioka M, Yoshioka N. Dynamic process of Vickers indentation made on glass surfaces. J Appl Phys 1995;78:3431-7. https://doi.org/10.1063/1.359973.

[94] Höhne L, Ullner C. How Does Indentation Velocity Influence the Recording Hardness Value? VDI Berichte 1995;1194:119-28.

[95] Li X, Jiang L, Li J, Mohagheghian I, Dear JP, Li L, et al. Elastic-plastic deformation in ionexchanged aluminosilicate glass by loading rate dependent nanoindentation. J Non Cryst Solids 2018;491:79-88. https://doi.org/10.1016/j.jnoncrysol.2018.04.003.

[96] Limbach R, Rodrigues BP, Wondraczek L. Strain-rate sensitivity of glasses. J Non Cryst Solids 2014;404:124-34. https://doi.org/10.1016/j.jnoncrysol.2014.08.023.

[97] Han W-T, Tomozawa M. Indentation Creep of Na2O . 3SiO2 Glasses with Various Water Contents. J Am Ceram Soc 1990;73:3626-32. https://doi.org/10.1111/j.11512916.1990.tb04268.x.

[98] Keulen NM. Indentation Creep of Hydrated Soda-Lime Silicate Glass Determined by Nanoindentation. J Am Ceram Soc 1993;76:904-12. https://doi.org/10.1111/j.11512916.1993.tb05314.x.

[99] Swain M, Wittling M. Indentation size effects for ceramics: Is there a fracture mechanics explanation. In: Bradt RC, Hasselman DPH, Munz D, Sakai M, Shevchenko VY, editors. Fract. Mech. Ceram. Vol. 11, New York: Plenum Press; 1996, p. 379-88.

[100] Choi BW, Park YW, Yoo BG, Shin DW, Jang J Il. Time-dependent plasticity of Li2O-SnO2B2O3-P2O5 ceramic glasses. J Ceram Process Res 2009;10:235-7.

[101] Pharr GM, Herbert EG, Gao Y. The Indentation Size Effect: A Critical Examination of Experimental Observations and Mechanistic Interpretations. Annu Rev Mater Res 2010;40:271-92. https://doi.org/10.1146/annurev-matsci-070909-104456.

[102] Peng Z, Gong J, Miao H. On the description of indentation size effect in hardness testing for ceramics: Analysis of the nanoindentation data. J Eur Ceram Soc 2004;24:2193-201. https://doi.org/10.1016/S0955-2219(03)00641-1.

[103] Kazembeyki M, Bauchy M, Hoover CG. New insights into the indentation size effect in silicate glasses. J Non Cryst Solids 2019;521:119494. 
https://doi.org/10.1016/j.jnoncrysol.2019.119494.

[104] Hays C, Kendall EG. An analysis of Knoop microhardness. Metallography 1973;6:275-82. https://doi.org/10.1016/0026-0800(73)90053-0.

[105] Li H, Bradt RC. The indentation load/size effect and the measurement of the hardness of vitreous silica. J Non Cryst Solids 1992;146:197-212. https://doi.org/10.1016/S00223093(05)80492-2.

[106] Li H, Ghosh A, Han YH, Bradt RC. The frictional component of the indentation size effect in low load microhardness testing. J Mater Res 1993;8:1028-32. https://doi.org/10.1557/JMR.1993.1028.

[107] Poumellec B, Guénot P, Riant I, Sansonetti P, Niay P, Bernage P, et al. UV induced densification during Bragg grating inscription in $\mathrm{Ge}: \mathrm{SiO} 2$ preforms. Opt Mater (Amst) 1995;4:441-9. https://doi.org/10.1016/0925-3467(94)00114-6.

[108] Aashia R, Madhav K V., Ramamurty U, Asokan S. Nanoindentation study on germaniadoped silica glass preforms: evidence for the compaction-densification model of photosensitivity. Opt Lett 2009;34:2414. https://doi.org/10.1364/ol.34.002414.

[109] Bellouard Y, Colomb T, Depeursinge C, Dugan M, Said AA, Bado P. Nanoindentation and birefringence measurements on fused silica specimen exposed to low-energy femtosecond pulses. Opt Express 2006;14:8360. https://doi.org/10.1364/oe.14.008360.

[110] Kongsuwan P, Wang H, Vukelic S, Yao YL. Characterization of Morphology and Mechanical Properties of Glass Interior Irradiated by Femtosecond Laser. J Manuf Sci Eng 2010;132:0410091-04100910. https://doi.org/10.1115/1.4002062.

[111] Sabapathy T, Kiran MSRN, Ayiriveetil A, Kar AK, Ramamurty U, Asokan S. Nanoindentation studies on waveguides inscribed in chalcogenide glasses using ultrafast laser. Opt Mater Express 2013;3:684. https://doi.org/10.1364/ome.3.000684.

[112] Ayiriveetil A, Sabapathy T, Varma GS, Ramamurty U, Asokan S. Structural and mechanical characterization on ultrafast laser written chalcogenide glass waveguides. Opt Mater Express 2016;6:2530. https://doi.org/10.1364/ome.6.002530.

[113] Ayiriveetil A, Varma GS, Chaturvedi A, Sabapathy T, Ramamurty U, Asokan S. Structural, mechanical and optical studies on ultrafast laser inscribed chalcogenide glass waveguide. Opt Mater (Amst) 2017;66:386-91. https://doi.org/10.1016/j.optmat.2017.02.030.

[114] Weber WJ, Ewing RC, Angell CA, Arnold GW, Cormack AN, Delaye JM, et al. Radiation effects in glasses used for immobilization of high-level waste and plutonium disposition. $\mathrm{J}$ Mater Res 1997;12:1946-78. https://doi.org/10.1557/jmr.1997.0266.

[115] Gin S, Jollivet P, Tribet M, Peuget S, Schuller S. Radionuclides containment in nuclear glasses: An overview. Radiochim Acta 2017;105:927-59. https://doi.org/10.1515/ract-20162658.

[116] Abbas A, Serruys Y, Ghaleb D, Delaye JM, Boizot B, Reynard B, et al. Evolution of nuclear glass structure under $\alpha$-irradiation. Nucl Instruments Methods Phys Res Sect B Beam Interact with Mater Atoms 2000;166:445-50. https://doi.org/10.1016/S0168-583X(99)00695-3.

[117] Peuget S, Noël PY, Loubet JL, Pavan S, Nivet P, Chenet A. Effects of deposited nuclear and electronic energy on the hardness of R7T7-type containment glass. Nucl Instruments Methods Phys Res Sect B Beam Interact with Mater Atoms 2006;246:379-86. https://doi.org/10.1016/j.nimb.2005.12.053.

[118] Zhang GF, Wang TS, Yang KJ, Chen L, Zhang LM, Peng HB, et al. Raman spectra and nano-indentation of Ar-irradiated borosilicate glass. Nucl Instruments Methods Phys Res Sect B Beam Interact with Mater Atoms 2013;316:218-21. https://doi.org/10.1016/j.nimb.2013.09.020.

[119] Peng HB, Sun ML, Yang KJ, Chen H, Yang D, Yuan W, et al. Effect of irradiation on hardness of borosilicate glass. J Non Cryst Solids 2016;443:143-7. https://doi.org/10.1016/j.jnoncrysol.2016.04.027.

[120] Peng HB, Sun ML, Du X, Yuan W, Yang D, Chen L, et al. Variation of hardness and modulus of borosilicate glass irradiated with $\mathrm{Kr}$ ions. Nucl Instruments Methods Phys Res 
Sect B Beam Interact with Mater Atoms 2017;406:561-5.

https://doi.org/10.1016/j.nimb.2017.04.057.

[121] Peng HBB, Liu FFF, Guan M, Zhang XYY, Sun MLL, Du X, et al. Variation of hardness and modulus of sodium borosilicate glass irradiated with different ions. Nucl Instruments Methods Phys Res Sect B Beam Interact with Mater Atoms 2018;435:214-8. https://doi.org/10.1016/j.nimb.2018.01.006.

[122] Sun ML, Peng HB, Duan BH, Liu FF, Du X, Yuan W, et al. Comparison of hardness variation of ion irradiated borosilicate glasses with different projected ranges. Nucl Instruments Methods Phys Res Sect B Beam Interact with Mater Atoms 2018;419:8-13. https://doi.org/10.1016/j.nimb.2018.01.017.

[123] Du X, Wang T-TT-STTS, Duan B-HH, Zhang X-YY, Liu F-FF, Lan C-LL, et al. Effects of energy deposition on mechanical properties of sodium borosilicate glass irradiated by three heavy ions: P, Kr, and Xe. Nucl Sci Tech 2019;30:1-9. https://doi.org/10.1007/s41365-0190632-0.

[124] Karakurt G, Abdelouas A, Guin J-PP, Nivard M, Sauvage T, Paris M, et al. Understanding of the mechanical and structural changes induced by alpha particles and heavy ions in the French simulated nuclear waste glass. J Nucl Mater 2016;475:243-54. https://doi.org/10.1016/j.jnucmat.2016.04.022.

[125] Yang KJ, Wang TS, Zhang GF, Peng HB, Chen L, Zhang LM, et al. Study of irradiation damage in borosilicate glass induced by He ions and electrons. Nucl Instruments Methods Phys Res Sect B Beam Interact with Mater Atoms 2013;307:541-4. https://doi.org/10.1016/j.nimb.2012.12.113.

[126] Chen L, Yuan W, Nan S, Du X, Zhang DF, Lv P, et al. Study of modifications in the mechanical properties of sodium aluminoborosilicate glass induced by heavy ions and electrons. Nucl Instruments Methods Phys Res Sect B Beam Interact with Mater Atoms 2016;370:42-8. https://doi.org/10.1016/j.nimb.2016.01.007.

[127] Lv P, Chen L, Zhang BT, Yuan W, Duan BH, Guan YD, et al. Composition-dependent mechanical property changes in Au-ion-irradiated borosilicate glasses. J Nucl Mater 2019;520:218-25. https://doi.org/10.1016/j.jnucmat.2019.04.025.

[128] Lv P, Chen L, Duan BH, Zhang DF, Wang TS. Composition dependence of mechanical property changes in electron irradiated borosilicate glasses. Nucl Instruments Methods Phys Res Sect B Beam Interact with Mater Atoms 2017;405:61-6. https://doi.org/10.1016/j.nimb.2017.04.095.

[129] Guan M, Zhang XY, Yang KJ, Wang TTS, Liu FF, Sun ML, et al. Difference in radiation effects of sodium borosilicate glass and vitreous silica with ions. J Non Cryst Solids 2019;518:118-22. https://doi.org/10.1016/j.jnoncrysol.2019.03.010.

[130] Gedeon O, Lukeš J, Jurek K. Reduced Young modulus and hardness of electron irradiated binary potassium-silicate glass. Nucl Instruments Methods Phys Res Sect B Beam Interact with Mater Atoms 2012;275:7-10. https://doi.org/10.1016/j.nimb.2011.12.017.

[131] Boolchand P, Bresser WJ, Georgiev DG, Wang Y, Wells J. Evidence for the Intermediate Phase in Chalcogenide Glasses BT - Phase Transitions and Self-Organization in Electronic and Molecular Networks. In: Thorpe MF, Phillips JC, editors., Boston, MA: Springer US; 2001, p. 65-84. https://doi.org/10.1007/0-306-47113-2_5.

[132] Phillips JC. Topology of covalent non-crystalline solids I: Short-range order in chalcogenide alloys. J Non Cryst Solids 1979;34:153-81. https://doi.org/10.1016/0022-3093(79)90033-4.

[133] Phillips JC. Topology of covalent non-crystalline solids II: Medium-range order in chalcogenide alloys and $\mathrm{A} \square \mathrm{Si}(\mathrm{Ge})$. J Non Cryst Solids 1981;43:37-77. https://doi.org/10.1016/0022-3093(81)90172-1.

[134] Thorpe MF. Continuous deformations in random networks. J Non Cryst Solids 1983;57:35570. https://doi.org/10.1016/0022-3093(83)90424-6.

[135] Phillips JC. Mathematical Principles of Intermediate Phases in Disordered Systems. Phase Transitions Self-Organization Electron. Mol. Networks, Boston: Kluwer Academic 
Publishers; 2005, p. 1-22. https://doi.org/10.1007/0-306-47113-2_1.

[136] Boolchand P, Georgiev DG, Goodman B. Discovery of the intermediate phase in chalcogenide glasses. J Optoelectron Adv Mater 2001;3:703-20.

[137] Varma GS, Kiran MSRN, Muthu DVS, Ramamurty U, Sood AK, Asokan S. Thermally reversing window in Ge 15Te 85 - XIn x glasses: Nanoindentation and micro-Raman studies. J Non Cryst Solids 2012;358:3103-8. https://doi.org/10.1016/j.jnoncrysol.2012.08.013.

[138] Sreevidya Varma G, Das C, Asokan S. Evidence of an intermediate phase in a quaternary Ag bearing telluride glass system using alternating DSC. Solid State Commun 2014;177:108-12. https://doi.org/10.1016/j.ssc.2013.10.003.

[139] Das C, Rao GM, Asokan S. Electrical switching behavior of amorphous Ge15Te 85 - XSix thin films with phase change memory applications. Mater Res Bull 2014;49:388-92. https://doi.org/10.1016/j.materresbull.2013.09.020.

[140] Das C, Kiran MSRN, Ramamurty U, Asokan S. Manifestation of intermediate phase in mechanical properties: Nano-indentation studies on Ge-Te-Si bulk chalcogenide glasses. Solid State Commun 2012;152:2181-4. https://doi.org/10.1016/j.ssc.2012.09.020.

[141] Sreevidya Varma G, Muthu DVS, Sood AK, Asokan S. Electrical switching, SET-RESET, and Raman scattering studies on Ge 15Te80-xIn5Agx glasses. J Appl Phys 2014;115:164505. https://doi.org/10.1063/1.4873237.

[142] Anbarasu M, Singh KK, Asokan S. Evidence for a thermally reversing window in bulk GeTe-Si glasses revealed by alternating differential scanning calorimetry. Philos Mag 2008;88:599-605. https://doi.org/10.1080/14786430801935305.

[143] Boussinesq J. Applications des potentiels à l'étude de l'équilibre et du mouvement des solides élastiques. Paris: Pub. Gauthier-Villars; 1885.

[144] Hertz H. Über die Berührung fester elastischer Körper. J Für Die Reine Und Angew Math 1881;92:156-71.

[145] Johnson KL. Contact Mechanics. Cambridge: Cambridge University Press; 1985. https://doi.org/10.1017/CBO9781139171731.

[146] Chakrabarty J. Theory of Plasticity. New York: McGraw-Hill Book Co.; 1987.

[147] Yoffe EH. Elastic stress fields caused by indenting brittle materials. Philos Mag A 1982;46:617-28. https://doi.org/10.1080/01418618208236917.

[148] Lacondemine T, Réthoré J, Maire É, Célarié F, Houizot P, Roux-Langlois C, et al. Direct observation of the displacement field and microcracking in a glass by means of X-ray tomography during in situ Vickers indentation experiment. Acta Mater 2019;179:424-33. https://doi.org/10.1016/j.actamat.2019.07.053.

[149] Kermouche G, Barthel E, Vandembroucq D, Dubujet P. Mechanical modelling of indentation-induced densification in amorphous silica. Acta Mater 2008;56:3222-8. https://doi.org/10.1016/j.actamat.2008.03.010.

[150] Keryvin V, Meng J-X, Gicquel S, Guin J-P, Charleux L, Sanglebœuf J-C, et al. Constitutive modeling of the densification process in silica glass under hydrostatic compression. Acta Mater 2014;62:250-7. https://doi.org/10.1016/j.actamat.2013.07.067.

[151] Lee EH, Radok JRM. The Contact Problem for Viscoelastic Bodies. J Appl Mech 1960;27:438-44. https://doi.org/10.1115/1.3644020.

[152] Ting TCT. The Contact Stresses Between a Rigid Indenter and a Viscoelastic Half-Space. J Appl Mech 1966;33:845-54. https://doi.org/10.1115/1.3625192.

[153] Kocer C, Collins RE. Angle of Hertzian Cone Cracks. J Am Ceram Soc 2005;81:1736-42. https://doi.org/10.1111/j.1151-2916.1998.tb02542.x.

[154] Jebahi M, André D, Dau F, Charles J, Iordanoff I. Simulation of Vickers indentation of silica glass. J Non Cryst Solids 2013;378:15-24. https://doi.org/10.1016/j.jnoncrysol.2013.06.007.

[155] Tumbajoy-Spinel DY, Feulvarch É, Bergheau J-M, Kermouche G. 2D axisymmetric X-FEM modeling of the Hertzian cone crack system. Comptes Rendus Mécanique 2013;341:715-25. https://doi.org/10.1016/j.crme.2013.09.004.

[156] Luo J, Vargheese KD, Tandia A, Hu G, Mauro JC. Crack nucleation criterion and its 
application to impact indentation in glasses. Sci Rep 2016;6:23720.

https://doi.org/10.1038/srep23720.

[157] Luo J, Lezzi PJ, Vargheese KD, Tandia A, Harris JT, Gross TM, et al. Competing Indentation Deformation Mechanisms in Glass Using Different Strengthening Methods. Front Mater 2016;3:1-11. https://doi.org/10.3389/fmats.2016.00052.

[158] Klement W, Willens RH, Duwez P. Non-crystalline Structure in Solidified Gold-Silicon Alloys. Nature 1960;187:869-70. https://doi.org/10.1038/187869b0.

[159] Inoue A. Stabilization of metallic supercooled liquid and bulk amorphous alloys. Acta Mater 2000;48:279-306. https://doi.org/10.1016/S1359-6454(99)00300-6.

[160] Schuh CA, Hufnagel TC, Ramamurty U. Mechanical behavior of amorphous alloys. Acta Mater 2007;55:4067-109. https://doi.org/10.1016/j.actamat.2007.01.052.

[161] Trexler MM, Thadhani NN. Mechanical properties of bulk metallic glasses. Prog Mater Sci 2010;55:759-839. https://doi.org/10.1016/j.pmatsci.2010.04.002.

[162] Greer AL, Cheng YQ, Ma E. Shear bands in metallic glasses. Mater Sci Eng R Reports 2013;74:71-132. https://doi.org/10.1016/j.mser.2013.04.001.

[163] Hufnagel TC, Schuh CA, Falk ML. Deformation of metallic glasses: Recent developments in theory, simulations, and experiments. Acta Mater 2016;109:375-93. https://doi.org/10.1016/j.actamat.2016.01.049.

[164] Inoue A, Zhang T, Masumoto T. Zr-Al-Ni Amorphous Alloys with High Glass Transition Temperature and Significant Supercooled Liquid Region. Mater Trans JIM 1990;31:177-83. https://doi.org/10.2320/matertrans1989.31.177.

[165] Peker A, Johnson WL. A highly processable metallic glass: Zr 41.2 Ti $13.8 \mathrm{Cu} 12.5 \mathrm{Ni} 10.0$ Be 22.5. Appl Phys Lett 1993;63:2342-4. https://doi.org/10.1063/1.110520.

[166] Yavari AR, Lewandowski JJ, Eckert J. Mechanical Properties of Bulk Metallic Glasses. MRS Bull 2007;32:635-8. https://doi.org/10.1557/mrs2007.125.

[167] Greaves GN. EXAFS and the structure of glass. J Non Cryst Solids 1985;71:203-17. https://doi.org/10.1016/0022-3093(85)90289-3.

[168] Davis LA. Hardness/strength ratio of metallic glasses. Scr Metall 1975;9:431-5. https://doi.org/10.1016/0036-9748(75)90177-5.

[169] Sargent PM, Donovan PE. Measurements of the microhardness of metallic glasses compared with some theoretical predictions. Scr Metall 1982;16:1207-12. https://doi.org/10.1016/0036-9748(82)90468-9.

[170] Donovan PE. Plastic flow and fracture of Pd40Ni40P20 metallic glass under an indentor. J Mater Sci 1989;24:523-35. https://doi.org/10.1007/BF01107437.

[171] Burgess T, Ferry M. Nanoindentation of metallic glasses. Mater Today 2009;12:24-32. https://doi.org/10.1016/S1369-7021(09)70039-2.

[172] Gao Y, Bei H. Strength statistics of single crystals and metallic glasses under small stressed volumes. Prog Mater Sci 2016;82:118-50. https://doi.org/10.1016/j.pmatsci.2016.05.002.

[173] Chen X-Q, Niu H, Li D, Li Y. Modeling hardness of polycrystalline materials and bulk metallic glasses. Intermetallics 2011;19:1275-81. https://doi.org/10.1016/j.intermet.2011.03.026.

[174] Wang WH. The elastic properties, elastic models and elastic perspectives of metallic glasses. Prog Mater Sci 2012;57:487-656. https://doi.org/10.1016/j.pmatsci.2011.07.001.

[175] Inoue A, Shen B, Koshiba H, Kato H, Yavari AR. Cobalt-based bulk glassy alloy with ultrahigh strength and soft magnetic properties. Nat Mater 2003;2:661-3. https://doi.org/10.1038/nmat982.

[176] Shen B, Inoue A. Enhancement of the fracture strength and glass-forming ability of CoFeTaB bulk glassy alloy. J Phys Condens Matter 2005;17:5647-53. https://doi.org/10.1088/0953-8984/17/37/003.

[177] Ohtsuki M, Tamura R, Takeuchi S, Yoda S, Ohmura T. Hard metallic glass of tungstenbased alloy. Appl Phys Lett 2004;84:4911-3. https://doi.org/10.1063/1.1763639.

[178] Schuh CA, Nieh TG. A nanoindentation study of serrated flow in bulk metallic glasses. Acta 
Mater 2003;51:87-99. https://doi.org/10.1016/S1359-6454(02)00303-8.

[179] Jiang WH, Atzmon M. Rate dependence of serrated flow in a metallic glass. J Mater Res 2003;18:755-7. https://doi.org/10.1557/JMR.2003.0103.

[180] Yang B, Nieh TG. Effect of the nanoindentation rate on the shear band formation in an Aubased bulk metallic glass. Acta Mater 2007;55:295-300. https://doi.org/10.1016/j.actamat.2006.08.028.

[181] Jang J, Yoo B-G, Kim J-Y. Rate-dependent inhomogeneous-to-homogeneous transition of plastic flows during nanoindentation of bulk metallic glasses: Fact or artifact? Appl Phys Lett 2007;90:211906. https://doi.org/10.1063/1.2742286.

[182] Yoo B-G, Lee K-W, Jang J. Instrumented indentation of a Pd-based bulk metallic glass: Constant loading-rate test vs constant strain-rate test. J Alloys Compd 2009;483:136-8. https://doi.org/10.1016/j.jallcom.2008.07.163.

[183] Schuh CA, Lund AC, Nieh TG. New regime of homogeneous flow in the deformation map of metallic glasses: elevated temperature nanoindentation experiments and mechanistic modeling. Acta Mater 2004;52:5879-91. https://doi.org/10.1016/j.actamat.2004.09.005.

[184] Yoo B-G, Kim J-Y, Jang J. Influence of Indenter Geometry on the Deformation Behavior of Zr60Cu30A110 Bulk Metallic Glass during Nanoindentation. Mater Trans 2007;48:1765-9. https://doi.org/10.2320/matertrans.MJ200752.

[185] Yoo B-G, Park K-W, Lee J-C, Ramamurty U, Jang J. Role of free volume in strain softening of as-cast and annealed bulk metallic glass. J Mater Res 2009;24:1405-16. https://doi.org/10.1557/jmr.2009.0167.

[186] Dubach A, Prasad KE, Raghavan R, Löffler JF, Michler J, Ramamurty U. Free-volume dependent pressure sensitivity of Zr-based bulk metallic glass. J Mater Res 2009;24:2697704. https://doi.org/10.1557/jmr.2009.0304.

[187] Haag F, Beitelschmidt D, Eckert J, Durst K. Influences of residual stresses on the serrated flow in bulk metallic glass under elastostatic four-point bending - A nanoindentation and atomic force microscopy study. Acta Mater 2014;70:188-97. https://doi.org/10.1016/j.actamat.2014.01.053.

[188] Pharr GM, Oliver WC, Cook RF, Kirchner PD, Kroll MC, Dinger TR, et al. Electrical resistance of metallic contacts on silicon and germanium during indentation. J Mater Res 1992;7:961-72. https://doi.org/10.1557/JMR.1992.0961.

[189] Ruffell S, Bradby JE, Williams JS, Warren OL. An in situ electrical measurement technique via a conducting diamond tip for nanoindentation in silicon. J Mater Res 2007;22:578-86. https://doi.org/10.1557/jmr.2007.0100.

[190] Kim Y-J, Lee WW, Choi I-C, Yoo B-G, Han SM, Park H-G, et al. Time-dependent nanoscale plasticity of $\mathrm{ZnO}$ nanorods. Acta Mater 2013;61:7180-8. https://doi.org/10.1016/j.actamat.2013.08.022.

[191] Yang Y, Fu XL, Wang S, Liu ZY, Ye YF, Sun BA, et al. Probing Stochastic Nano-Scale Inelastic Events in Stressed Amorphous Metal. Sci Rep 2014;4:6699. https://doi.org/10.1038/srep06699.

[192] Singh G, Narayan RL, Asiri AM, Ramamurty U. Discrete drops in the electrical contact resistance during nanoindentation of a bulk metallic glass. Appl Phys Lett 2016;108:181903. https://doi.org/10.1063/1.4948540.

[193] MULHEARN T. The deformation of metals by vickers-type pyramidal indenters. J Mech Phys Solids 1959;7:85-8. https://doi.org/10.1016/0022-5096(59)90013-4.

[194] Van Der Zwaag S, Hagan JT, Field JE. Studies of contact damage in polycrystalline zinc sulphide. J Mater Sci 1980;15:2965-72. https://doi.org/10.1007/BF00550362.

[195] Jana S, Ramamurty U, Chattopadhyay K, Kawamura Y. Subsurface deformation during Vickers indentation of bulk metallic glasses. Mater Sci Eng A 2004;375-377:1191-5. https://doi.org/10.1016/j.msea.2003.10.068.

[196] Jana S, Bhowmick R, Kawamura Y, Chattopadhyay K, Ramamurty U. Deformation morphology underneath the Vickers indent in a Zr-based bulk metallic glass. Intermetallics 
2004;12:1097-102. https://doi.org/10.1016/j.intermet.2004.04.018.

[197] Ramamurty U, Jana S, Kawamura Y, Chattopadhyay K. Hardness and plastic deformation in a bulk metallic glass. Acta Mater 2005;53:705-17.

https://doi.org/10.1016/j.actamat.2004.10.023.

[198] Bhowmick R, Raghavan R, Chattopadhyay K, Ramamurty U. Plastic flow softening in a bulk metallic glass. Acta Mater 2006;54:4221-8. https://doi.org/10.1016/j.actamat.2006.05.011.

[199] Eswar Prasad K, Ramamurty U. Effect of temperature on the plastic zone size and the shear band density in a bulk metallic glass. Mater Sci Eng A 2012;535:48-52. https://doi.org/10.1016/j.msea.2011.12.040.

[200] Zhang H, Jing X, Subhash G, Kecskes LJ, Dowding RJ. Investigation of shear band evolution in amorphous alloys beneath a Vickers indentation. Acta Mater 2005;53:3849-59. https://doi.org/10.1016/j.actamat.2005.04.036.

[201] Li WH, Zhang TH, Xing DM, Wei BC, Wang YR, Dong YD. Instrumented indentation study of plastic deformation in bulk metallic glasses. J Mater Res 2006;21:75-81. https://doi.org/10.1557/jmr.2006.0037.

[202] Yoo B-G, Jang J. A study on the evolution of subsurface deformation in a Zr-based bulk metallic glass during spherical indentation. J Phys D Appl Phys 2008;41:074017. https://doi.org/10.1088/0022-3727/41/7/074017.

[203] Yoo B-G, Kim Y-J, Oh J-H, Ramamurty U, Jang J. On the hardness of shear bands in amorphous alloys. Scr Mater 2009;61:951-4. https://doi.org/10.1016/j.scriptamat.2009.07.037.

[204] Lund AC, Schuh CA. The Mohr-Coulomb criterion from unit shear processes in metallic glass. Intermetallics 2004;12:1159-65. https://doi.org/10.1016/j.intermet.2004.07.001.

[205] Schuh CA, Lund AC. Atomistic basis for the plastic yield criterion of metallic glass. Nat Mater 2003;2:449-52. https://doi.org/10.1038/nmat918.

[206] Vaidyanathan R, Dao M, Ravichandran G, Suresh S. Study of mechanical deformation in bulk metallic glass through instrumented indentation. Acta Mater 2001;49:3781-9. https://doi.org/10.1016/S1359-6454(01)00263-4.

[207] Patnaik MNM, Narasimhan R, Ramamurty U. Spherical indentation response of metallic glasses. Acta Mater 2004;52:3335-45. https://doi.org/10.1016/j.actamat.2004.03.028.

[208] Zhang HW, Subhash G, Jing XN, Kecskes LJ, Dowding RJ. Evaluation of hardness-yield strength relationships for bulk metallic glasses. Philos Mag Lett 2006;86:333-45. https://doi.org/10.1080/09500830600788935.

[209] Ai K, Dai LH. A new modified expanding cavity model for characterizing the spherical indentation behavior of bulk metallic glass with pile-up. Scr Mater 2007;56:761-4. https://doi.org/10.1016/j.scriptamat.2007.01.017.

[210] Lu J, Ravichandran G. Pressure-dependent flow behavior of Zr 41.2 Ti $13.8 \mathrm{Cu} 12.5 \mathrm{Ni} 10$ Be 22.5 bulk metallic glass. J Mater Res 2003;18:2039-49. https://doi.org/10.1557/JMR.2003.0287.

[211] Packard CE, Schuh CA. Initiation of shear bands near a stress concentration in metallic glass. Acta Mater 2007;55:5348-58. https://doi.org/10.1016/j.actamat.2007.05.054.

[212] Trichy GR, Scattergood RO, Koch CC, Murty KL. Ball indentation tests for a Zr-based bulk metallic glass. Scr Mater 2005;53:1461-5. https://doi.org/10.1016/j.scriptamat.2005.08.010.

[213] Narasimhan R. Analysis of indentation of pressure sensitive plastic solids using the expanding cavity model. Mech Mater 2004;36:633-45. https://doi.org/10.1016/S01676636(03)00075-9.

[214] Keryvin V, Eswar Prasad K, Gueguen Y, Sanglebœuf J-C, Ramamurty U. Temperature dependence of mechanical properties and pressure sensitivity in metallic glasses below glass transition. Philos Mag 2008;88:1773-90. https://doi.org/10.1080/14786430802286971.

[215] Prasad KE, Keryvin V, Ramamurty U. Pressure sensitive flow and constraint factor in amorphous materials below glass transition. J Mater Res 2009;24:890-7. https://doi.org/10.1557/jmr.2009.0113. 
[216] Albano F, Falk ML. Shear softening and structure in a simulated three-dimensional binary glass. J Chem Phys 2005;122:154508. https://doi.org/10.1063/1.1885000.

[217] Park K-W, Lee C-M, Wakeda M, Shibutani Y, Falk ML, Lee J-C. Elastostatically induced structural disordering in amorphous alloys. Acta Mater 2008;56:5440-50. https://doi.org/10.1016/j.actamat.2008.07.033.

[218] Ke HB, Wen P, Peng HL, Wang WH, Greer AL. Homogeneous deformation of metallic glass at room temperature reveals large dilatation. Scr Mater 2011;64:966-9. https://doi.org/10.1016/j.scriptamat.2011.01.047.

[219] Choi I-C, Yoo B-G, Kim Y-J, Jang J. Indentation creep revisited. J Mater Res 2012;27:3-11. https://doi.org/10.1557/jmr.2011.213.

[220] Li WH, Shin K, Lee CG, Wei BC, Zhang TH, He YZ. The characterization of creep and time-dependent properties of bulk metallic glasses using nanoindentation. Mater Sci Eng A 2008;478:371-5. https://doi.org/10.1016/j.msea.2007.06.015.

[221] Castellero A, Moser B, Uhlenhaut DI, Torre FHD, Löffler JF. Room-temperature creep and structural relaxation of $\mathrm{Mg}-\mathrm{Cu}-\mathrm{Y}$ metallic glasses. Acta Mater 2008;56:3777-85. https://doi.org/10.1016/j.actamat.2008.04.021.

[222] Yoo B-G, Kim K-S, Oh J-H, Ramamurty U, Jang J. Room temperature creep in amorphous alloys: Influence of initial strain and free volume. Scr Mater 2010;63:1205-8. https://doi.org/10.1016/j.scriptamat.2010.08.034.

[223] Yoo B-G, Choi I-C, Kim Y-J, Ramamurty U, Jang J. Room-temperature anelasticity and viscoplasticity of $\mathrm{Cu}-\mathrm{Zr}$ bulk metallic glasses evaluated using nanoindentation. Mater Sci Eng A 2013;577:101-4. https://doi.org/10.1016/j.msea.2013.04.031.

[224] Yu PF, Feng SD, Xu GS, Guo XL, Wang YY, Zhao W, et al. Room-temperature creep resistance of Co-based metallic glasses. Scr Mater 2014;90-91:45-8. https://doi.org/10.1016/j.scriptamat.2014.07.013.

[225] Yoo B-G, Oh J-H, Kim Y-J, Park K-W, Lee J-C, Jang J. Nanoindentation analysis of timedependent deformation in as-cast and annealed $\mathrm{Cu}-\mathrm{Zr}$ bulk metallic glass. Intermetallics 2010;18:1898-901. https://doi.org/10.1016/j.intermet.2010.02.032.

[226] Huang YJ, Chiu YL, Shen J, Chen JJJ, Sun JF. Indentation creep of a Ti-based metallic glass. J Mater Res 2009;24:993-7. https://doi.org/10.1557/jmr.2009.0106.

[227] Huang YJ, Shen J, Chiu YL, Chen JJJ, Sun JF. Indentation creep of an Fe-based bulk metallic glass. Intermetallics 2009;17:190-4. https://doi.org/10.1016/j.intermet.2008.09.014.

[228] Zhao XN, Cao QP, Wang C, Wang XD, Zhang DX, Qu SX, et al. Dependence of roomtemperature nanoindentation creep behavior and shear transformation zone on the glass transition temperature in bulk metallic glasses. J Non Cryst Solids 2016;445-446:19-29. https://doi.org/10.1016/j.jnoncrysol.2016.05.022.

[229] Murali P, Ramamurty U. Embrittlement of a bulk metallic glass due to sub-Tg annealing. Acta Mater 2005;53:1467-78. https://doi.org/10.1016/j.actamat.2004.11.040.

[230] Xu J, Ma E. Damage-tolerant $\mathrm{Zr}-\mathrm{Cu}-\mathrm{Al}$-based bulk metallic glasses with record-breaking fracture toughness. J Mater Res 2014;29:1489-99. https://doi.org/10.1557/jmr.2014.160.

[231] Narayan RL, Raut D, Ramamurty U. A quantitative connection between shear band mediated plasticity and fracture initiation toughness of metallic glasses. Acta Mater 2018;150:69-77. https://doi.org/10.1016/j.actamat.2018.03.011.

[232] Shao L, Ketkaew J, Gong P, Zhao S, Sohn S, Bordeenithikasem P, et al. Effect of chemical composition on the fracture toughness of bulk metallic glasses. Materialia 2020;12:100828. https://doi.org/10.1016/j.mtla.2020.100828.

[233] Tandaiya P, Narasimhan R, Ramamurty U. On the mechanism and the length scales involved in the ductile fracture of a bulk metallic glass. Acta Mater 2013;61:1558-70. https://doi.org/10.1016/j.actamat.2012.11.033.

[234] Nagendra N, Ramamurty U, Goh T., Li Y. Effect of crystallinity on the impact toughness of a La-based bulk metallic glass. Acta Mater 2000;48:2603-15. https://doi.org/10.1016/S13596454(00)00052-5. 
[235] Conner RD, Dandliker RB, Johnson WL. Mechanical properties of tungsten and steel fiber

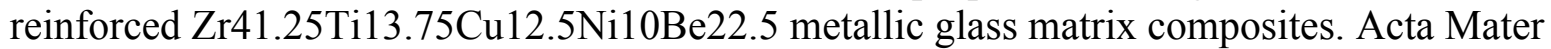
1998;46:6089-102. https://doi.org/10.1016/S1359-6454(98)00275-4.

[236] Basu J, Nagendra N, Li Y, Ramamurty U. Microstructure and mechanical properties of a partially crystallized La-based bulk metallic glass. Philos Mag 2003;83:1747-60. https://doi.org/10.1080/0141861861031000104163.

[237] Hofmann DC, Suh J-Y, Wiest A, Duan G, Lind M-L, Demetriou MD, et al. Designing metallic glass matrix composites with high toughness and tensile ductility. Nature 2008;451:1085-9. https://doi.org/10.1038/nature06598.

[238] Narayan RL, Boopathy K, Sen I, Hofmann DC, Ramamurty U. On the hardness and elastic modulus of bulk metallic glass matrix composites. Scr Mater 2010;63:768-71. https://doi.org/10.1016/j.scriptamat.2010.06.010.

[239] Gentile JM, Hofmann DC, Trelewicz JR. Microstructural dependence of the incipient to homogeneous flow transition in metallic glass composites. Scr Mater 2020;188:32-6. https://doi.org/10.1016/j.scriptamat.2020.06.066.

[240] Page TF, Oliver WC, McHargue CJ. The deformation behavior of ceramic crystals subjected to very low load (nano)indentations. J Mater Res 1992;7:450-73. https://doi.org/10.1557/JMR.1992.0450.

[241] Mason JK, Lund AC, Schuh CA. Determining the activation energy and volume for the onset of plasticity during nanoindentation. Phys Rev B - Condens Matter Mater Phys 2006;73:114. https://doi.org/10.1103/PhysRevB.73.054102.

[242] Jang J, Bei H, Becher PF, Pharr GM. Experimental Analysis of the Elastic-Plastic Transition During Nanoindentation of Single Crystal Alpha-Silicon Nitride. J Am Ceram Soc 2012;95:2113-5. https://doi.org/10.1111/j.1551-2916.2012.05251.x.

[243] Bei H, Lu ZP, George EP. Theoretical Strength and the Onset of Plasticity in Bulk Metallic Glasses Investigated by Nanoindentation with a Spherical Indenter. Phys Rev Lett 2004;93:125504. https://doi.org/10.1103/PhysRevLett.93.125504.

[244] Wang L, Bei H, Gao YF, Lu ZP, Nieh TG. Effect of residual stresses on the onset of yielding in a Zr-based metallic glass. Acta Mater 2011;59:7627-33. https://doi.org/10.1016/j.actamat.2011.09.029.

[245] Bei H, Lu ZPP, Shim S, Chen G, George EPP. Specimen Size Effects on Zr-Based Bulk Metallic Glasses Investigated by Uniaxial Compression and Spherical Nanoindentation. Metall Mater Trans A 2010;41:1735-42. https://doi.org/10.1007/s11661-009-9994-y.

[246] Shim S, Bei H, George EP, Pharr GM. A different type of indentation size effect. Scr Mater 2008;59:1095-8. https://doi.org/10.1016/j.scriptamat.2008.07.026.

[247] Packard CE, Franke O, Homer ER, Schuh CA. Nanoscale strength distribution in amorphous versus crystalline metals. J Mater Res 2010;25:2251-63. https://doi.org/10.1557/jmr.2010.0299.

[248] Wagner H, Bedorf D, Küchemann S, Schwabe M, Zhang B, Arnold W, et al. Local elastic properties of a metallic glass. Nat Mater 2011;10:439-42. https://doi.org/10.1038/nmat3024.

[249] Tsai P, Kranjc K, Flores KM. Hierarchical heterogeneity and an elastic microstructure observed in a metallic glass alloy. Acta Mater 2017;139:11-20. https://doi.org/10.1016/j.actamat.2017.07.061.

[250] Liu YH, Wang D, Nakajima K, Zhang W, Hirata A, Nishi T, et al. Characterization of Nanoscale Mechanical Heterogeneity in a Metallic Glass by Dynamic Force Microscopy. Phys Rev Lett 2011;106:125504. https://doi.org/10.1103/PhysRevLett.106.125504.

[251] Tönnies D, Samwer K, Derlet PM, Volkert CA, Maaß R. Rate-dependent shear-band initiation in a metallic glass. Appl Phys Lett 2015;106:171907. https://doi.org/10.1063/1.4919134.

[252] Derlet PM, Maaß R. The stress statistics of the first pop-in or discrete plastic event in crystal plasticity. J Appl Phys 2016;120:225101. https://doi.org/10.1063/1.4971871.

[253] Perepezko JH, Imhoff SD, Chen M-WW, Wang JQ, Gonzalez S. Nucleation of shear bands 
in amorphous alloys. Proc Natl Acad Sci U S A 2014;111:3938-42.

https://doi.org/10.1073/pnas.1321518111.

[254] Zhao Y, Park J-M, Jang J, Ramamurty U. Bimodality of incipient plastic strength in facecentered cubic high-entropy alloys. Acta Mater 2021;202:124-34.

https://doi.org/10.1016/j.actamat.2020.10.066.

[255] Nag S, Narayan RL, Jang J, Mukhopadhyay C, Ramamurty U. Statistical nature of the incipient plasticity in amorphous alloys. Scr Mater 2020;187:360-5.

https://doi.org/10.1016/j.scriptamat.2020.06.045.

[256] Gao M, Perepezko JH. Trimodal shear band nucleation distribution in a Gd-based metallic glass via nanoindentation. Mater Sci Eng A 2021;801:140402.

https://doi.org/10.1016/j.msea.2020.140402.

[257] Choi I-C, Zhao Y, Yoo B-G, Kim Y-J, Suh J-Y, Ramamurty U, et al. Estimation of the shear transformation zone size in a bulk metallic glass through statistical analysis of the first pop-in stresses during spherical nanoindentation. Scr Mater 2012;66:923-6.

https://doi.org/10.1016/j.scriptamat.2012.02.032.

[258] Choi I-C, Zhao Y, Kim Y-J, Yoo B-G, Suh J-Y, Ramamurty U, et al. Indentation size effect and shear transformation zone size in a bulk metallic glass in two different structural states. Acta Mater 2012;60:6862-8. https://doi.org/10.1016/j.actamat.2012.08.061.

[259] Zhao Y, Choi I-C, Seok M-Y, Kim M-H, Kim D-H, Ramamurty U, et al. Effect of hydrogen on the yielding behavior and shear transformation zone volume in metallic glass ribbons. Acta Mater 2014;78:213-21. https://doi.org/10.1016/j.actamat.2014.06.046.

[260] Ma Y, Peng GJ, Debela TT, Zhang TH. Nanoindentation study on the characteristic of shear transformation zone volume in metallic glassy films. Scr Mater 2015;108:52-5.

https://doi.org/10.1016/j.scriptamat.2015.05.043.

[261] Johnson WL, Samwer K. A universal criterion for plastic yielding of metallic glasses with a (T/Tg)2/3 temperature dependence. Phys Rev Lett 2005;95:195501.

https://doi.org/10.1103/PhysRevLett.95.195501.

[262] Schuh CA, Lund AC. Application of nucleation theory to the rate dependence of incipient plasticity during nanoindentation. J Mater Res 2004;19:2152-8.

https://doi.org/10.1557/JMR.2004.0276.

[263] Pan D, Inoue A, Sakurai T, Chen MW. Experimental characterization of shear transformation zones for plastic flow of bulk metallic glasses. Proc Natl Acad Sci 2008;105:14769-72. https://doi.org/10.1073/pnas.0806051105.

[264] Bhattacharyya A, Singh G, Eswar Prasad K, Narasimhan R, Ramamurty U. On the strain rate sensitivity of plastic flow in metallic glasses. Mater Sci Eng A 2015;625:245-51. https://doi.org/10.1016/j.msea.2014.12.004.

[265] Jiang WH, Liu FX, Jiang F, Qiu KQ, Choo H, Liaw PK. Strain-rate dependence of hardening and softening in compression of a bulk-metallic glass. J Mater Res 2007;22:2655-8. https://doi.org/10.1557/JMR.2007.0351.

[266] Dubach A, Dalla Torre FH, Loffler J. Constitutive model for inhomogeneous flow in bulk metallic glasses. Acta Mater 2009;57:881-92. https://doi.org/10.1016/j.actamat.2008.10.027.

[267] Mukai T, Nieh T., Kawamura Y, Inoue A, Higashi K. Effect of strain rate on compressive behavior of a Pd40Ni40P20 bulk metallic glass. Intermetallics 2002;10:1071-7. https://doi.org/10.1016/S0966-9795(02)00137-1.

[268] Jang J, Yoo B-G, Kim Y-J, Oh J-H, Choi I-C, Bei H. Indentation size effect in bulk metallic glass. Scr Mater 2011;64:753-6. https://doi.org/10.1016/j.scriptamat.2010.12.036.

[269] Dolan MD, Dave NC, Ilyushechkin AY, Morpeth LD, McLennan KG. Composition and operation of hydrogen-selective amorphous alloy membranes. J Memb Sci 2006;285:30-55. https://doi.org/10.1016/j.memsci.2006.09.014.

[270] Sarker S, Chandra D, Hirscher M, Dolan M, Isheim D, Wermer J, et al. Developments in the $\mathrm{Ni}-\mathrm{Nb}-\mathrm{Zr}$ amorphous alloy membranes. Appl Phys A 2016;122:168. https://doi.org/10.1007/s00339-016-9650-5. 
[271] Yoo B-G, Oh J-H, Kim Y-J, Jang J. Effect of hydrogen on subsurface deformation during indentation of a bulk metallic glass. Intermetallics 2010;18:1872-5. https://doi.org/10.1016/j.intermet.2010.01.031.

[272] Zhao Y, Choi I-C, Seok M-Y, Ramamurty U, Suh J-Y, Jang J. Hydrogen-induced hardening and softening of $\mathrm{Ni}-\mathrm{Nb}-\mathrm{Zr}$ amorphous alloys: Dependence on the $\mathrm{Zr}$ content. Scr Mater 2014;93:56-9. https://doi.org/10.1016/j.scriptamat.2014.08.029.

[273] Dong F, He M, Zhang Y, Luo L, Su Y, Wang B, et al. Effects of hydrogen on the nanomechanical properties of a bulk metallic glass during nanoindentation. Int J Hydrogen Energy 2017;42:25436-45. https://doi.org/10.1016/j.ijhydene.2017.08.141.

[274] Dong F, He M, Zhang Y, Wang B, Luo L, Su Y, et al. Investigation of shear transformation zone and ductility of Zr-based bulk metallic glass after plasma-assisted hydrogenation. Mater Sci Eng A 2019;759:105-11. https://doi.org/10.1016/j.msea.2019.05.027.

[275] Perez-Bergquist AG, Bei H, Leonard KJ, Zhang Y, Zinkle SJ. Effects of ion irradiation on Zr52.5Cu17.9Ni14.6Al10Ti5 (BAM-11) bulk metallic glass. Intermetallics 2014;53:62-6. https://doi.org/10.1016/j.intermet.2014.04.016.

[276] Liu T, Guo W, Crespillo ML, Jin K, Zhang Y, Bei H, et al. Indirectly probing the structural change in ion-irradiated $\mathrm{Zr}$-Based metallic glasses from small scale mechanical tests. Intermetallics 2020;121:106794. https://doi.org/10.1016/j.intermet.2020.106794.

[277] Raghavan R, Boopathy K, Ghisleni R, Pouchon MA, Ramamurty U, Michler J. Ion irradiation enhances the mechanical performance of metallic glasses. Scr Mater 2010;62:462-5. https://doi.org/10.1016/j.scriptamat.2009.12.013.

[278] Raghavan R, Kombaiah B, Döbeli M, Erni R, Ramamurty U, Michler J. Nanoindentation response of an ion irradiated Zr-based bulk metallic glass. Mater Sci Eng A 2012;532:40713. https://doi.org/10.1016/j.msea.2011.11.004.

[279] Anand L. Granular materials: constitutive equations and strain localization. J Mech Phys Solids 2000;48:1701-33. https://doi.org/10.1016/S0022-5096(99)00066-6.

[280] Anand L, Su C. A theory for amorphous viscoplastic materials undergoing finite deformations, with application to metallic glasses. J Mech Phys Solids 2005;53:1362-96. https://doi.org/10.1016/j.jmps.2004.12.006.

[281] Su C, Anand L. Plane strain indentation of a Zr-based metallic glass: Experiments and numerical simulation. Acta Mater 2006;54:179-89. https://doi.org/10.1016/j.actamat.2005.08.040.

[282] Szlufarska I. Atomistic simulations of nanoindentation. Mater Today 2006;9:42-50. https://doi.org/10.1016/S1369-7021(06)71496-1.

[283] Shi Y, Falk ML. Stress-induced structural transformation and shear banding during simulated nanoindentation of a metallic glass. Acta Mater 2007;55:4317-24. https://doi.org/10.1016/j.actamat.2007.03.029.

[284] Păduraru A, Andersen UG, Thyssen A, Bailey NP, Jacobsen KW, Schiøtz J. Computer simulations of nanoindentation in $\mathrm{Mg}-\mathrm{Cu}$ and $\mathrm{Cu}-\mathrm{Zr}$ metallic glasses. Model Simul Mater Sci Eng 2010;18:055006. https://doi.org/10.1088/0965-0393/18/5/055006.

[285] Li J, Van Vliet KJ, Zhu T, Yip S, Suresh S. Atomistic mechanisms governing elastic limit and incipient plasticity in crystals. Nature 2002;418:307-10. https://doi.org/10.1038/nature00865.

[286] Bowden PB, Jukes JA. The plastic flow of isotropic polymers. J Mater Sci 1972;7:52-63. https://doi.org/10.1007/BF00549550.

[287] Wrucke AJ, Han C-S, Majumdar P. Indentation size effect of multiple orders of magnitude in polydimethylsiloxane. J Appl Polym Sci 2013;128:258-64. https://doi.org/10.1002/app.38161.

[288] Briscoe BJ, Fiori L, Pelillo E. Nano-indentation of polymeric surfaces. J Phys D Appl Phys 1998;31:2395-405. https://doi.org/10.1088/0022-3727/31/19/006.

[289] Anand L, Ames NM. On modeling the micro-indentation response of an amorphous polymer. Int J Plast 2006;22:1123-70. https://doi.org/10.1016/j.ijplas.2005.07.006. 
[290] Calleja FJB, Sanditov DS, Privalko VP. Review: the microhardness of non-crystalline materials. J Mater Sci 2002;37:4507-16. https://doi.org/10.1023/A:1020648908142.

[291] Cheng L, Xia X, Yu W, Scriven LE, Gerberich WW. Flat-punch indentation of viscoelastic material. J Polym Sci Part B Polym Phys 2000;38:10-22. https://doi.org/10.1002/(SICI)1099-0488(20000101)38:1<10::AID-POLB2>3.0.CO;2-6.

[292] Cheng Y-T, Cheng C-M. Relationships between initial unloading slope, contact depth, and mechanical properties for conical indentation in linear viscoelastic solids. J Mater Res 2005;20:1046-53. https://doi.org/10.1557/JMR.2005.0141.

[293] Han CS. Influence of the molecular structure on indentation size effect in polymers. Mater Sci Eng A 2010;527:619-24. https://doi.org/10.1016/j.msea.2009.08.033.

[294] Lim YY, Chaudhri MM. Experimental investigations of the normal loading of elastic spherical and conical indenters on to elastic flats. Philos Mag 2003;83:3427-62. https://doi.org/10.1080/14786430310001608701.

[295] Oyen ML, Toivola YA, Cook RF. Load Dispersion behavior during sharp indentation of Viscous elastic plastic materials. MatRes Soc Symp 2001;649:1-6.

[296] VanLandingham MR, Villarrubia JS, Guthrie WF, Meyers GF. Nanoindentation of polymers: an overview. Macromol Symp 2001;167:15-44. https://doi.org/10.1002/15213900(200103)167:1<15::AID-MASY15>3.0.CO;2-T.

[297] Voyiadjis GZ, Malekmotiei L, Samadi-Dooki A. Indentation size effect in amorphous polymers based on shear transformation mediated plasticity. Polymer (Guildf) 2018;137:7281. https://doi.org/10.1016/j.polymer.2018.01.006.

[298] Wai SW, Spinks GM, Brown HR, Swain M. Surface roughness: Its implications and inference with regards to ultra microindentation measurements of polymer mechanical properties. Polym Test 2004;23:501-7. https://doi.org/10.1016/j.polymertesting.2004.01.001. 